TÁBATA TAKAHASHI FRANÇA

\title{
AVALIAÇÃO DA FORMAÇÃO DE NETS EM PACIENTES COM DEFICIÊNCIA DE CD40 LIGANTE
}

Dissertação apresentada ao Programa de PósGraduação em Imunologia do Instituto de Ciências Biomédicas da Universidade de São Paulo, para obtenção de Título de Mestre em Ciências. 
TÁBATA TAKAHASHI FRANÇA

\section{AVALIAÇÃO DA FORMAÇÃO DE NETS EM PACIENTES COM DEFICIÊNCIA DE CD40 LIGANTE}

Dissertação apresentada ao Programa de PósGraduação em Imunologia do Instituto de Ciências Biomédicas da Universidade de São Paulo, para obtenção do Título de Mestre em Ciências.

Área de Concentração: Imunologia

Orientador: Prof. Dr. Antônio Condino Neto

Versão Original. 
CATALOGAÇÃO NA PUBLICAÇÃO (CIP)

Serviço de Biblioteca e informação Biomédica

do Instituto de Ciências Biomédicas da Universidade de São Paulo

Ficha Catalográfica elaborada pelo (a) autor(a)

Takahashi França, Tábata

Avaliação da formação de NETs em pacientes com deficiência de CD4OL / Tábata Takahashi França; orientador Antonio Condino Neto. -- São Paulo, 2017 .

$80 \mathrm{p}$.

Dissertação (Mestrado) -- Universidade de São Paulo, Instituto de Ciências Biomédicas.

1. Neutrófilos. 2. NETs. 3. X-HIGM. 4. Deficiência de CD40L. 5. IFN-y. I. Condino Neto, Antonio, orientador. II. Título. 


\section{UNIVERSIDADE DE SÃO PAULO \\ INSTITUTO DE CIÊNCIAS BIOMÉDICAS}

Candidata:

Título da Dissertação:

Orientador:
Tábata Takahashi França

Avaliação da formação de NETs em pacientes com deficiência de CD40L.

Prof. Dr. Antonio Condino Neto

A Comissão Julgadora dos trabalhos de Defesa da Dissertação de Mestrado, em sessão pública realizada a considerou

\section{( ) Aprovada ( ) Reprovada}

\begin{tabular}{|c|c|}
\hline \multirow[t]{2}{*}{ Examinador (a): } & $\begin{array}{l}\text { Assinatura: } \\
\text { Nome: .......... }\end{array}$ \\
\hline & Instituição: \\
\hline \multirow[t]{3}{*}{ Examinador (a): } & Assinatura: \\
\hline & Nome: \\
\hline & Institui \\
\hline
\end{tabular}

Examinador (a): $\quad$ Assinatura:

Nome:

Instituição:

Presidente: Assinatura:

Nome:

Instituição: 
Cidade Universitaria "Armando de Salles Cliveira"

Av. Prod. Lineu Prestes, 2415 - cep, 05500 -000 Sao Paulo, SP - Bras

Telefone :(55) (11) 3091.7733 telefax : (55) (11) 3091.405

o-mall copg icb.usp.be

São Paulo, 04 de março de 2015.

\section{$\underline{\text { PARECER 1220/CEPSH }}$}

A Comissão de Ética em Pesquisas em Seres Humanos do ICB, nesta data, APRovou o projeto intitulado: "Avaliação da formação de neutrophil extracellular traps em pacientes com deficiência de cd40 ligante e influência do tratamento in vitro com interferon-gamma" do pesquisador Antonio Condino Neto e aluna Tábata Takahashi França.

Cabe aos pesquisadores elaborar e apresentar a este Comitê, relatórios anuais (parciais e final), de acordo com a Resolução n ${ }^{\circ} 466 / 12$, item II, II.19 e II.20, do Conselho Nacional de Saúde, conforme modelo constante no site: icb.usp.br.

Aos pesquisadores cabe também finalizar o processo junto à Plataforma Brasil quando do encerramento deste.

CEP em 04.03.2016.

O primeiro relatório deverá ser encaminhado à Secretaria deste

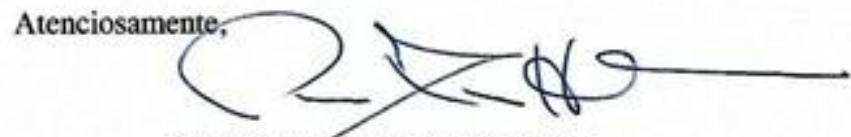

Prof. Dr.PAOLo M.A.Zanotto

Coordenador da Comissão de Ética em

Pesquisas com Seres Humanos - ICB/USP

Comissăo de Ética em Pesquisa com Seres Humanos do Instituto de Ciéncias Biomédicas / USP Aprovada pela Comissăo Nacional de Ética em Pesquisa - CONEP, em 10 de fevereiro de 1998. 
A minha família,

pois a ela devo tudo que sou, pois sem ela eu nada seria... 


\section{AGRADECIMENTOS}

Acima de tudo, agradeço aos meus pais, Ildeu e Masae, por todo amor, ensinamentos, apoio, incentivo e broncas, e também as minhas irmãs, Natalia e Talita, por toda amizade e por estarem sempre presentes.

Ao meu orientador professor Antonio Condino Neto, pela oportunidade, pelos conselhos, pelo incentivo e acima de tudo por acreditar no meu potencial.

Agradeço, também:

Ao apoio de toda minha família, tios e tias, primos e primas, que por serem tantos se torna impossível citar um a um, porém cada qual a sua maneira contribuíram de maneira única para esta caminhada.

A Christina Arslanian e Silvana Lucchinni, por todo apoio e carinho, e por tornarem o dia a dia do laboratório mais fácil e acolhedor.

Aos amigos do laboratório de Imunologia Humana (LIH), Renata, Lucila, Paola, Marina, José Antonio, Edgar, Christiane e Nuria, e a tantos outros que não estão mais por perto, mas que contribuíram imensamente para este trabalho como Otávio, Paulo Vítor e Leandro, por toda parceria, discussões científicas, risadas, aprendizados, angústias compartilhadas e vitórias comemoradas.

Aos amigos da vida, em especial Marcela e Márita, por toda amizade e por nunca me deixarem esquecer que há vida além do laboratório.

As médicas, Dra. Beatriz Costa Carvalho, Dra. Cristina Weber Worm, Dra. Janáira, bem como às suas respectivas equipes, pela imensa colaboração, coleta e envio de amostras de sangue dos pacientes, sem as quais este trabalho não teria sido possível.

Aos pacientes e aos seus pais, por colaborarem e entenderem a importância da pesquisa, e para os quais este trabalho é realizado.

Aos integrantes da banca de qualificação Professor Alexandre Steiner, Dra Ester

Sabino e Dra Évelin Komegae, pelas ricas críticas e sugestões durante o Exame de Qualificação.

Aos amigos do Departamento de Imunologia, em especial Eni, Aurea e Grace, por todo suporte e apoio sempre presentes.

Aos Professores do Departamento de Imunologia por todo conhecimento compartilhado e ensinamentos oferecidos.

Aos colegas de Departamento de Imunologia por todos os momentos vividos. 


\section{Agradecimento especial}

Agradeço especialmente à FAPESP pela bolsa-Mestrado e Auxílio concedido, sem o qual não seria possível a realização deste estudo. 
"Quanto mais aumenta nosso conhecimento, mais evidente fica nossa ignorância". (John F. Kennedy) 


\section{RESUMO}

FRANÇA, T. T. Avaliação da formação de NETs em pacientes com deficiência de CD40L. 2017. 80 f. Dissertação (Mestrado em Imunologia) - Instituto de Ciências Biomédicas, Universidade de São Paulo, São Paulo, 2017.

Os neutrófilos são o tipo celular mais abundante na circulação humana e compõem a primeira linha de defesa contra patógenos nos sítios de infecção. Estudos recentes demonstram que as armadilhas extracelulares de neutrófilos (NETs) formam uma estrutura extracelular capaz de anular fatores de virulência e destruir microrganismos. Pacientes portadores da síndrome de Hiper-IgM ligada ao X (X-HIGM), imunodeficiência rara causada por mutações no gene codificante da molécula CD40 ligante (CD40L), apresentam grande susceptibilidade a infecções, com alta incidência de infecções oportunistas causadas por fungos. Tendo em vista que a resposta de neutrófilos apresenta grande importância para o controle de infecções fúngicas e estudos que apontam influência da interação CD40-CD40L na granulopoiese, propusemos investigar se a suscetibilidade aumentada a infecções em pacientes deficientes de CD40L poderiam estar relacionadas à falha na formação de NETs. A geração de NETs frente ao estímulo com PMA mostrou-se diminuída nos pacientes deficientes de CD40L em comparação com indivíduos saudáveis. A geração de EROs (espécies reativas do oxigênio) frente a estimulação com PMA e $C$. albicans mostrou-se similar entre os dois grupos avaliados, no entanto os pacientes deficientes de CD40L não foram capazes de aumentar a produção de EROs após tratamento com IFN- $\gamma$ como observado nos indivíduos saudáveis. Avaliação do estágio de maturação dos neutrófilos indica a presença de neutrófilos periféricos imaturos nos pacientes deficientes de CD40L. Os resultados obtidos indicam que pacientes deficientes de CD40L apresentam falha na geração de NETs pela estimulação com PMA, alteração possivelmente relacionada a maturação incompleta dos neutrófilos. O estudo contribui para o avanço no conhecimento sobre a imunopatologia da deficiência do CD40L e para elucidação dos mecanismos envolvidos na suscetibilidade aumentada a infecções em pacientes deficientes de CD40L, além de abrir novas perspectivas para a elucidação da interação CD40-CD40L e sua função na resposta imune.

Palavras-chave: Neutrófilos. NETs. X-HIGM. Deficiência de CD40L. IFN- $\gamma$. 


\begin{abstract}
FRANÇA, T. T. Evaluation of NET formation in CD40L-deficient patients. 2017. 80 p. Masters thesis (Immunology) - Instituto de Ciências Biomédicas, Universidade de São Paulo, São Paulo, 2017.

Neutrophils are the most abundant cell type in human circulation and are the first line of defense against pathogens at sites of infection. Recent studies have shown that neutrophil extracellular traps (NETs) form an extracellular structure able to neutralize virulence factors and destroy microorganisms. Patients with X-linked Hyper-IgM syndrome (X-HIGM), a rare immunodeficiency caused by mutations in the gene encoding the molecule CD40 ligand (CD40L), are highly susceptible to infections with elevated incidence of opportunistic infections caused by fungi. Since neutrophil responses are important to control fungal infection and studies indicate the influence of the CD40-CD40L interaction on granulopoiesis, we proposed to investigate whether the increased susceptibility to infections in CD40Ldeficient patients could be related to failure in NET formation. NET formation against PMA stimulus was decreased in CD40L-deficient patients compared to healthy subjects. ROS generation against PMA and $C$. albicans was similar between the investigated groups, although CD40L-deficient patients were not able to increase the production of ROS after treatment with IFN- $\gamma$ as observed on healthy individuals. Evaluation of neutrophils' maturation stage indicates the presence of immature peripheral neutrophils in CD40Ldeficient patients. The results indicate that CD40L-deficient patients present a failure in NET generation in a stimulus-dependent manner, likely related to incomplete neutrophil maturation. This study contributes to expand the knowledge on the immunopathology of CD40L deficiency and contributes to elucidate the mechanisms involved in increased susceptibility to infections in CD40L-deficient patients. In addition, our findings bring new perspectives for the understanding of CD40-CD40L interaction and its function in the immune response.
\end{abstract}

Keywords: Neutrophils. NETs. X-HIGM. CD40L deficiency. IFN- $\gamma$. 


\section{LISTA DE ILUSTRAÇÕES}

Figura 1 - Mecanismos de resposta dos neutrófilos.

Figura 2 - Função das NETs na resposta imune.

Figura 3 - Esquema da estrutura do CD40LG.

Figura 4 - A interação CD40-CD40L na resposta imune.

Figura 5 - Avaliação da geração de NETs em pacientes deficientes de CD40L.

Figura 6 - Visualização da formação de NETs pelos pacientes deficientes de CD40L.

Figura 7 - Avaliação da produção de EROs em pacientes deficientes de CD40L.

Figura 8 - Avaliação do perfil de maturação dos neutrófilos de pacientes deficientes de CD40L. 


\section{LISTA DE TABELAS}

Tabela 1 - Fatores microbicidas, proteicos e químicos que estimulam a formação de NETs.

Tabela 2 - Manifestações clínicas na deficiência de CD40L.

Tabela 3 - Pacientes envolvidos no estudo: mutações, histórico de infecções fúngicas e ensaios realizados.

Tabela 4 - Estímulos utilizados para a ativação/desafio dos neutrófilos. 


\section{LISTA DE ABREVIATURAS E SIGLAS}

$\mathrm{Ca}^{+} \quad$ íons de cálcio

CD40L CD40 ligante

CD40LG gene CD40L

CD40Ls CD40 ligante solúvel

DCs células dendríticas

DGC doença granulomatosa crônica

EROs espécies reativas do oxigênio

FSC parâmetro de tamanho celular

G-CSF fator estimulador de colônias de granulócitos

GM-CSF fator estimulador de colônias de granulócitos-monócitos

HIGM Síndrome de hiper IgM

HSCT transplante de células tronco hematopoiéticas

IDPs imunodeficiências primárias

IFN- $\gamma \quad$ interferon-gama

Ig imunoglobulina

MFI intensidade mediana de fluorescência

MOI multiplicidade de infecção

MPO enzima mieloperoxidase

NE elastase de neutrófilo

NETs armadilhas extracelulares de neutrófilos

NK célula natural killer

PAD-4 pepitidil-arginina deaminase tipo 4

PBS tampão fosfato salino

PKC proteína quinase $\mathrm{C}$

PMA phorbol 12-myristate 13-acetate

PMN leucócitos polimorfonucleares

$\mathrm{RCF}$ força centrífuga relativa

RFU unidade relativa de fluorescência

RPMI meio Roswell Park Memorial Institute

SFB soro fetal bovino

SSC parâmetro de complexidade celular 
TCLE

TNF

URL

X-HIGM
Termo de Consentimento Livre e Esclarecido

fator de necrose tumoral

unidade relativa de luz

Síndrome de Hiper IgM ligada ao X 


\section{SUMÁRIO}

1 INTRODUÇÃO ..................................................................................................................... 18

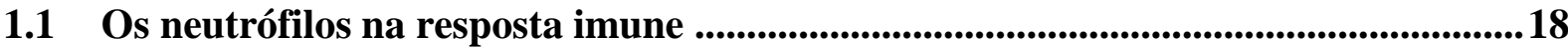

1.2 Armadilhas extracelulares de neutrófilos - NETs ................................................20

1.3 Deficiência de CD40L: A Síndrome de Hiper IgM ligada ao X.................................. 23

1.4 A interação CD40-CD40L na resposta imune ...........................................................25

1.5 Interferon-gama

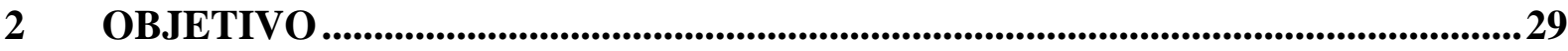

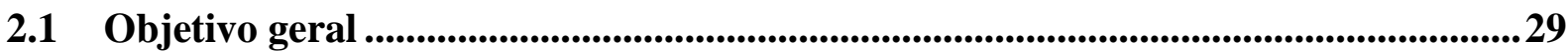

2.2 Objetivos específicos ......................................................................................................29

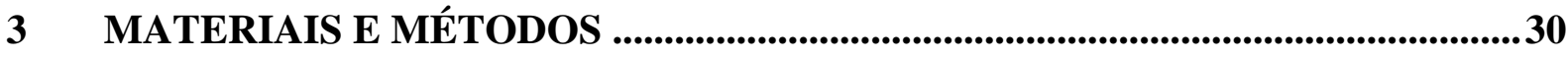

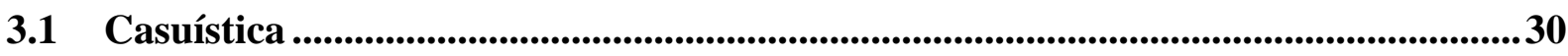

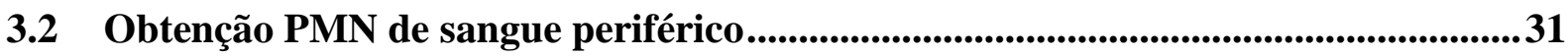

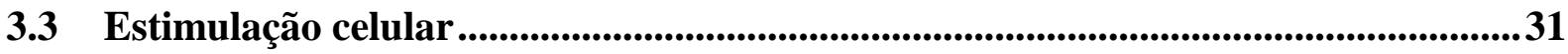

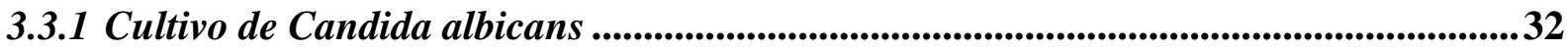

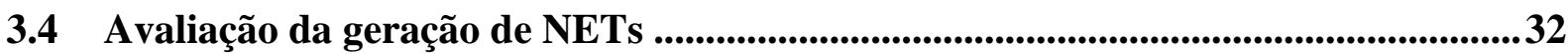

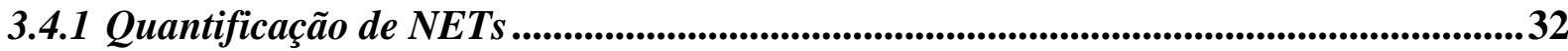

3.4.2 Visualização da formação de NETs ...................................................................................33

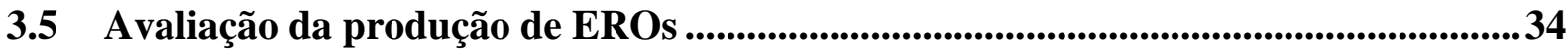

3.6 Avaliação do perfil de maturação ............................................................................................. 34

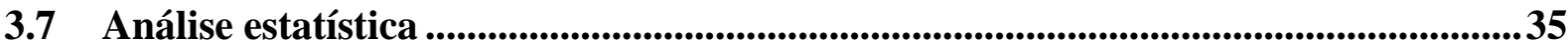

$4 \quad$ RESULTADOS.............................................................................................................................36

4.1 Avaliação da geração de NETs .........................................................................................36

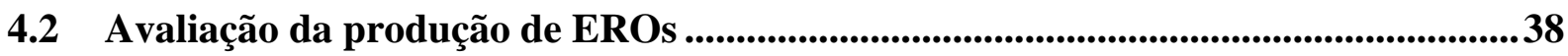

4.3 Avaliação do perfil de maturação dos neutrófilos.....................................................39

5 DISCUSSÃO

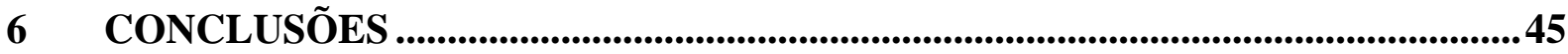




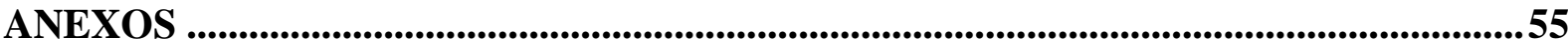

A- Avaliação da pureza da separação celular ............................................................................55

B- Avaliação da viabilidade celular ....................................................................................................56

C- Avaliação morfológica das $C$. albicans utilizadas nos protocolos experimentais .........57

D- Marcação de neutrófilos para visualização da formação de NETs .................................58

E- Avaliação da expressão de CD40 nos neutrófilos de pacientes deficientes de CD40L 59

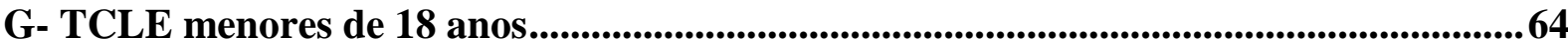

H- TCLE maiores de 18 anos .........................................................................................................66

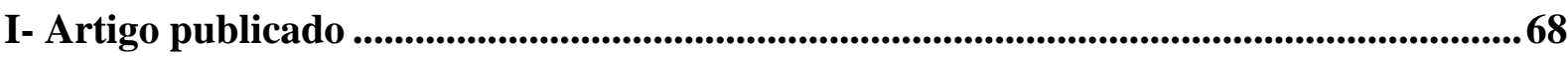




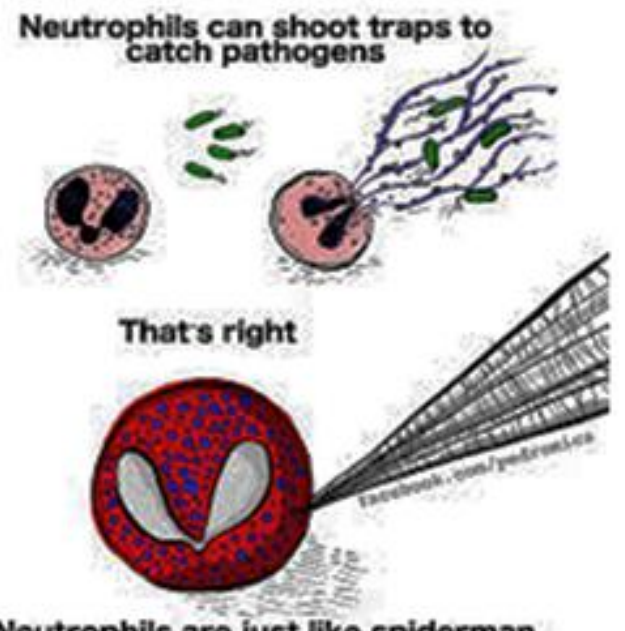

Neutrophils are just like spiderman 


\section{INTRODUÇÃO}

\subsection{Os neutrófilos na resposta imune}

Os neutrófilos, também conhecidos como leucócitos polimorfonucleares (PMN), constituem a população mais abundante de leucócitos circulantes em humanos e possuem papel essencial na defesa do hospedeiro contra microrganismos invasores. Eles medeiam as fases iniciais das reações inflamatórias e fornecem importante contribuição para o recrutamento, ativação e diferenciação de outros leucócitos $(1,2,3)$.

Os neutrófilos se desenvolvem na medula óssea a partir de células tronco hematopoiéticas em um processo denominado granulopoiese, processo no qual progenitores mielóides se diferenciam sequencialmente em células mielocíticas, mieloblastos, promielócitos, mielócitos, metamielócitos, bastonetes e por fim em neutrófilos maturos (4). Ao atingir seu estágio final de maturação, os neutrófilos são liberados para a circulação sanguínea e encontram-se aptos a realizarem suas funções efetoras fundamentais para manutenção da homeostasia e controle de infecções.

A principal citocina envolvida na regulação do ciclo de vida dos neutrófilos é o fator estimulador de colônias de granulócitos, o G-CSF (do inglês granulocyte colony-stimulating factor). Esta importante citocina é produzida por monócitos, macrófagos, fibroblastos, células endoteliais e células do estroma da medula óssea após estímulo e atua na proliferação celular, sobrevivência e diferenciação dos neutrófilos $(5,6)$. A nível celular, o G-CSF estimula a proliferação de células progenitoras mielóides, induz a diferenciação de progenitores mielóides para linhagem neutrofílica e participa de todo processo de maturação dos neutrófilos, tendo grande influência na fase de diferenciação de metamielócitos em neutrófilos maturos (7).

A resposta inflamatória dependente de neutrófilos é um processo composto de diversas etapas sequenciais que envolvem o rolamento e firme adesão dos neutrófilos circulantes ao endotélio vascular ativado, o extravasamento e migração de neutrófilos em direção ao foco inflamatório e por fim a ação efetora de eliminação de microrganismos invasores $(8,9)$ (Figura 1). O recrutamento de neutrófilos para o sítio infeccioso é a primeira etapa da resposta inflamatória e este processo é iniciado por alterações vasculares e endoteliais em reposta à mediadores inflamatórios, como as citocinas TNF e IL-6, que induzem a expressão endotelial das selectinas P e E. A interação de baixa afinidade destas selectinas com seus 
ligantes presente nos neutrófilos, como a PSGL1, levam ao rolamento dos neutrófilos na superfície endotelial. Os mediadores inflamatórios também induzem a expressão endotelial dos ligantes de integrina, como VCAM-1 e ICAM-1, que se ligam às integrinas VLA-4, LFA1 e MAC-1 presente nos neutrófilos e levam a uma firme adesão dos neutrófilos ao endotélio. A subsequente transmigração e diapedese envolve a interação de diversas moléculas como LFA-1, MAC-1, VLA-4 e CD99 aos seus ligantes presentes no endotélio e na matriz extracelular $(11,12)$.

Figura 1 - Mecanismos de resposta dos neutrófilos.

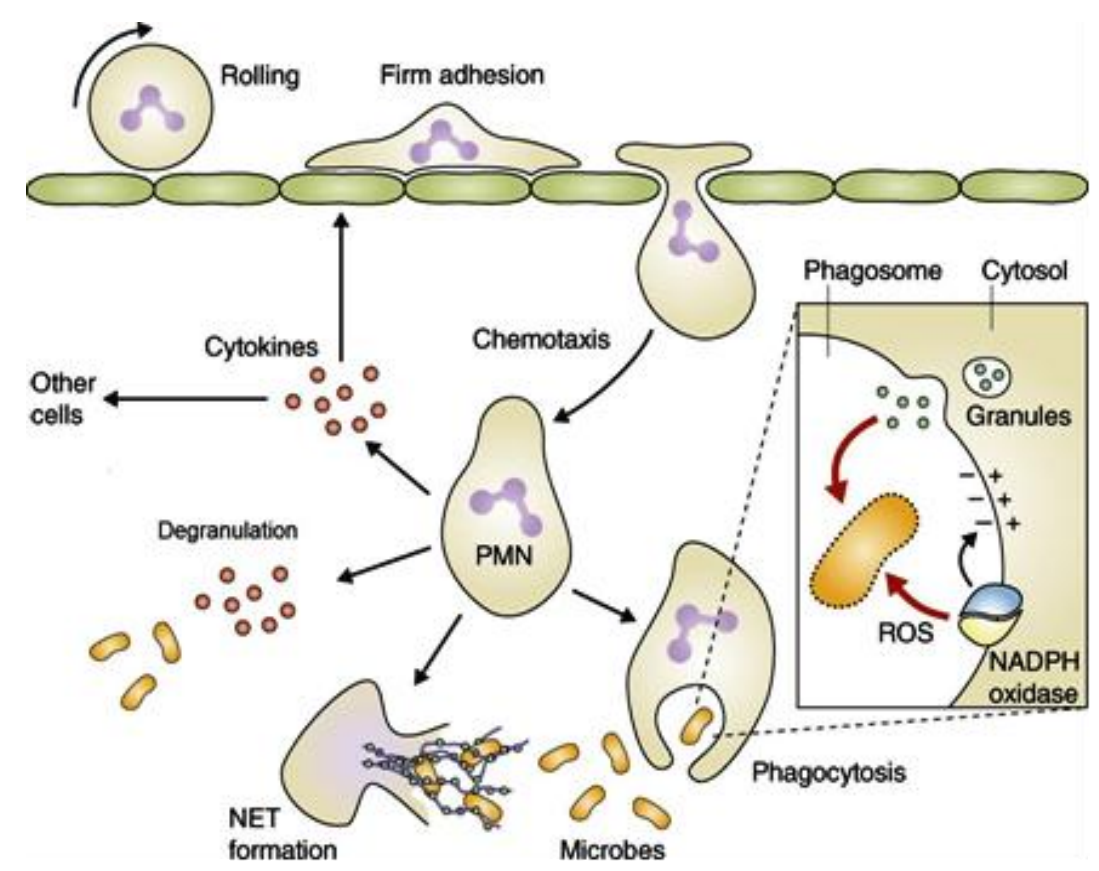

Após a migração para o sítio inflamatório, os neutrófilos fagocitam e digerem microrganismos invasores (dependente da ação de agentes microbicidas presente nos grânulos e ação da enzima NADPH-oxidase), secretam citocinas, liberam produtos de seus grânulos no meio extracelular (degranulação) e formam NETs (10, adaptado).

Os principais mecanismos pelos quais os neutrófilos eliminam os patógenos no sítio infeccioso são pela ação das proteínas antibacterianas presente nos grânulos e pela geração de espécies reativas do oxigênio (EROs) (12- 15). A geração de EROs no fagossomo é considerado mecanismo crítico para destruição de microrganismos e ocorre em processo conhecido como explosão respiratória, o qual gera fatores como o ânion superóxido e o peróxido de hidrogênio, poderosos agentes oxidantes capazes de danificar a estrutura celular de diversos microrganismos (13, 16- 19 ). A enzima responsável pelo metabolismo do oxigênio é a NADPH-oxidase, complexo multiproteico composto por componentes 
citoplasmáticos (proteínas p47-phox, p67-phox e p40-phox) que após estímulo se translocam em direção ao componente de membrana do complexo, conhecido como citocromo- $b_{558}$ (formado por p22-phox e gp91-phox), culminando na ativação do complexo enzimático e subsequente geração de EROs (19- 21). Estes reativos gerados nos fagossomos atuam juntamente coma as enzimas lisossomais na destruição dos microrganismos fagocitados (13).

Outro mecanismo utilizado por neutrófilos para eliminação de patógenos consiste na liberação das armadilhas extracelulares de neutrófilos (NETs, do inglês Neutrophil Extracellular Traps), estruturas liberadas por neutrófilos ativados que possuem funções microbicidas e agem sobre patógenos presentes no meio extracelular (22).

\subsection{Armadilhas extracelulares de neutrófilos - NETs}

As NETs, descritas pela primeira vez por Brinkman e colaboradores em 2004, são estruturas extracelulares compostas de cromatina descondensada e fatores antimicrobianos derivados dos grânulos que são liberadas pelos neutrófilos após estímulo por diferentes compostos químicos, fatores proteicos e patógenos como bactérias, fungos, vírus encapsulados e protozoários $(23,24)$ (Tabela 1).

Tabela 1 - Fatores microbicidas, proteicos e químicos que estimulam a formação de NETs (23, adaptado).

\begin{tabular}{ll}
\hline Fatores microbicidas & Fatores químicos \\
\hline Aspergillus fumigatus & -toxina de Staphylococcus epidermidis \\
Candida albicans & Anticorpo \\
Cryptococcus neoformans & Ion de cálcio \\
Eimeria bovis & Glucose oxidase \\
Enterococcus Faecallis & GM-CSF + C5a \\
Escherichia coli & GM-CSF + LPS \\
Haemophilus influenzae & Peróxido de hidrogênio \\
Helicobacyer pylori & Interferon-a + C5a \\
Klebsiella pneumoniae & Interleucina 8 \\
Lactococcus lactis & Lipopolisacarídeo (LPS) \\
Leishmania amazonensis & \\
donovani/major/chagasi & Óxido nítrico \\
Listeria monocytogenes & Phorbol-12-myristate-13-acetate (PMA) \\
Mannheimia haemolytica & PMA + Ionomicina \\
Mycobacterium Tuberculosis & Fator ativador de plaquetas \\
Serratia marcescens & Receptor Toll-like 4 (TLR-4) \\
Shigella flexneri & TNF-a \\
\hline
\end{tabular}


Diversos estudos indicam que as NETs estão presentes em grande quantidade nos sítios inflamatórios e além de atuarem ativamente na eliminação dos microrganismos servem também como uma barreira física que impede sua disseminação e fornece sinais para outras células imunes como linfócitos, DCs e macrófagos (25- 30) (Figura 2). No entanto, esta resposta dos neutrófilos tem papel fundamental não somente na resolução de infecções, mas também no agravamento de quadros inflamatórios, infecções e doenças autoimunes (31- 33).

Figura 2 - Função das NETs na resposta imune.

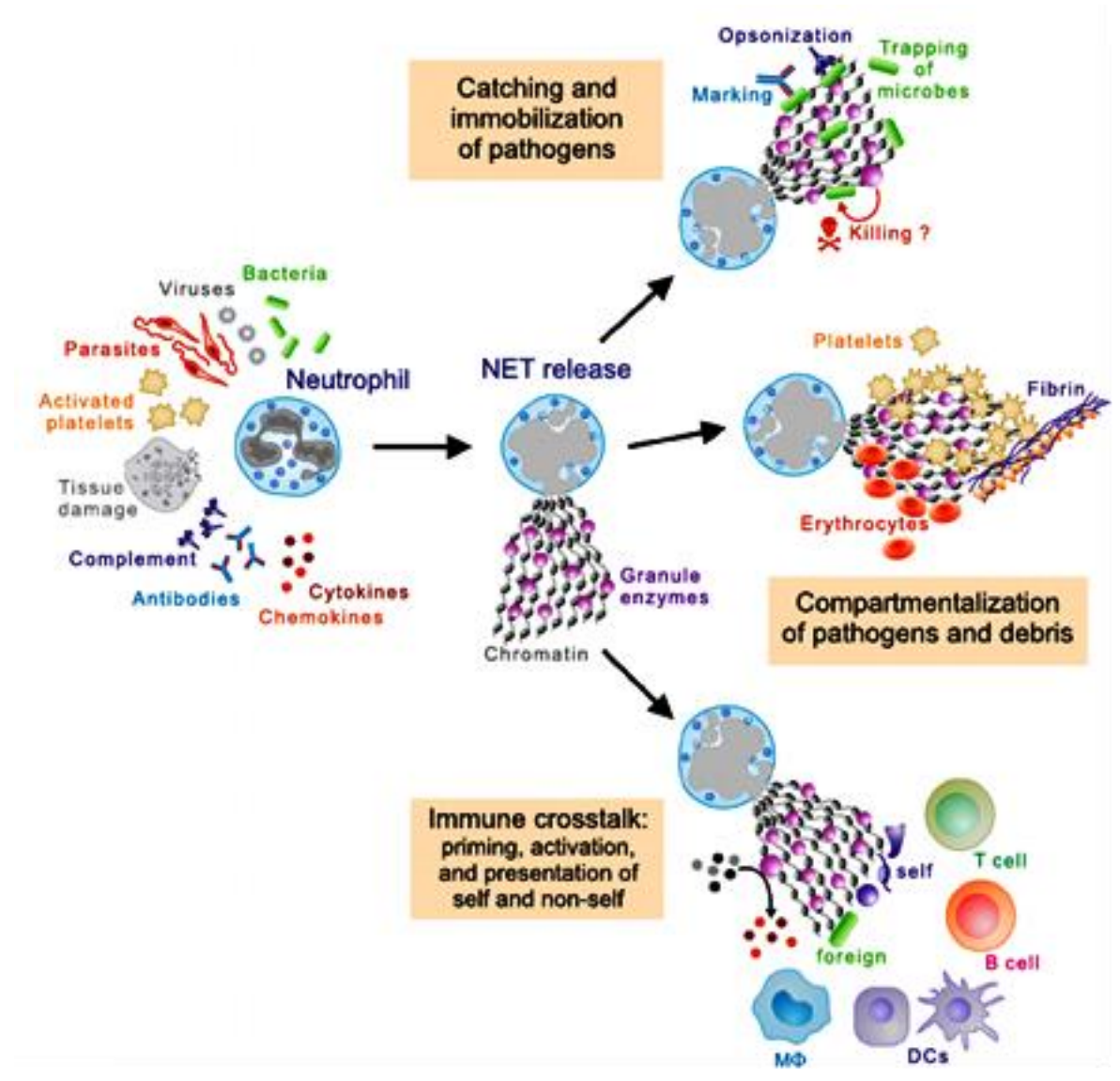

As NETs podem ser desencadeadas por diversos estímulos, como em resposta a infecção, dano tecidual e inflamação. Após liberadas, as NETs capturam os patógenos e ajudam na sua eliminação, provavelmente através da ação de enzimas presentes em sua estrutura. Além disso, as NETS promovem a formação de trombos que evitam a disseminação de microrganismos de detritos celulares. Acredita-se que estas estruturas extracelulares também desempenhem papel crucial na regulação das respostas imunes pela sua interação com outros tipos celulares (47).

As NETs são compostas em sua maioria por DNA nuclear e sua liberação resulta em morte celular conhecida como NETose, embora tenha sido descrito mecanismo de formação de NETs independente de morte celular através da liberação de DNA nuclear para o meio extracelular por meio de vesículas secretoras (34). Além disso, evidências que apontam que o 
DNA extracelular pode ter origem mitocondrial indicam vias alternativas de formação de NETs independente de morte celular (35).

A formação de NETs foi descrita inicialmente como um processo dependente da geração de EROs pelo complexo enzimático da NADPH-oxidase $(36,37)$ e que o requerimento de EROs é estímulo-dependente (38-40). Outros fatores como a ativação da via de sinalização Raf-MEK-ERK, o requerimento de arginina-peptidil-deaminase tipo 4 (PAD-4, do inglês Peptidyl-arginine-deiminase type 4) e das enzimas elastase de neutrófilos (NE, do inglês neutrophil elastase) e mieloperoxidase (MPO) mostraram-se necessárias para a formação das NETs (41-44). Embora o mecanismo pelo qual as NETs são formadas ainda não seja completamente conhecido, acredita-se que as EROs estejam envolvidas na liberação das enzimas NE e MPO dos grânulos citoplasmáticos, que então se translocam para o núcleo e digerem as histonas nucleossomais promovendo a descondensação da cromatina, processo dependente de PAD-4. Em seguida, a membrana nuclear é rompida e a cromatina liberada no citoplasma, misturando-se com os componentes citoplasmáticos. Por fim, o rompimento da membrana citoplasmática culmina na liberação das NETs para o meio extracelular $(14,24$, 45- 47).

Neutrófilos deficientes em algum dos componentes demonstrados como essenciais para a formação de NETs, como EROs e MPO, são incapazes de formar estas estruturas (14, 37, 44, 48). Neutrófilos de pacientes com a doença granulomatosa crônica (DGC), imunodeficiência primária (IDP) causada por mutações nos genes que codificam as subunidades da NADPH-oxidase, não produzem EROs e são incapazes de gerar NETs, o que se acredita ter relação com a suscetibilidade a infecções oportunistas apresentada por estes pacientes (37). O envolvimento deste mecanismo de resposta na imunopatologia e na susceptibilidade a infecções oportunistas apresentada por pacientes com IDPs ainda não é conhecida, embora falhas na geração de NETs têm sido descritas como fator contribuinte para o aumento da suscetibilidade a infecções em diversas condições clínicas $(37,46,49)$.

A resposta apropriada de neutrófilos é essencial para o controle de infecções causadas por diversas classes de patógenos, sendo de grande importância para a resposta contra infecções fungicas (50- 52). Pacientes com doenças que apresentam a característica hematológica de neutropenia recorrente exibem suscetibilidade aumentada a infecções (5355), ilustrando a importância dos neutrófilos na contenção de infecções. A redução do número de neutrófilos é uma manifestação hematológica presente em diversas condições clínicas de origem geneticamente heterogêneas, com etiologia muitas vezes não conhecidas (56). A neutropenia pode ocorrer em decorrência de diversos fatores, como defeitos na granulopoiese, 
destruição periférica ou distribuição anormal nos tecidos (57). Uma doença que apresenta como característica hematológica a neutropenia crônica é a Síndrome de Hiper IgM ligada ao X (X-HIGM, do inglês X-linked Hiper IgM) (58).

\subsection{Deficiência de CD40L: A Síndrome de Hiper IgM ligada ao X}

As Síndromes de Hiper-IgM (HIGM) são um grupo heterogêneo de desordens genéticas que levam a defeitos na troca de classe das imunoglobulinas (Ig), resultando em níveis séricos elevados ou normais de $\operatorname{IgM}$ associado à deficiência ou ausência dos anticorpos IgG, $\operatorname{IgA}$ e $\operatorname{IgE}(59,60)$. As HIGMs podem ser causadas por mutações autossômicas recessivas, nas quais o defeito genético está localizado em genes que codificam a molécula de CD40 e em moléculas envolvidas na geração e reparo de quebras de DNA geradas durante a troca de classe das Ig, como a enzima desaminase induzida por ativação (AID, do inglês activation-induced cytidine deaminase) e a enzima uracil-N-glicosidase (UNG), ou podem ser causadas por mutações no gene do CD40 ligante (CD40L) localizado no cromossomo X, levando à X-HIGM ou deficiência de CD40L (61), subtipo mais grave e de maior incidência dentre as HIGM (70\% dos casos, frequência estimada em 1/1.000.000 de nascimentos) (60, $62)$.

A deficiência do CD40L foi descrita pela primeira vez em 1961 por Rosen e Burtin. Os pacientes descritos apresentavam linfonodos estruturalmente pouco organizados e ausência de centro germinativo, além de níveis séricos de $\operatorname{IgG}$ baixos associados a elevação nos níveis de IgM (63- 65). Contudo, embora a síndrome tenha sido inicialmente caracterizada pelos níveis séricos elevados de IgM, dados atuais revelam que em $40 \%$ dos casos os níveis séricos encontram-se normais, enquanto que $6 \%$ dos pacientes apresentam níveis séricos de $\operatorname{IgM}$ baixos (66).

Pacientes deficientes de CD40L normalmente apresentam infecções recorrentes já no primeiro ano de vida, além de neutropenia crônica, distúrbios gastrointestinais e alterações hematológicas (Tabela 2), condições letais na ausência de intervenção médica apropriada (61, 62, 67). Além de infecções bacterianas intra e extracelulares, pacientes deficientes de CD40L apresentam alta susceptibilidade a infecções fúngicas, particularmente por Pneumocytis jiroveci, Candida albicans, Cryptococcus e Histoplasma (68, 69). Estudo recente revelou que pacientes brasileiros com deficiência de CD40L apresentam incidência aumentada de infecções fúngicas em comparação com pacientes da Europa e da América do Norte (82\% e 
34-57\%, respectivamente), além de apresentarem infecções por microrganismos até então não descritos em nestes pacientes, como pelo fungo oportunista Paracoccidioides brasiliensis (70).

Tabela 2 - Manifestações clínicas na deficiência de CD40L (61).

\begin{tabular}{ll}
\hline Manifestações clínicas & $\mathbf{N}(\%)^{*}$ \\
\hline Pneumonia & $110(81)$ \\
$\quad$ Pneumocystis jiroveci & $56(41)$ \\
Infecção do trato respiratório superior & $88(65)$ \\
Neutropenia & $88(65)$ \\
Crônica & $52(38)$ \\
Intermitente/ cíclica & $36(27)$ \\
Anemia & $30(22)$ \\
Diarréia & $55(41)$ \\
Ulcera oral & $49(36)$ \\
Sepse & $18(13)$ \\
Hepatite & $16(12)$ \\
Colangite esclerosante & $16(12)$ \\
Infecções do sistema nervoso central & $16(12)$ \\
Tumores & $5(4)$ \\
\hline
\end{tabular}

* Registro EUA/Europeu, 135 pacientes no total.

Devido às alterações na produção de anticorpos, pacientes deficientes de CD40L são comumente submetidos à terapia de reposição de $\operatorname{Ig}$ por meio de administração intravenosa ou subcutânea, a qual reduz significativamente a frequência e gravidade das infecções $(68,69)$, apesar de não ser eficaz na prevenção de distúrbios hematológicos e desenvolvimento de tumores (61). Associada à reposição de Ig, terapias antifúngicas e antibacterianas podem ser administradas para prevenir ou tratar infecções em curso, enquanto que a administração de GCSF recombinante mostrou-se eficaz na reversão dos quadros de neutropenia apresentados pelos pacientes $(68,69,71,72)$, embora alguns pacientes persistam com os quadros de neutropenia mesmo em tratamento com G-CSF, característica intrigante e de etiologia ainda desconhecida. Atualmente a única intervenção curativa definitiva disponível para pacientes deficientes de CD40L é o transplante de células tronco hematopoiéticas (HSCT, do inglês hematopoietic stem cell transplantation) $(67,69,73,74)$, procedimento ainda pouco frequente na América Latina, como mostram dados que apontam que menos de $10 \%$ dos transplantes necessários no tratamento de IDPs na América Latina são realizados (75).

Apesar dos protocolos de tratamento mostarem eficácia na redução da incidência de infecções em pacientes com defiência de CD40L $(58,76)$, infecções oportunistas causadas por 
fungos persistem como causa significativa de morbidade e mortalidade nestes pacientes (69) e a expectativa de vida de pacientes deficientes de CD40L é menor que $20 \%$ até a idade de 25 anos (77), demonstrando assim a necessidade de desenvolvimento de novas estratégias terapêuticas para tratamento desta doença e que visem o restabelecimento da resposta microbicida e melhora na qualidade de vida destes pacientes.

Uma marcante característica clínica apresentada por pacientes com deficiência de CD40L é a neutropenia crônica, manifestada de forma cíclica ou intermitente (57, 58). A etiologia da neutropenia nestes pacientes não é completamente conhecida, mas acredita-se que a ausência da interação do CD40L solúvel (CD40Ls) com células estromais da medula óssea possua relação com este achado clínico.

\subsection{A interação CD40-CD40L na resposta imune}

O CD40L, também conhecido como CD154, é uma proteína de membrana do tipo II pertencente à família do fator de necrose tumoral (TNF, do inglês tumor necrosis factor) expressa na superfície celular como trímero. O gene do CD40L (CD40LG) está localizado no cromossomo $\mathrm{X}$ e é composto por cinco éxons que codificam a porção intracelular, transmembrana e extracelular da molécula (78) (Figura 3). O CD40L é altamente expresso por células TCD4+ e plaquetas após ativação, o qual pode ser clivado em sua forma CD40Ls e agir de maneira sistêmica (79), além de ser expresso em menor quantidade por células TCD8+, células natural killer (NK), células B, DCs e células endoteliais $(4,79)$.

Figura 3 - Esquema da estrutura do CD40LG.

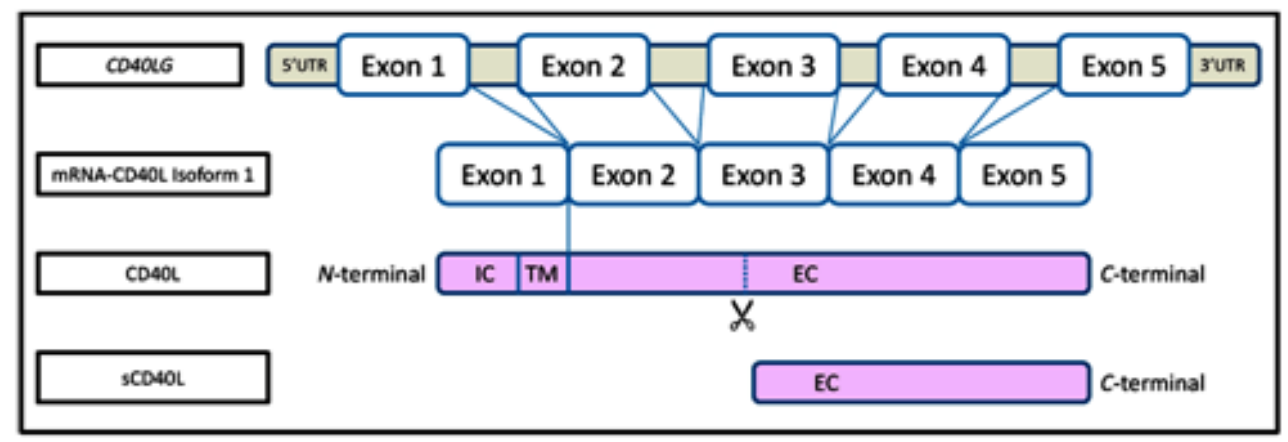

O CD40LG é formado por cinco éxons que formam o domínio intracelular (IC), transmembrana (TM) e extracelular (EC). Em células TCD4+ e plaquetas, a proteína pode ser clivada e gerar a isoforma solúvel do CD40L (79, adaptado). 
O principal receptor do $\mathrm{CD} 40 \mathrm{~L}$ é o $\mathrm{CD} 40$, proteína transmembrana do tipo I pertencente à superfamília de receptores do TNF cujo gene encontra-se localizado no cromossomo 20 (80). O CD40 é constitutivamente expresso em células B, monócitos, macrófagos, neutrófilos, plaquetas, células endoteliais, células epiteliais, DCs, fibroblastos e adipócitos $(4,79)$. Após a interação com seu ligante, ocorre na porção citoplasmática do CD40 o recrutamento de proteínas adaptadoras do tipo TRAF, que iniciam diferentes vias de sinalização intracelulares, incluindo a ativação das vias de NF-ķB, MAPKs, PI3K e PLC\}. A sinalização pode também ocorrer através da ação de proteínas capazes de ligar diretamente à porção citoplasmática do CD40 ativado, como a Jak3, gerando subsequente ativação da via Jak-STAT (78, 81- 83). No entanto, outras moléculas com ligação no CD40L foram identificadas recentemente, como as moléculas $\alpha \mathrm{M} \beta 2$ ou Mac-1, $\alpha \operatorname{Ilb} \beta 3$ e $\alpha 5 \beta 1$, reforçando a importância da sinalização pelo CD40L em diferentes contextos da resposta imune (84).

A sinalização CD40-CD40L exerce importantes efeitos em diversos tipos celulares (Figura 4). Em células B, a sinalização promove a formação do centro germinativo, a troca de classe e hipermutação somática das Igs e a geração de células B de memória, razão pela qual pacientes deficientes de CD40L apresentam produção de anticorpos alterada (65). Em DCs, a sinalização pelo CD40 induz a produção de citocinas e a expressão de moléculas coestimulatórias, gerando sinais de maturação para que as DCs adquiram as características necessárias para a efetiva ativação das células $\mathrm{T}$ e desencadeamento da resposta imune adaptativa (86). Em fagócitos, a interação do CD40 com o CD40L induz a ativação de macrófagos e aumento da expressão de Mac-1 pelos neutrófilos. Além disso, estudos sugerem que a ligação do CD40Ls ao CD40 presente nos neutrófilos aumenta o burst oxidativo dos neutrófilos, contribuindo para a eliminação de microrganismos invasores (87- 89).

Outra importante função da sinalização CD40-CD40L ocorre na medula óssea. Células estromais da medula óssea expressam constitucionalmente o receptor CD40 em sua superfície e a ligação com o CD40Ls induz aumento a secreção de G-CSF e GM-CSF (do inglês granulocyte-macrophage colony-stimulating factor), citocinas essenciais na regulação da granulopoiese (4). Além disso, o G-CSF na medula óssea suprime a expressão de CXCL-12 pelas células estromais, molécula envolvida na retenção de neutrófilos na medula óssea devido à sua interação com o receptor CXCR4 expresso nestas células, participando desta maneira da regulação do número de neutrófilos no sangue (90). 
Figura 4 - A interação CD40-CD40L na resposta imune.

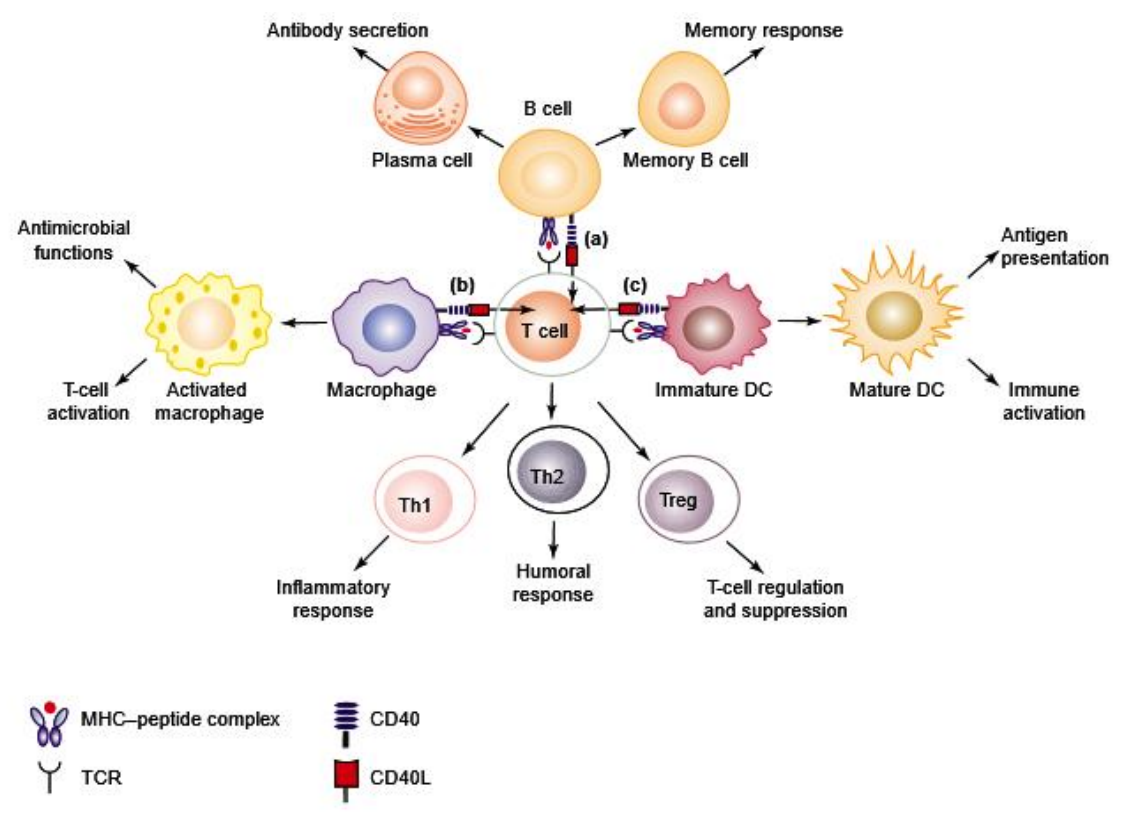

Células T expressando CD40L interagem com o CD40 expresso por células B e induz diferentes funções em células $B$, macrófagos e DCs (85).

A etiologia da neutropenia apresentada pelos pacientes com deficiência de CD40L não é completamente conhecida, mas acredita-se que a ausência da interação CD40Ls-CD40 na medula óssea durante a geração e maturação dos neutrófilos possua relação com esta característica hematológica (4), embora a influência da ausência desta interação durante a maturação dos neutrófilos sobre o perfil celular posteriormente apresentado permaneça não elucidada. Suportando esta teoria, estudos apontam que o tratamento com G-CSF recombinante resulta em contagens normais de neutrófilos em pacientes deficientes de CD40L $(71,72)$. O tratamento com G-CSF tem sido amplamente utilizado no tratamento de neutropenias de etiologias distintas e mostrou-se eficaz na reversão de neutropenias severas, embora não seja eficiente na correção de defeitos funcionais apresentado por estes neutrófilos (91).

\subsection{Interferon-gama}

Os interferons são uma grande família de citocinas estruturalmente relacionadas que medeiam a resposta imune natural e adquirida contra patógenos intra e extracelulares. Os 
interferons são classificados nos tipos I, II e III e diferem entre si de acordo com a sequência do receptor, locus genético e células responsáveis pela sua produção (92). O interferon-gama (IFN- $\gamma)$, também conhecido como interferon do tipo II, é uma proteína trimérica produzida principalmente pelas células NK, linfócitos $\mathrm{T} \mathrm{CD}^{+}$do subtipo Th1 e pelos linfócitos $\mathrm{T} \mathrm{CD} 8^{+}$, e em menor proporção por macrófagos, DCs e células B $(92,93)$. A produção de IFN- $\gamma$, que se dá principalmente em resposta à citocina IL-12 secretada pelas células apresentadoras de antígenos, possui papel essencial na defesa do hospedeiro e regulação da resposta imune, apresentando atividade antiviral, antimicrobicida e antitumoral $(94,95)$. A via de sinalização JAK-STAT é a principal iniciada após a estimulação pelo IFN- $\gamma$, embora possa ocorrer também ativação de vias independentes de STAT-1, como a via das MAP kinase, PI3K e NFķB (96).

Nos neutrófilos, as principais ações do IFN- $\gamma$ são a estimulação da transdução de sinal, expressão gênica, liberação de citocinas e melhora de funções efetoras como burst oxidativo, fagocitose e citotoxicidade celular dependente de anticorpos, além de diminuir a taxa de apoptose dos neutrófilos (97). Uma vez que a principal função dos neutrófilos é a eliminação dos microrganismos invasores, diversos estudos investigaram a capacidade do IFN- $\gamma$ modular esta função e mostram o IFN- $\gamma$ como potente estimulador da atividade citotóxica (97), inclusive contra fungos oportunistas causadores de infecções em pacientes com deficiência de CD40L, como A. fumigatus (98), C. albicans (99, 100) e P. brasiliensis (101). Em concordância com estes resultados, estudo com neutrófilos de pacientes deficientes de CD40L tratados in vitro com IFN- $\gamma$ recombinante mostrou melhora na geração de EROs e na capacidade microbicida (manuscrito em análise, Journal of Allergy and Clinical Immunology).

Atualmente o IFN- $\gamma$ é licenciado para a aplicação clínica em tuberculose, osteopetrose e defeitos do eixo IFN- $\gamma$ / IL-12 (95). A principal indicação do IFN- $\gamma$ é a DGC, com o objetivo de melhorar a função microbicida dos fagócitos e levando assim a melhora significativa na qualidade de vida do paciente, havendo redução de $70 \%$ na incidência de infecções graves $(102,103,104)$. Tendo em vista a importância da resposta de neutrófilos contra patógenos invasores e a influência do IFN- $\gamma$ na melhora da atividade microbicida e demais funções efetoras dos neutrófilos, o IFN- $\gamma$ emerge como potencial ferramenta terapêutica para tratamento de doenças que apresentam como característica susceptibilidade aumentada a infecções possivelmente relacionadas a defeitos funcionais de neutrófilos. 


\section{OBJETIVO}

\section{$2.1 \quad$ Objetivo geral}

Avaliar a geração de NETs em pacientes deficientes de CD40L e verificar a influência do tratamento in vitro com IFN- $\gamma$ sobre esta resposta.

\subsection{Objetivos específicos}

Avaliar em neutrófilos de pacientes deficientes de CD40L:

- Geração de NETs;

- Produção de EROs;

- Perfil de maturação;

- Efeito do tratamento in vitro com IFN- $\gamma$ sobre as respostas avaliadas. 


\section{MATERIAIS E MÉTODOS}

\subsection{Casuística}

O estudo utilizou amostras de sangue periférico de indivíduos sadios, sem a presença de doença infectocontagiosa ou congênita diagnosticada até o momento da coleta (grupo controle) e amostras de pacientes deficientes de CD40L previamente diagnosticados (105). As características moleculares das mutações genéticas dos pacientes selecionados para participar do estudo encontram-se descritas na Tabela 3.

Tabela 3 - Pacientes envolvidos no estudo: mutações, histórico de infecções fúngicas e ensaios realizados.

\begin{tabular}{|c|c|c|c|c|c|c|}
\hline \multirow{2}{*}{ Pct } & \multirow{2}{*}{ Mutação } & \multirow{2}{*}{ Tipo de mutação } & \multirow{2}{*}{$\begin{array}{l}\text { Infecções } \\
\text { fúngicas }\end{array}$} & \multicolumn{3}{|c|}{ Ensaios realizados } \\
\hline & & & & NETs & EROs & FEN \\
\hline $\mathrm{P} 1$ & c.633_634insAGCC & Inserção & N/I & $\mathrm{x}$ & $\mathrm{x}$ & $\mathrm{x}$ \\
\hline $\mathrm{P} 2$ & c.213_216delATAG & Deleção frameshift & P. joroveci & $\mathrm{x}$ & & $\mathrm{x}$ \\
\hline P3 & c. $433 \mathrm{~T}>\mathrm{G}$ & Missense & P. joroveci & $\mathrm{x}$ & $\mathrm{x}$ & $\mathrm{x}$ \\
\hline $\mathrm{P} 4$ & c. $213-1 \mathrm{G}>\mathrm{T}$ & Sítio de splice & & & $\mathrm{x}$ & \\
\hline P5 & c. $213-1 \mathrm{G}>\mathrm{T}$ & Sítio de splice & $\begin{array}{l}P . \text { joroveci } \\
\text { Aspergilus sp. }\end{array}$ & $\mathrm{x}$ & $\mathrm{x}$ & $\mathrm{x}$ \\
\hline P6 & c. $475 \mathrm{G}>\mathrm{A}$ & Nonsense & C. albicans & & $\mathrm{x}$ & $\mathrm{x}$ \\
\hline P7 & c. $213 \_216$ delATAG & Deleção frameshift & $\begin{array}{l}\text { C. albicans } \\
P . \text { joroveci }\end{array}$ & $\mathrm{x}$ & & \\
\hline
\end{tabular}

Pct: paciente; N/I: Infecção do trato urinário por fungo não identificado; FEN: ensaio de fenotipagem para avaliar perfil de maturação.

As amostras de sangue destinadas ao desenvolvimento do protocolo experimental foram coletadas somente de pacientes em condições clínicas estáveis de saúde, evitando deste modo qualquer alteração no quadro clínico do paciente. A coleta de amostra de sangue dos indivíduos sadios ocorreu pareada a coleta dos pacientes, mantendo desta maneira as mesmas condições de coleta, armazenamento e transporte das amostras dos dois grupos.

Pacientes menores de idade estavam acompanhados dos pais ou responsáveis no momento da coleta, e a retirada de sangue só ocorreu após assinatura do Termo de Consentimento Livre e Esclarecido (TCLE). Todos os procedimentos realizados não ultrapassaram os limites descritos de risco mínimo, de acordo com a regulamentação da convenção de Genebra para pesquisa com seres humanos e do Conselho Nacional de Saúde. O projeto de pesquisa, o protocolo experimental e o termo de consentimento contemplaram os 
quesitos éticos aprovados pelo Comitê de Ética em Pesquisas com Seres Humanos do ICB USP.

\subsection{Obtenção PMN de sangue periférico}

Os PMNs humanos foram isolados a partir de sangue periférico coletado em tubo com heparina (BD Vacutainer, EUA) por sedimentação em Dextran (Sigma-Aldrich, EUA) seguido de centrifugação em gradiente de Ficoll-Hypaque (GE Healthcare, Suiça). Resumidamente, 15-20 mL de sangue foram diluídos em $15 \mathrm{~mL}$ de Dextran 6\% e sedimentados durante 25-30 minutos a $37{ }^{\circ} \mathrm{C}$. A fração rica em leucócitos e pobre em eritrócitos (camada superior) foi colocada sobre $12 \mathrm{~mL}$ de Ficoll-Hypaque (densidade = 1,077 $\mathrm{g} / \mathrm{mL}$ ) e seguida de separação por centrifugação a $900 \mathrm{RCF}$ (força centrífuga relativa, do inglês relative centrifugal force) durante 20 minutos sem freio. A camada superior foi então desprezada e a lise hipotônica das hemácias foi realizada pela adição de $3 \mathrm{~mL}$ de água destilada estéril gelada seguida da adição de $5 \mathrm{~mL}$ de PBS estéril (tampão fosfato salino, do inglês phosphate buffered saline) e centrifugação a 600 RCF durante 10 minutos. Os neutrófilos foram então ressuspendidos em meio RPMI 1640 (Life Technologies, EUA), sem vermelho de fenol, suplementado com $5 \%$ de soro fetal bovino (SFB) inativado pelo calor. A pureza da separação celular foi rotineiramente avaliada por citometria de fluxo, analisando-se os marcadores de superfície CD11b e CD16 (106) (ANEXO A).

\subsection{Estimulação celular}

Os estímulos utilizados nos protocolos experimentais, suas respectivas concentrações e breve descrição de suas atividades encontram-se na Tabela 4. As concentrações utilizadas nos protocolos experimentais foram definidas após ensaios de padronização com diferentes concentrações (dados não apresentados). Para verificar a toxicidade das concentrações de selecionadas, foi realizado ensaio de viabilidade celular pela utilização do reagente LIVE/DEAD® (Life Technologies) por citômetro de fluxo Atune NXT (Thermo Fisher Scientific), adaptados a partir das especificações do fabricante (ANEXO B). 
Tabela 4 - Estímulos utilizados para a ativação/desafio dos neutrófilos

\begin{tabular}{|c|c|c|}
\hline Composto & $\begin{array}{l}\text { Concentração ou } \\
\text { proporção }\end{array}$ & Descrição \\
\hline PBS & & $\begin{array}{l}\text { Solução tamponada utilizada como controle } \\
\text { negativo de estimulação }\end{array}$ \\
\hline PMA & $50 \mathrm{nM}$ & $\begin{array}{l}\text { Ativador de proteína quinase } \mathrm{C}(\mathrm{PKC}) \text { utilizado } \\
\text { como estímulo para ativação }\end{array}$ \\
\hline IFN- $\gamma$ & 100 ou $1000 \mathrm{UI} / \mathrm{mL}$ & Citocina importante para ativação de fagócitos \\
\hline C. albicans & $\left(\mathrm{MOI}^{*} 1: 2\right)$ & $\begin{array}{l}\text { Fungo causador de infecções oportunistas no } \\
\text { grupo de pacientes em estudo }\end{array}$ \\
\hline
\end{tabular}

* multiplicidade de infecção (do inglês multiplicity of infection).

\subsubsection{Cultivo de Candida albicans}

As C. albicans foram cultivadas em tubo cônico de $50 \mathrm{~mL}$ com $5 \mathrm{~mL}$ de caldo Sabouraud a $37{ }^{\circ} \mathrm{C}$ pelo período de $14-16$ horas, sob agitação. Após o período de cultura, as C. albicans foram centrifugadas a $900 \mathrm{RCF}$ por 5 minutos, o sobrenadante descartado e resuspendidas em $1 \mathrm{~mL}$ de PBS para contagem do número de leveduras em câmara hemocitométrica. Uma vez que a geração de NETs frente ao patógeno mostrou-se dependente do tamanho e morfologia do patógeno, sendo a morfologia fúngica de hifa a ideal para indução de NETs (107), a capacidade das C. albicans em alternar sua morfologia de levedura para hifa após incubação com os neutrófilos foi avaliada. Para tanto, os neutrófilos foram pulsados com $C$. albicans na morfologia de levedura e a morfologia do fungo avaliada em diferentes tempos por microscopia de luz. A partir de 30 minutos as C. albicans iniciam a transição morfológica de levedura para hifa (formação de tubos germinativos), sendo que com 2 horas de cocultura com neutrófilos todas as $C$. albicans já adquirem a morfologia de hifa, condição ideal para o estudo (ANEXO C).

\subsection{Avaliação da geração de NETs}

\subsubsection{Quantificação de NETs}

A quantificação das NETs foi realizada em fluorímetro com leitor de microplacas como previamente descrito, com adaptações (108). Os neutrófilos ( 1 x $10^{5}$ células) foram 
tratados por 2 horas com IFN-y e posteriormente estimulados com PMA ou C. albicans (concentrações descritas na Tabela 4), por período de 3 horas, em placa de 96 poços preta, estéril e com fundo transparente. Após tempo de estímulo, o sobrenadante foi cuidadosamente retirado e foi adicionado aos poços $50 \mu \mathrm{L}$ de Sytox Orange na concentração de $5 \mu \mathrm{M}$ (Life Technologies, EUA) durante 10 minutos, em temperatura ambiente e protegido de luz, para marcação do DNA extracelular. Após marcação, a placa foi imediatamente lida em fluorímetro Spectra Max M3 (Molecular Devices, EUA), utilizando comprimento de onda de excitação de $547 \mathrm{~nm}$ e detecção de $570 \mathrm{~nm}$. Os resultados foram analisados em Software Prism 4.0 e expressos em Unidade Relativa de Fluorescência (RFU, do inglês Relative Fluorescence Units).

\subsubsection{Visualização da formação de NETs}

A visualização das NETs em microscópio de fluorescência foi realizada conforme previamente descrito, com adaptações (109) (ANEXO D). Resumidamente, os neutrófilos isolados $\left(2 \times 10^{5}\right.$ células $)$ foram sedimentados por uma hora em lamínulas de $13 \mathrm{~mm}$ de diâmetro (Knittel Glass, Alemanha) em placas de 24 poços. Após sedimentação, as células foram tratadas por 2 horas com IFN-y e posteriormente estimuladas com PMA ou C. albicans (concentrações descritas na Tabela 4) por 3 horas. Após tempo de estímulo, as células foram fixadas com paraformaldeído (4\%) por 12 horas e então lavadas com PBS, permeabilizadas em solução de Triton X-100 (0,5\%) e bloqueadas com Tampão de bloqueio (3\% de soro humano AB, $1 \%$ de albumina sérica bovina, e 0,05\% de Tween 20 em PBS) por 30 minutos a $37{ }^{\circ} \mathrm{C}$. Após o bloqueio, as células foram incubadas com anticorpos primários anti-histona H2A/ H2B (doado por Prof. Arturo Zychlinsky, Max Planck Institute, Alemanha) e antielastase de neutrófilos (Calbiochem, USA) por 1 hora e marcadas com anticorpos secundários Alexa Fluor 488 e Alexa Fluor 546 (Invitrogen, USA), respectivamente, por 1 hora. Para marcação do DNA, foi utilizado Hoechst 33342 (Santa Cruz Biotec, USA). As lamínulas foram montadas em Mowiol sobre lâminas e analisadas em microscópio de fluorescência AXIO Vert A.1 (Carl Zeiss, Alemanha). 


\subsection{Avaliação da produção de EROs}

A produção de EROs foi avaliada através de ensaio de quimioluminescência, como previamente descrito, com adaptações (110). Resumidamente, os neutrófilos ( 1 x $10^{5}$ células) foram incubados em microplacas de 96 poços, brancas e de fundo chato, em volume final de $200 \mu \mathrm{L}$ de PBS por poço e suspensão celular tratada ou não com IFN-y por 2 horas. Após tempo de tratamento, foram acrescentados aos poços PMA ou C. albicans (concentrações descritas na Tabela 4) e em seguida adicionado aos poços o substrato Luminol (100 $\mu \mathrm{M}$, Sigma, EUA) para leitura imediata da placa. As reações foram monitorizadas por duas horas, a $37{ }^{\circ} \mathrm{C}$, usando luminômetro de microplacas (EG\&G Berthold LB96V, Alemanha). Os resultados foram analisados em software Prism 4.0, expressos em Unidades Relativas de Luz (URL) e posteriormente analisados de acordo com os valores de área sob a curva gerados (AUC, do inglês Area Under Curve).

\subsection{Avaliação do perfil de maturação}

O perfil de maturação celular foi avaliado pela quantificação da expressão das moléculas CD11b, CD15 e CD16, conforme previamente descrito (106). Para tanto, neutrófilos foram incubados com PBS contendo $10 \%$ de soro humano $\mathrm{AB}$ e $2 \%$ de SFB durante 10 minutos para evitar ligações não específicas. Após incubação, as células $\left(5 \times 10^{5}\right.$ células) foram incubadas com os anticorpos anti-CD15, anti-CD16 e anti-CD111b (BD Biosciences, EUA) por 30 minutos a $4{ }^{\circ} \mathrm{C}$ em ambiente escuro (em volume final de $100 \mu \mathrm{L}$ de RPMI) em tubos de poliestireno de $5 \mathrm{~mL}$ com fundo arredondado (tubos de citometria). Após tempo de incubação, as células foram lavadas duas vezes com $500 \mu \mathrm{L}$ de PBS (centrifugação a 900 RCF por 5 minutos) e fixadas em PBS contendo paraformaldeído (0,5\%). A análise foi realizada em citômetro de fluxo Atune NxT (Thermo Fisher Scientific, USA). A população das células analisadas foi determinada em escala linear utilizando os parâmetros de tamanho celular (FSC, do inglês foward scater) versus complexidade celular (SSC, do inglês side scater). Após a seleção da população celular, fez-se a aquisição de 10.000 eventos em cada amostra para avaliação dos marcadores. Para a análise utilizou-se o software FlowJo (Tree Star Inc., Ashland, OR, EUA). A partir desta análise, foram obtidos dados de mediana da intensidade de fluorescência (MFI, do inglês Median Fluorescence Intensity). 


\subsection{Análise estatística}

As análises estatísticas foram realizadas com o software Prism 5.00 (GraphPad Software, USA). Após aplicação de teste de normalidade (D'Agostino-Pearson) verificamos o teste estatístico mais indicado. Devido à distribuição amostral apresentada e ao número de análises realizadas, foi aplicado o teste estatístico não paramétrico de Mann-Whitney para comparação entre os grupos avaliados no estudo (indivíduos saudáveis versus pacientes deficientes de CD40L). Para comparar o efeito do tratamento celular dentro do mesmo grupo de indivíduos empregou-se o teste pareado não paramétrico de Wilcoxon. O nível de significância adotado foi de $\mathrm{p}<0,05$. 


\section{RESULTADOS}

\subsection{Avaliação da geração de NETs}

A quantificação da geração de NETs foi realizada após estimulação dos neutrófilos por 3 horas com PMA ou C. albicans. A geração de NETs pelos neutrófilos dos pacientes deficientes de CD40L mostrou-se significativamente reduzida em comparação com indivíduos saudáveis após estímulo com PMA (Figura 5). A geração de NETs frente ao estímulo com $C$. albicans não mostrou diferença estatisticamente significativa, quando comparados pacientes e indivíduos saudáveis. O tratamento com IFN-y não influenciou o padrão de resposta apresentado por ambos os grupos avaliados.

Figura 5 - Avaliação da geração de NETs em pacientes deficientes de CD40L.

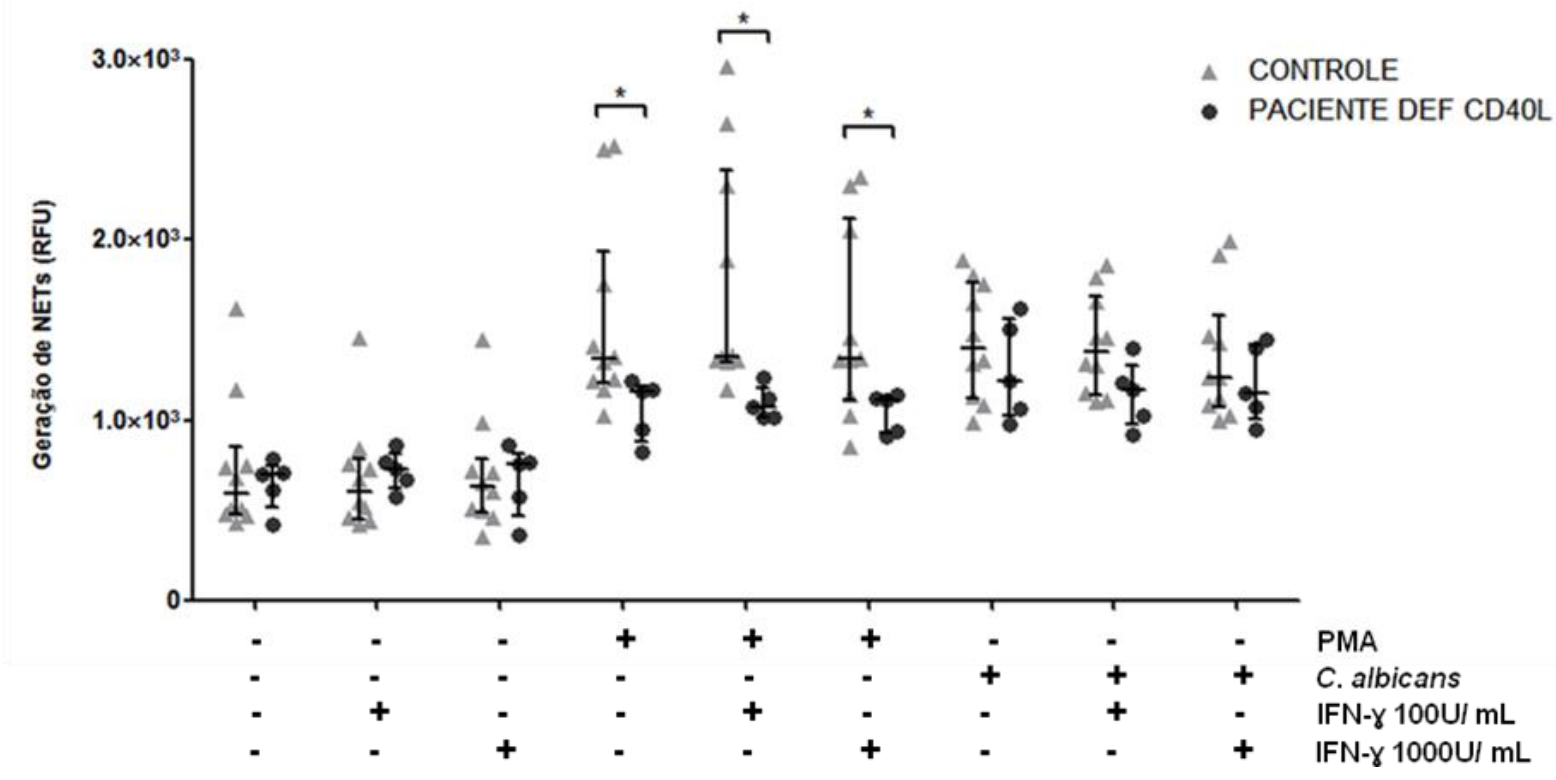

Os neutrófilos ( 1 x $10^{5}$ células) foram tratados com IFN-y nas concentrações indicadas por 2 horas em estufa de $\mathrm{CO}_{2}$ a $37{ }^{\circ} \mathrm{C}$. Após tempo de tratamento, foram adicionados aos poços indicados PMA ou C. albicans e os neutrófilos incubados pelo período de 3 horas em estufa para geração de NETs. Quantificação da geração de NETs realizada em fluorímetro após marcação com reagente SYTOX Orange®. A geração de NETs pelos neutrófilos dos pacientes deficientes de CD40L mostrou-se significativamente reduzida em comparação com indivíduos saudáveis após o estimulo com PMA. *p<0,05 dentre os grupos comparados, teste de Mann-Whitney. $\mathrm{n}=10$, indivíduos saudáveis (CONTROLE); $\mathrm{n}=5$, pacientes deficientes de CD40L (PACIENTE DEF CD40L). 
Confirmando resultados obtidos na quantificação em fluorímetro, avaliação por microscopia de fluorescência mostrou redução na geração de NETs pelos neutrófilos dos pacientes quando comparados com indivíduos saudáveis estimulados com PMA (Figura 6), sendo que o tratamento com IFN-y não influenciou no padrão de resposta apresentado por ambos os grupos avaliados (imagens não apresentadas).

Figura 6 - Visualização da formação de NETs pelos pacientes deficientes de CD40L.

Controle
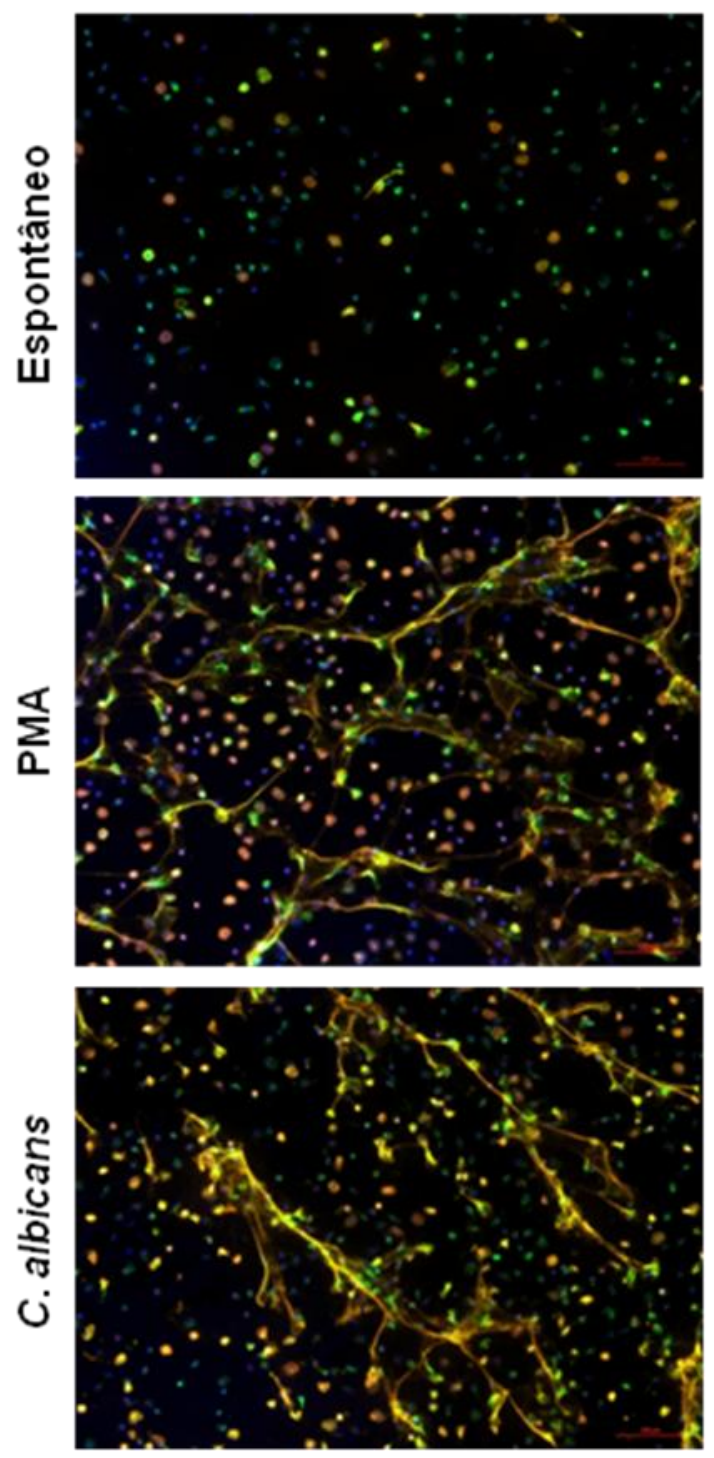

Paciente Def CD40L
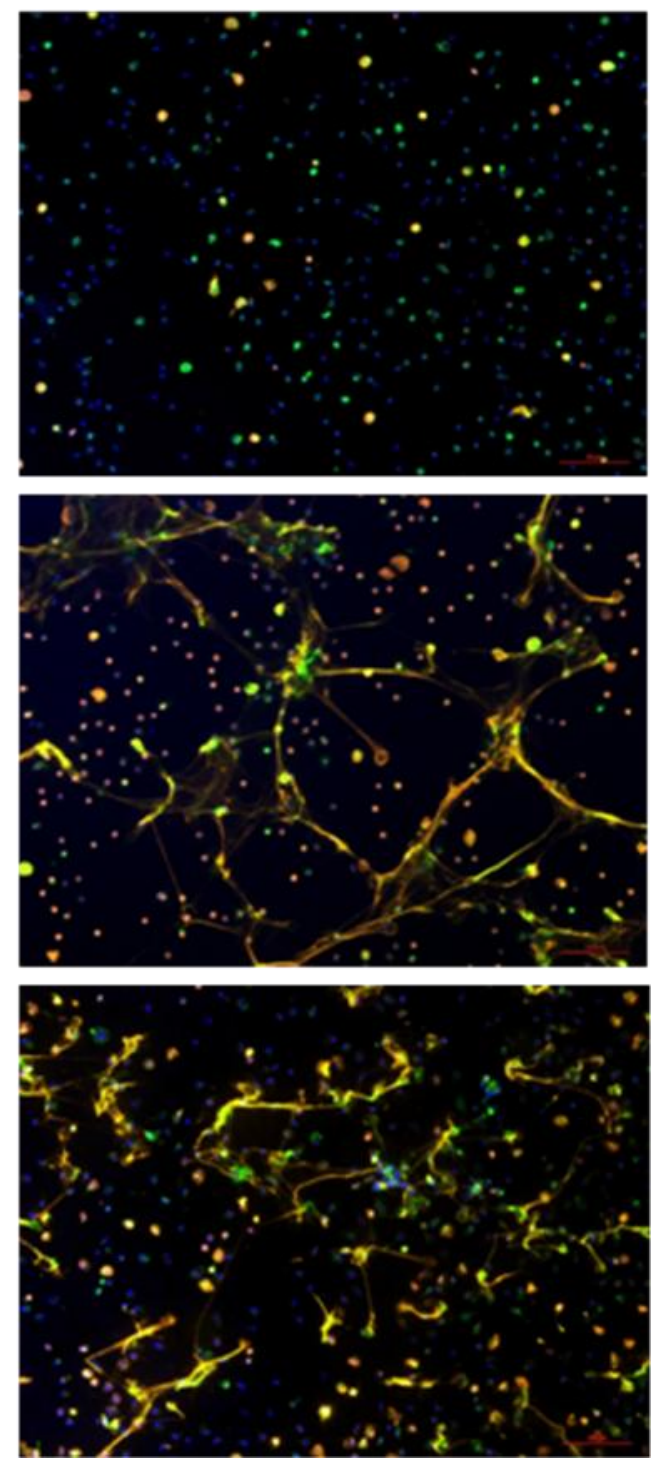

Os neutrófilos $\left(2 \times 10^{5}\right.$ células) de indivíduos saudáveis (Controle) e pacientes deficientes de CD40L (Paciente Def CD40L) foram tratados com IFN-y por 2 horas em estufa de $\mathrm{CO}_{2}$ a $37{ }^{\circ} \mathrm{C}$. Após tempo de tratamento, os neutrófilos foram estimulados com PMA ou $C$. albicans pelo período de 3 horas em estufa para geração de NETs, seguido de fixação, permeabilização celular e marcação de NETs com anticorpos anti-histona H2A/H3B (laranja) e anti-elastase de neutrófilo (verde), além de marcação do DNA com Hoechst 33342 (azul). A geração de NETs pelos neutrófilos dos pacientes mostrou-se reduzida em comparação com os indivíduos saudáveis após o estimulo com PMA. Figura representativa de 3 experimentos independentes. 


\subsection{Avaliação da produção de EROs}

As EROs foram descritas como essenciais para a geração de NETs pelo estímulo com PMA (40), A avaliação da produção de EROs foi realizada pelo estímulo dos neutrófilos com PMA ou C. albicans, com ou sem pré-tratamento com IFN-y, e geração monitorada pelo período de 2 horas em luminômetro. A partir da cinética da produção de EROs (dado não apresentado), a produção total de EROs foi quantificada pelo cálculo de AUC. Valores expressos gerados a partir do cálculo da taxa de aumento da produção de EROs nos diferentes tratamentos em comparação com a geração espontânea de cada indivíduo avaliado (Figura 7).

Figura 7 - Avaliação da produção de EROs em pacientes deficientes de CD40L.

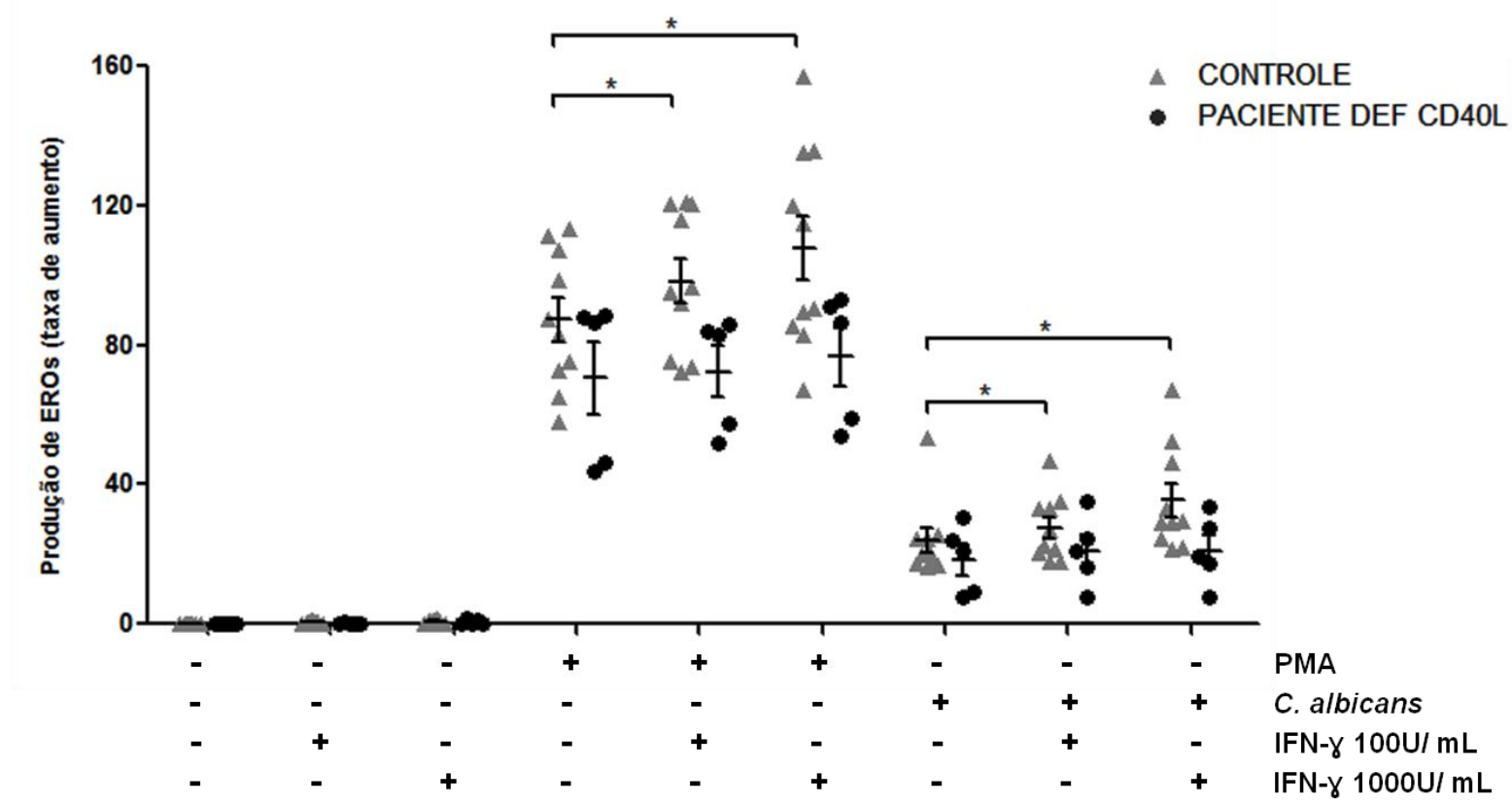

Os neutrófilos ( 1 x $10^{5}$ células) foram incubados com IFN-y nas concentrações indicadas por 2 horas em estufa de $\mathrm{CO}_{2}$ a $37{ }^{\circ} \mathrm{C}$. Após tempo de tratamento, foram adicionados aos poços indicados PMA ou C. albicans e geração de EROs monitorada por período de 2 horas em luminômetro. A produção de EROs não apresentou diferença significativamente estatística quando comparados pacientes e indivíduos saudáveis. Neutrófilos de indivíduos saudáveis apresentaram aumento significativo na geração de EROs após tratamento com IFN- $\gamma$, padrão não observado nos pacientes avaliados. ${ }^{*} \mathrm{p}<0,05$ dentre os tratamentos comparados, teste de Wilcoxon. $\mathrm{n}=10$, indivíduos saudáveis (CONTROLE); $\mathrm{n}=5$, pacientes deficientes de CD40L (PACIENTE DEF CD40L).

A produção de EROs frente aos estímulos com PMA e C. albicans não apresentou diferença significativamente estatística, quando comparados indivíduos saudáveis e pacientes deficientes de CD40L. Os neutrófilos dos pacientes deficientes de CD40L não responderam ao tratamento com IFN- - , ao contrário do observado em neutrófilos de indivíduos saudáveis 
que apresentaram aumento significativo na produção de EROs quando desafiados com PMA ou C. albicans após tratamento de 2 horas com IFN-y.

\subsection{Avaliação do perfil de maturação dos neutrófilos}

Uma vez que pacientes deficientes de CD40L apresentam defeito na granulopoiese e episódios de neutropenia recorrentes, o perfil de maturação dos neutrófilos periféricos foi avaliado pela quantificação da expressão das moléculas de superfície CD11b, CD15 e CD16 (Figura 8).

Figura 8 - Avaliação do perfil de maturação dos neutrófilos de pacientes deficientes de CD40L.

A

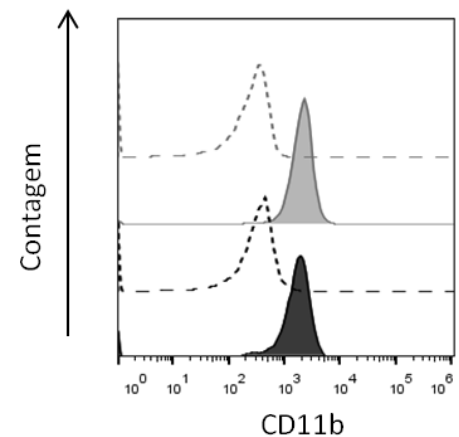

CD11b

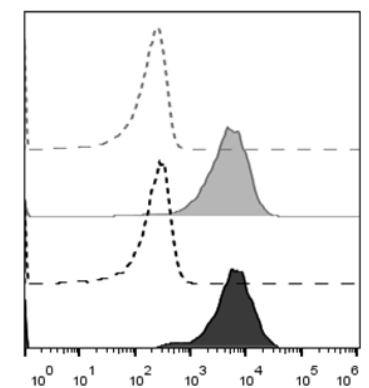

CD15 $\triangle$ CONTROLE

- PACIENTE DEF CD40L

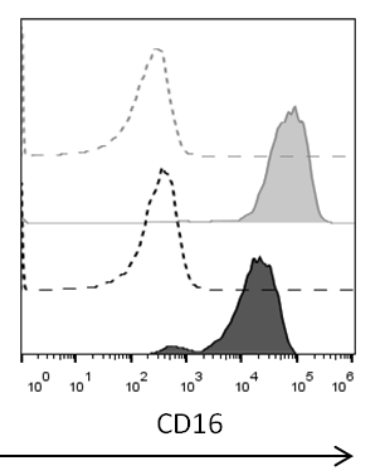

Fluorescência

B

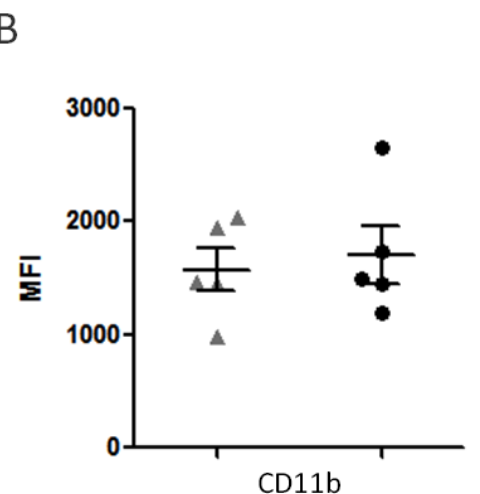

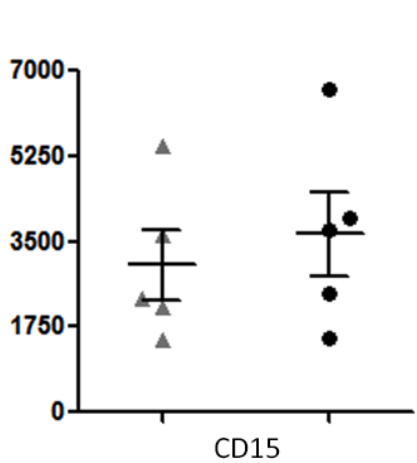

Os neutrófilos $\left(5 \times 10^{5}\right.$ células/mL) de indivíduos saudáveis (CONTROLE) e de pacientes deficientes de CD40L (PACIENTE DEF CD40L) foram marcados para as moléculas de superfície CD11b, CD15 e CD16. (A) Histograma representativo da expressão das moléculas CD16, CD15 e CD11b por indivíduos saudáveis e pacientes deficientes de CD40L. (B) Gráfico de expressão das moléculas CD16, CD15 e CD11b em indivíduos saudáveis e pacientes expressos em MFI. A expressão da molécula CD16 mostrou-se reduzida em pacientes em comparação com indivíduos saudáveis, fenótipo $\mathrm{CD} 15^{+} \mathrm{CD} 11 \mathrm{~b}^{+} \mathrm{CD} 16^{-}$característico de neutrófilos imaturos. $*_{\mathrm{p}}<0,05$ dentre os grupos comparados, de teste de Mann-Whitney. $\mathrm{n}=5$, para ambos grupos avaliados. 
Os neutrófilos dos pacientes deficientes de CD40L apresentaram expressão reduzida da molécula CD16, quando comparados com expressão dos neutrófilos de indivíduos saudáveis. Contudo, apresentaram expressão similar das moléculas CD15 e CD11b (perfil $\left.\mathrm{CD} 15^{+} \mathrm{CD} 11 \mathrm{~b}^{+} \mathrm{CD} 16^{-}\right)$, padrão de expressão característico de neutrófilos imaturos (106). 


\section{DISCUSSÃO}

Pacientes portadores da X-HIGM, imunodeficiência rara causada pela deficiência do CD40L, apresentam grande susceptibilidade a infecções por diversas classes de microrganismos, sendo que infecções oportunistas causadas por fungos representam significante causa de morbidade e mortalidade mesmo em pacientes em tratamento com os protocolos medicamentosos atualmente utilizados. Uma vez que as respostas de neutrófilos apresentam grande importância para o controle de infecções fúngicas (50-52) e estudo que aponta a influência da interação CD40-CD40L na granulopoiese (111), o presente trabalho teve como objetivo investigar se a suscetibilidade aumentada a infecções em pacientes com deficiência de CD40L poderiam estar relacionadas a defeitos na formação de NETs, mecanismo importante na resposta contra patógenos extracelulares, além de verificar o efeito do tratamento in vitro com IFN- $\gamma$ sobre essa resposta.

Diversos estudos indicam que as NETs estão presentes em grande quantidade nos sítios inflamatórios e são produzidas por neutrófilos ativados pelo contato com diversos patógenos, inclusive patógenos aos quais pacientes deficientes de CD40L são suscetíveis como C. albicans $(112,113)$ e A. fumigatus $(114,115)$, além de serem geradas pela ativação com diversos compostos químicos e produtos biológicos (23; Tabela 1). Assim, o presente estudo avaliou a geração de NETs a partir de neutrófilos pulsados com o fungo C. albicans ou ativados com o composto químico PMA, indutor clássico da geração de NETs (22). A geração de NETs após estímulo com PMA mostrou-se reduzida nos pacientes deficientes de CD40L em comparação com indivíduos saudáveis, embora a geração de NETs em resposta a $C$. albicans não tenha apresentado diferença estatisticamente significativa, quando comparados pacientes e indivíduos saudáveis (Figura 5 e 6).

Além de ser importante mecanismo de resposta dos neutrófilos frente aos patógenos, diversos estudos apontam as EROs como fator essencial para geração de NETs (22, 43, 44), fato corroborado por estudos em pacientes com DGC, IDP causada por mutações em componentes da NADPH-oxidase que apresentam defeitos na geração de EROs e ausência da geração de NETs $(35,36,37,116,117)$. Assim, para verificar se a diminuição na geração de NETs observada nos pacientes deficientes de CD40L estaria relacionada a defeitos na explosão respiratória dos neutrófilos, a produção de EROs foi quantificada por ensaio de quimioluminescência. Os resultados indicam que a diminuição na geração de NETs apresentada pelos pacientes deficientes de CD40L não decorre de defeitos na geração de EROs, uma vez que produção de EROs frente aos estímulos com PMA e C. albicans não 
apresentou diferença significativamente estatística, quando comparados indivíduos saudáveis e pacientes deficientes de CD40L (Figura 7). Além disso, a ativação adequada da explosão respiratória por neutrófilos estimulados com PMA descarta a possibilidade de defeitos na via de sinalização da PKC, uma vez que a diminuição de resposta pela ativação da via mostrou-se específica para geração de NETs.

Estudos indicam que o IFN-y atua de maneira significativa sobre os neutrófilos em sua fase de produção e estágios de diferenciação na medula (118), na expressão gênica dos neutrófilos $(119,120)$ ou potencializando respostas efetoras importantes na resposta contra patógenos $(98,118,121,122)$, mostrando-se eficaz para redução do número de infecções severas em pacientes sob tratamento $(103,123)$. O presente estudo avaliou a influência do tratamento in vitro com IFN-y sobre a geração de NETs, mecanismo ainda não descrito na literatura. Na contramão dos estudos que mostram a influência do IFN-y sobre respostas efetoras de neutrófilos, os resultados obtidos mostram que o pré-tratamento dos neutrófilos com IFN-y não influenciou no padrão de geração de NETs em ambos os grupos avaliados no estudo (indivíduos saudáveis e pacientes deficientes de CD40L; Figura 5). Uma possível hipótese para o resultado obtido é que devido ao tratamento com IFN-y ter sido realizado em neutrófilos que já concluíram o processo de diferenciação e maturação que sofrem na medula óssea, estes neutrófilos podem já apresentar possíveis defeitos gerados em decorrência de alterações durante o processo de desenvolvimento e maturação, defeitos estes não corrigíveis pelo tratamento com IFN-Y. Assim, é necessário estudos que visem avaliar a influencia do IFN-y sob a diferenciação/maturação dos neutrófilos e o padrão de resposta apresentado pelos neutrófilos quando estes sob a influencia do IFN-y durante sua geração.

A avaliação do efeito do IFN-y sobre a geração de EROs mostrou que os neutrófilos de indivíduos saudáveis apresentaram aumento significativo na produção de EROs frente a estimulação com PMA ou C. albicans quando os neutrófilos foram pré-tratados com IFN-Y (Figura 7), resultados que vão de acordo com a literatura disponível $(98,119,121,122)$. No entanto, os pacientes deficientes de CD40L não foram capazes de responder ao tratamento com IFN-y como observados nos indivíduos saudáveis, mantendo resposta similar em comparação com neutrófilos desafiados sem o pré-tratamento (Figura 7).

A sinalização pelo IFN-y é gerada pela ativação de receptor de superfície celular e resulta na ativação de vias intracelulares que culminam na transcrição de genes mediadores de respostas biológicas (96). A via de sinalização intracelular do IFN-y melhor caracterizada é a via JAK-STAT, que leva à fosforilação e translocação nuclear do fator transcricional STAT1 (96, 124). Estudo sobre a expressão gênica de neutrófilos em diferentes estágios de 
diferenciação desenvolvidos por Martinelli e colaboradores (106) mostraram que neutrófilos maturos apresentam expressão aumentada de genes relacionados a sinalização e resposta aos IFNs tipo I e II em comparação a expressão por neutrófilos imaturos. O mesmo estudo revelou que os IFNs são fortes indutores da fosforilação de STAT 1 em neutrófilos maturos, padrão não observado em neutrófilos imaturos. Desta maneira, evidências apontam que a transdução de sinal e ativação celular pelo IFN- $\gamma$ é mais eficiente em neutrófilos maduros em comparação com neutrófilos imaturos.

Uma vez que os neutrófilos de pacientes deficientes de CD40L não mostraram resposta ao tratamento com IFN- $\gamma$, mantendo similar a produção de EROs após o tratamento e em oposição ao aumento na produção observado em neutrófilos de indivíduos saudáveis (Figura 7), levantou-se a suspeita de que esta ausência de resposta ao IFN- $\gamma$ poderia estar relacionada a presença de neutrófilos periféricos imaturos nos pacientes. Assim, o perfil de maturação dos neutrófilos foi investigado pela avaliação das moléculas de superfície CD15, CD16 e CD11b, como previamente descrito (106). Confirmando suspeita, a avaliação revelou que os neutrófilos dos pacientes deficientes de CD40L apresentaram expressão significativamente reduzida da molécula CD16 quando comparados com expressão de indivíduos saudáveis, embora tenham apresentado expressão similar das moléculas CD15 e $\mathrm{CD} 11 b$ (perfil $\mathrm{CD} 15^{+} \mathrm{CD} 11 \mathrm{~b}^{+} \mathrm{CD} 16^{-}$), padrão de expressão característico de neutrófilos imaturos (Figura 8), em concordância com estudos que apontam maturação da linhagem mielocítica interrompida no estágio pró-mielócito/mielócito na medula óssea de alguns pacientes $(56,58)$.

Neutrófilos imaturos apresentam comprometimento de diversas funções, uma vez que a expressão gênica de receptores de anticorpos (p. ex. CD16), citocinas, quimiocinas, assim como moléculas envolvidas na transdução de sinal ocorre durante estágios de diferenciação terminal destas células (106). Diversos mecanismos podem estar afetados em neutrófilos imaturos, como diminuição na expressão de receptores de reconhecimento e capacidade reduzida de interação com bactérias (125), diminuição na fagocitose e sinalização de $\mathrm{Ca}^{+}$ (126), resistência a apoptose espontânea (127) e diminuição da capacidade migratória frente a diferentes estímulos (128), embora os mecanismos afetados sejam diferentes dentre as condições patológicas avaliadas, sugerindo que o mecanismo alterado que leva à imaturidade influencie no perfil de resposta subsequentemente apresentado. Além disso, estudos indicam que neutrófilos imaturos apresentam redução na geração de NETs $(106,129,130)$. Estes dados levantam fortes indícios que a diminuição na geração de NETs apresentada pelos 
pacientes deficientes de CD40L (Figuras 5 e 6) está possivelmente relacionada com a imaturidade apresentada pelos neutrófilos dos pacientes (Figura 8).

Uma vez que pacientes com deficiência de CD40L apresentam expressão normal de CD40, tanto em linfócitos B quanto em neutrófilos (ANEXO E), acredita-se que os defeitos apresentados não estejam relacionados à sinalização direta pela interação CD40L-célula. Tendo em vista que a ausência da sinalização pelo CD40L resulta em desregulação no processo de granulopoiese, como ilustrado pela neutropenia recorrente em pacientes com deficiência de CD40L, acredita-se que a influência da sinalização pelo CD40L sobre os neutrófilos seja a nível medular. Na medula óssea, a interação do CD40Ls secretado por plaquetas e linfócitos B com o CD40 expresso de maneira constitucional por células estromais da medula óssea induzem a secreção dos fatores de crescimento G-CSF e GM-CSF, citocinas centrais no processo de granulopoiese (4). Assim, acredita-se que a ausência da interação CD40-CD40Ls e consequente alteração na produção de fatores essenciais para geração e maturação de neutrófilos resultam em alterações no microambiente medular durante o processo de granulopoiese levando a liberação de neutrófilos com maturação incompleta, apresentando perfil celular e padrão de resposta alterados. As consequências da ausência da interação CD40-CD40L na medula óssea durante a maturação dos neutrófilos sobre o perfil celular posteriormente apresentado ainda necessitam de maior investigação.

Nossos dados indicam que a diminuição na geração de NETs pode estar relacionada a presença de neutrófilos periféricos imaturos, consequência da ausência da sinalização CD40CD40Ls na medula óssea durante o processo de granulopoiese. Além disso, a ausência de resposta ao tratamento celular com IFN-y em pacientes deficientes de CD40L sugerem defeitos na via de sinalização do IFN-y nos neutrófilos, levantando a possibilidade da existência outros defeitos ainda não descritos. Os resultados obtidos contribuem para a elucidação dos mecanismos imunopatológicos envolvidos na maior suscetibilidade a infecções em pacientes com deficiência de CD40L, além de melhor entendimento sobre a função da interação CD40-CD40Ls na medula óssea e sua influência na resposta imune. Ademais, o avanço no conhecimento associado ao estudo do efeito do tratamento com IFN- $\gamma$ possibilita o desenvolvimento e implantação de novas estratégias terapêuticas que visem melhora na qualidade de vida dos pacientes afetados pela síndrome. 


\section{CONCLUSÕES}

Os dados obtidos no estudo nos permitem concluir que:

- Pacientes deficientes de CD40L apresentam diminuição na geração de NETs pelo estímulo com PMA;

- Redução na geração de NETs em pacientes deficientes de CD40L não está relacionada a defeitos na produção de EROs;

- Pacientes deficientes de CD40L apresentam neutrófilos periféricos com perfil de maturação incompleta. 


\section{REFERÊNCIAS}

1. ETHUIN, F., et al. Human neutrophils produce interferon- $\gamma$ upon stimulation by interleukin-12. Lab Invest, v. 84, n. 10, p. 1363-1371, 2004.

2. BENNOUNA, S., et al. Cross-talk in the innate immune system: neutrophils instruct recruitment and activation of dendritic cells during microbial infection. J. Immuno,.v. 171, n. 11, p. 6052-6058, 2003.

3. CHERTOV, O., et al. Identification of human neutrophilderived cathepsin $\mathrm{G}$ and azurocidin/CAP37 as chemoattractants for mononuclear cells and neutrophils. J Exp Med, v. 186, n. 5, p. 739-747, 1997.

4. MAVROUDI, I., et al. The role of CD40/CD40 Ligand Interactions in Bone Marrow Granulopoiesis. Scientific World Journal, v. 11, p. 2011-2019, 2011.

5. LIU, F., et al. Impaired production and increased apoptosis of neutrophils in granulocyte colony-stimulating factor receptor-deficient mice. Immunity, v. 5, n. 5, p. 491$501,1996$.

6. LIESCHKE, G., et al. Mice lacking granulocyte colony-stimulating factor have chronic neutropenia, granulocyte and macrophage progenitor cell deficiency, and impaired neutrophil mobilization. Blood, v. 4, n. 6, p. 1737-1746, 1994.

7. ROBERTS, A. G-CSF: A key regulator of neutrophil production, but that's not all! Growth Factors, v. 23, n. 1, p. 33-41, 2005.

8. FAURSCHOU, M., et al. Neutrophil granules and secretory vesicles in inflammation. Microbes Infect, v. 5, p. 1317-1327, 2003.

9. THEILGAARD-MONCH, K., et al. Systems biology of neutrophil differentiation and immune response. Curr Opin Immunol, v. 18, p. 54-60, 2006.

10. MÓCSAI, A.. Diverse novel functions of neutrophils in immunity, inflammation, and beyond. J Exp Med, v. 210, n. 7, p. 1283-1299, 2013.

11. SADIK, C., et al. Neutrophils cascading their way to inflammation. Trends Immunol, v. 32, n. 10, p. 452-460, 2011.

12. KOLACZKOWSHA, E., et al. Neutrophil recruitment and function in health and inflammation. Nature, v. 13,n. 3, p. 159-175, 2013.

13. ELSBACH, P., et al. Oxygen-independent antimicrobial systems of phagocytes. Inflammation, v. 2, n. 3, p. 603-636, 1992.

* De acordo com:

ASSOCIAÇÃO BRASILEIRA DE NORMAS TÉCNICAS. NBR 6023: informação e documentação: referências: elaboração. Rio de Janeiro, 2002. 
14. BORREGAARD, N. Neutrophils, from marrow to microbes. Immunity, v. 33, n. 5, p. 657-670, 2010.

15. HAGER, M., et al. Neutrophil granules in health and disease. J Intern Med, v. 268, n. 1, p. 25-34, 2010.

16. DALE, D., et al. The phagocytes: neutrophils and monocytes. Blood, v. 112, n. 4, p. 935-945, 2008.

17. WEISS, S. Tissue destruction by neutrophils. N Engl J Med, v. 320, n. 6, p. 365-376, 1989.

18. SELSTED, M., et al. Primary structures of three human neutrophil defensins. J Clin Invest, v. 76, n. 4, p. 1436-1439, 1985.

19. PRUCHNIAK, M., et al. Life of neutrophil: From stem cell to neutrophil extracellular traps. Respir Physiol Neurobiol, v. 187, n. 1, p. 68-73, 2013.

20. ARRUDA, M., et al. NADPH oxidase activity: in the crossroad of neutrophil life and death. Front Biosci, v. 14, p. 4546-4556, 2009.

21. DAHLGREN, C., et al. Respiratory burst in human neutrophils. J Immunol Methods, v. 233, p. 3-14, 1999.

22. BRINKMANN, V., et al. Neutrophil extracellular traps kill bacteria. Science, v. 303, n. 5663, p.1532-1535, 2004.

23. ZAWROTNIAK, M., et al. Neutrophil extracellular traps (NETs)- formation and implications. Acta Biochim Pol, v. 60, n. 3, p. 277-284, 2013.

24. YANG, H., et al. New insights into neutrophil extracellular traps: mechanisms of formation and role in inflammation. Front Immunol, v. 7, p. 302-310, 2016.

25. TILLACK, K., et al. T lymphocyte priming by neutrophil extracellular traps links innate and adaptive immune responses. J Immunol, v. 188, n. 7, p.3150-3159, 2012.

26. FARRERA, C., et al. Macrophage clearence of neutrophil extracellular traps is a silent process. J Immunol, v. 191, n. 5, p. 2647-2656, 2013.

27. BARRIENTOS, L., et al. Neutrophil extracellular traps Downregulate Lipopolysaccharide-Induced Activation of Monocyte-Derived Dendritic cells. J Immunol, v. 19, n. 11, p. 5689-5698, 2014.

28. LANDE, R., et al. Neutrophils activate plasmacytoid dendritic cells by releasing selfDNA-peptide complexes in systemic lupus erythematosus. Sci Transl Med, v. 3, n. 73, p. 73ra19, 2011.

29. WARNATSCH, A., et al. Neutrophil extracellular traps license macrophages and Th17 cells for cytokine production in atherosclerosis. Science, v. 349, n. 6245, p. 316-320, 2015. 
30. LIN, A., et al. Mast cells and neutrophils release IL-17 through extracellular trap formation in psoriasis. J Immunol, v. 187, n. 1, p. 490-500, 2011.

31. SIMON, D., et al. Extracellular DNA traps in allergic, infectious, and autoimmune diseases. Allergy, v. 68, n. 4, p. 409-416, 2013.

32. BARNADO, A., et al. At the Bedside: Neutrophil extracellular traps (NETs) as targets for biomarkers and therapies in autoimmune disease. J Leuk Biol, V. 99, n. 2, p. 265-278, 2016.

33. MITSIOS, A., et al. NETopathies? Unraveling the dark side of odl diseases through neutrophils. Front Immunol. v. 7, 678.

34. PILSCZEK, F., et al. A novel mechanism of rapid nuclear Neutrophil extracellular trap formation in response to Staphylococcus aureus. J Immunol, v. 185, n. 12, p. 7413-7425, 2010.

35. YOUSEFI, S., et al. Viable neutrophils release mitochondrial DNA to form neutrophil extracellular traps. Cell Death Differ, v. 16, n.11, p. 1438-1444, 2009.

36. FUCHS, T., et al. Novel cell death program leads to neutrophil extracellular traps. J Cell Biol, v. 176, n. 2, p. 231-241, 2007.

37. BIANCHI, M., et al. Restoration of NET formation by gene therapy in CGD controls aspegillosis. Blood, v. 114, n. 13, p. 2619-2622, 2009.

38. PARKER, H., et al. Requirements for NADPH oxidase and myeloperoxidase in neutrophil extracellular trap formation differ depending on the stimulus. J Leukoc Biol, v. 92, n. 4, p. 841-849, 2012.

39. ARAI, Y., et al. Uric acid induces NADPHoxidase-independent neutrophil extracellular trap formation. Biochem Biophys Res Commun, v. 443, n. 2, p. 556-561, 2014.

40. STOIBER, W., et al. The role of reactive oxygen species (ROS) in the formation of estracellular traps (ETs) in humans. Biomolecules,v. 5, p. 702-723, 2015.

41. LI, P., et al. PAD-4 is essential for antibacterial innate immunity mediated by neutrophil extracellular traps. J Exp Med, v. 207, n. 7, p. 1053-1062, 2010.

42. HAKKIM, A., et al. Activation of the Raf-MEK-ERK pathway is required for neutrophil extracellular trap formation. Nat Chem Biol, v. 7, n. 2, p. 75-77, 2011.

43. PAPAYANNOPOULOS, V., et al. Neutrophil elastase and mieloperoxidase regulate the formation of neutrophil extracellular traps. J Cell Biol, v. 191, n. 3, p. 677-691, 2010.

44. METZLER, K., et al. Myeloperoxidase is required for neutrophil extracellular traps formation: implications for innate immunity. Blood, v. 117, n. 3, p. 953-959, 2011.

45. BRINKMANN, V., et al. Neutrophil extracellular traps: Is the immunity the second function of chromatin? J Cell Biol, v. 198, n. 5, p. 773-783, 2012. 
46. BRANZK, N., et al. Molecular mechanisms regulating NETosis in infection and disease. Semin Immunophathol, v. 35, n. 4, p. 513-530, 2013.

47. BEITER, T., et al. Neutrophil Extracellular Traps: A Walk on the Wild Side of Exercise Immunology. Sports Med, v. 45, n. 5, p. 625-640, 2015.

48. LÖGTERS, T., et al. The clinical value of neutrophil extracellular traps. Med Microbiol Immunol, v. 198, n. 4, p. 211-219, 2009.

49. YOST, C., et al. Impaired neutrophil extracellular trap (NET) formation: a novel innate immune deficiency of human neonates. Blood, v. 113, n. 25, p. 6419-6427, 2009.

50. BRAKHAGE. A., et al. Interaction of phagocytes with filamentous fungi. Curr Opin Microbiol, v. 13, n. 4, p. 409-415, 2010.

51. ROMANI, L. Immunity to fungal infections. Nature Rev, v. 11, n. 1, p. 275-288, 2004.

52. ERWIG, L., et al. Interactions of fungal pathogens with phagocytes. Nature Rev Microbiol, v. 14, n. 3, p. 163-173, 2016.

53. KUFE, D., et al. Holland-Frei Cancer Medicine. 6 ed. Hamilton (ON): BC Decker. 2003. 2900 p.

54. NETH, O., et al. Susceptibility to infection in patients with neutropenia: the role of the innate immune system. Br J Haematol, v. 129, n. 6, p. 713-722, 2005.

55. WALKOVICH, K., et al. How to approach neutropenia in childhood. Pediatr Rev, v. 34, n. 4, p.173-184, 2013.

56. JASINSKA, A., et al. Successful haploidentical PBSCT with subsequent T-cell addbacks in a boy with HyperIgM syndrome presenting as severe congenital neutropenia. Pediatr Transplantation, v. 17, n. 1, p. 37-40, 2013.

57. REAZEI, N., et al. Neutropenia in patients with prymary antibody deficiency disorders. Iran J Allergy Asthma Immunol, v. 3, n. 2, p. 77-81, 2004.

58. LEVY, J., et al. Clinical spectrum of X-linked hyper-IgM syndrome. J Pediatr, v. 131, n. 1, p. 47-54, 1997.

59. NOTARANGELO, L., et al. Immunodeficiency with hyper-IgM (HIM). Immunodefic Ver, v. 3, n. 2, p. 101-121, 1992.

60. DAVIES, E., et al. Update on the hyper immunoglobulin $\mathbf{M}$ syndromes. British $\mathbf{J}$ Haematol, v. 149, n. 2, p. 167-180, 2010.

61. QAMAR, N., et al. The hyper IgM syndromes. Clinic Rev Allerg Immunol. v. 46, n 2, p. 120-130, 2014. 
62. TSAI, H., et al. X-linked hyper-IgM syndrome with CD40LG mutation: two case reports and literature review in Taiwanese patients. J Microb, v. 20, n. 1, p. 113-118, 2015.

63. ROSEN, F., et al. Recurrent bacterial infections and dysgammaglobulinemia: deficiency of \&S gammaglobulins in the presence of elevated 19S gamma-globulins. Report of two cases. Pediatrics, v. 28, p. 182-195, 1961.

64. BURTIN, P. Um example d'agammaglobulinemie atypique. Ver Franc Étud Clin Biol, v. 6, p. 286-289, 1961.

65. SCHNEIDER, L. X-Linked hyper IgM syndrome. Clin Ver Allergy Immunol, v. 19, n. 2, p. 205-215, 2000.

66. HEINOLD, A., et al. Pitfalls of “'hyper'-IgM syndrome: a new CD40 ligand mutation in the presence of low IgM levels. A case report and a critical review of the literature. Infection, v. 38, n. 6, p. 491-496, 2010.

67. ALLEWELT, H., et al. Hematopoietic Stem Cell Transplantation for CD40 Ligand Deficiency: Single Institution Experience. Pedriatr Blood Cancer, v. 62, n. 12, p. 2216$2222,2015$.

68. WINKELSTEIN, J., et al. The X-linked hyper-IgM syndrome: clinical and immunologic features of 79 patients. Medicine, v. 82, n. 6, p. 373-384, 2003.

69. DE LA MORENA, M., et al. Long-term outcomes of 176 patients with X-linked hyper-IgM syndrome treated with or without hematopoietic cell transplantation. J Allergy Clin Immunol. pii: S0091-6749, 2016.

70. CABRAL-MARQUES O, et al. Expanding the clinical and genetic spectrum of human CD40L deficiency: the occurrence of paracoccidioidomycosis and other unusual infections in brasilian patients. J Clin Immunol.,v. 32, n. 2, p. 212-220, 2012.

71. WANG. W., et al. Successful treatment of neutropenia in the hyperimmunoglobulin M syndrome with granulocyte colony-stimulating factor. Am J Pediatr Hematol Oncol, v. 259, n. 5097, p. 990-993, 1994.

72. MORI, M., et al. Mutation analysis and therapeutic response to granulocyte colonystimulating factor in a case of hyperimmunoglobulin $\mathbf{M}$ syndrome with chronic neutropenia. $\mathbf{J}$ Padiatr Hematol Oncol, v. 22, n. 3, p. 288-289, 2000.

73. GENNERY, A., et al. Treatment of CD40 ligand deficiency by hematopoietic stem cell transplantation: A survey of the European experience, 1993-2002. Blood, v. 103, n. 3, p. 1152-1157, 2004.

74. TOMIZAWA, D., et al. Allogeneic hematopoietic stem cell transplantation for seven children with X-linked hyper-IgM syndrome: A single center experience. Am J Hematol, v. 76, p. 33-39, 2004. 
75. COSTA-CARVALHO, B., et al. Latin American challenges with the diagnosis and ytreatment of primary immunodeficiency diseases. Expert Rev Clin Immunol, v. 21, p. 1-7, 2016.

76. CUNNINGHAM-RUNDLES, C. Key aspects for successful immunoglobulin therapy of primary immunodeficiences. Clin Exp Immunol, v. 164, n. 2, p. 16-19, 2011.

77. AGHAMOHAMMADI, A., et al. Clinical and laboratory findings in hyper-IgM syndrome with novel CD40L and AICDA mutations. J Clin Immunol, v. 29, n. 6, p.769-776, 2009.

78. KOOTEN, C., et al. CD40-CD40 ligand. J Leuk Biol, v. 67, n. 1, p. 2-17, 2000.

79. ALOUI, C., et al. The signaling role of CD40 ligand in platelet biology and in platelet component transfusion. Int J Mol Sci, v. 15, n. 12, p. 2242-2264, 2014.

80. RAMESH, N., et al. Chromosomal localization of the gene for human B-cell antigen CD40. Somat Cell Mol Genet, v. 19, n. 3, p. 295-298, 1993.

81. HSING, Y., et al. Characterization of CD40 signaling determinants regulating nuclear factor-kappa B activation in B lymphocytes. J Immunol, v. 159, n. 10, p. 4898-4906, 1997.

82. KARRAS, J., et al. Induction of STAT protein signaling through the CD40 receptor in B lymphocytes: distinct STAT activation following surface Ig and CD40 receptor engagement. J Immunol. V. 159, n. 7, p. 4350-4355, 1997.

83. BISHOP, G., et al. TRAF proteins in CD40 signaling. Adv Exp Med Biol, v. 597, p. 131-151, 2007.

84. HASSAN, G., et al. CD40 Ligand: A neo-in flammatory molecule in vascular diseases. Immunobiol, v. 217, n. 5, p. 521-532, 2012.

85. MATHUR, R., et al. The conundrum of CD40 funnction: host protection or disease promotion? Trends Parasitol, v. 22, p. 117-122, 2006.

86. ELGUETA, R., et al. Molecular mechanism and function of CD40/CD40L engagement in the immune system. Immunol Ver, v. 229, n. 1, p. 1-31, 2009.

87. LI, G., et al. CD40 Ligand promotes Mac-1 expression, leukocyte recruitment, and neointima formation after vascular injury. Am J Pathol, v. 172, n. 4, p. 1141-1152, 2006.

88. VANICHAKARN, P., et al. Neutrophil CD40 enhances platelet-mediated inflammation. Thromb Research, v. 122, n. 3, p. 346-358, 2008.

89. JIN, R., et al. Soluble CD40 Ligand stimulates cd40-dependent activation of the $\beta 2$ integrin Mac-1 and protein kinase $\mathrm{C}$ zeda $(\mathrm{PKC} \zeta)$ in neutrophils: implications for neutrophil platelet interactions and neutrophil oxidative burst. PLoS One, v. 8, n. 6, p. e64631, 2013.

90. NATHAN, C. Neutrophils and immunity: challenges and opportunities. Nat Rev Immunol, v. 6, n. 3, p. 173-182, 2006. 
91. DONINI, M., et al. G-CSF treatment of severe congenital neutropenia reverses neutropenia but does not correct the underlying functional deficiency of the neutrophil in defending against microorganisms. Blood, v. 109, n. 11, p. 4716-4723, 2007.

92. POLLARD, K., et al. Interferon- $\gamma$ and Systemic Autoimmunity. Discov Med, v. 16, n. 87, p. 123-131, 2013.

93. FRUCHT, D., et al. IFN-gamma production by antigen-presenting cells: mechanisms emerge. Trends Immunol, v. 22, n. 10, p. 556-560, 2001.

94. GOLLAB, J., et al. Direct stimulation of macrophages by IL-12 and IL-18-a bridge too far? Immunol. Lett, v. 72, n. 3, p. 153-157, 2000.

95. MILlER, C., et al. Clinical use of interferon-y. Ann N Y Acad Sci. v. 1182, p. 69-79, 2009.

96. GOUGH, D., et al. IFN- $\mathrm{\gamma}$ sinaling- Does it mean JAK-STAT. Cytokine Growth Factor Ver, v. 19, n. 5, p. 383-394, 2008.

97. ELLIS, T., et al. Interferon-c activation of polymorphonuclear neutrophil function. Immunology, v. 112, n. 1, p. 2-12, 2004.

98. ROILIDES, E., et al. Enhancement of oxidative response and damage caused by human neutrophils to Aspergillus fumigatus hyphae by granulocyte colony-stimulating factor and gamma interferon. Infect Immun, v. 61, n. 4, p. 1185-1193, 1993.

99. DJEU, J., et al. Growth inhibition of Candida albicans by human polymorphonuclear neutrophils: activation by Interferon-c and tumor necrosis factor. J Immunol, v. 137, n. 9, p. 2980-2984, 1986.

100. DIAMOND, R., et al. Disparate effects if interferon-c and tumor necrosis factor-a on early neutrophil respiratory burst and fungicidal responses to Candida albicans hyphae in vitro. J Clin Invest, v. 87, p. 711-720, 1991.

101. KURITA, N., et al. Effect of cytokines on antifungal activity of human polymorphonuclear leucocytes against yeast cells of Paracoccidioides brasiliensis. Med Mycol, v. 38, n. 2, p.177-182, 2000.

102. EZEKOWITZ, A., et al. Restoration of phagocyte function by interferon- $\gamma$ in X-Linked Chronic Granulomatous Disease occurs at the level of a progenitor cell. Blood, v. 76, n. 12, p. 2443-2448, 1990.

103. GALLIN, J., et al. A controlled Trial of interfern gamma to prevent infection in chronic granulomatous disease. N Engl J Med, v. 324, n. 8, p. 509-516, 1991.

104. ERRANTE, P., et al. The use of interferon-gamma therapy in chronic granulomatous disease. Recent Pat Antiinfect Drug Discov, v. 3,n. 3, p. 225-230, 2008. 
105. CABRAL-MARQUES O, et al. First report of the Hyper-IgM syndrome registry of the Latin America Society for Immunodeficiences: Novel mutations, unique infections and outcomes. J Clin Immunol, v. 34, n. 2, p. 146-156, 2014.

106. MARTINELLI, S., et al. Induction of genes mediating interferon-dependent extracellular trap formation during neutrophil differentiation. J Biol Chem, v. 279, n. 42, p. 4423-4432, 2004.

107. BRANZK, N., et al. Neutrophils sense microbe size and selectively release neutrophil extracellular traps in response to large pathogens. Nat Immunol, v. 15, n. 11, p. 1017-1025, 2014.

108. LIPPOLIS, J., et al. Neutrophil extracellular trap formation by bovine neutrophils is not inhibited by Milk. Vet Immun Immunoph, v.113, p. 248-255, 2006.

109. BRINKMAN, V., et al. Neutrophil extracellular traps: How to generate and visualize them. J Vis Exp, v. 24, n. 36, Pii: 1724, 2010.

110. HATANAKA, E., et al. Systematic study on ROS production induced by oleic, linoleic, and $y$-linolenic acids in human and rat neutrophils. Free Radic Biol Med, v. 41, n. 7, p. 1124-1132, 2006.

111. MAVROUDI, I., et al. The CD40/CD40 ligand interactions exert pleiotropic effects na boné marrow granulopoiesis. J Leuk Biol. V 89, p. 771- 783, 2011.

112. URBAN, C., et al. Neutrophil extracellular traps capture and kill C. albicans yeast and hyphal forms. Cell Microbiol, v. 8, n. 4, p. 668-676, 2006.

113. BYRD, A., et al. An extracellular matrix-based mechanism of rapid neutrophil extracellular trap formation in response to Candida albicans. J Immunol, v. 190, p. 41364148, 2014.

114. BRUNS, S., et al. Production of extracellular traps against Aspergillus fumigatus in vitro and in infected lung tissue is dependent on invading neutrophils and influenced by Hydrophobin RodA. PLoS Pathog, v. 6, n. 4, e1000873.

115. MCCORMICK, A., et al. NETs formed by human neutrophils inhibit growth of the pathogenic mold Aspergillus fumigatus. Microbes Infect, v. 12, n. 12, p. 928-936, 2010.

116. REMIJSEN, Q., et al. Neutrophil extracellular trap cell death requires both autophagy and superoxide generation. Cell Research. V. 21, p. 290- 304, 2011.

117. BIANCHI, M., et al. Restoration of anti-Aspergillus defense by neutrophil estracellular traps in human chronic granulomatous disease after gene therapy is calprotectindependent. J Allergy Clin Immunol. v. 277, n. 5, p. 1243-1252, 2011.

118. SNOECK, H., et al. Interferon-y and interleukin-4 reciprocally regulate the production of monocyte/macrophages and neutrophils through a direct effect on commited monopotential bone marrow progenitor cells. Eur J Immunol. v. 23, p. 1072-1077, 1993. 
119. TERRI, N., et al. Interferon- $\gamma$ activation of polymorphonuclear neutrophil function. Immunol. v.112, p. 2-12, 2004.

120. CONDINO-NETO, A., et al. Interferon-gamma improves splicing efficiency of CYBB gene transcripts in an interferon-responsive variant of chronic granulomatous disease due to a splice site consensus region mutation. Blood. v. 95, n. 11, p. 3548-3554, 2000.

121. BERTON, G., et al. Gamma interferon is able to enhance the oxidative metabolism of human neutrophils. Biochem Biophys Res Commun. V. 138, n. 3, p. 1276-1282, 1986.

122. CASSATELLA, R., et al. Interferon-gamma activates human neutrophil oxygen metabolism and exocytosis. Immunol. V. 63, p. 499-506, 1988.

123. MILANÉS-VIRELLES, M., et al. Adjuvante interferon gamma in patients with pulmonary atypical mycobacteriosis: a randomized, Double-blind, placebo-controlled study. BMC Infect Dis. V. 8, n. 17, p. 1-13, 2008.

124. SCHRODER, K., et al. Interferon-y: an overview of signals, mechanisms and functions. J Leuk Biol. v. 75, n.2, p. 163-189, 2004.

125. PILLAY, J., et al. A subset of neutrophils in human systemic inflammation inhibits $\mathrm{T}$ cell responses through Mac-1. J Leukoc Biol. v. 122, n.1, p. 327-336, 2012.

126. TANEJA, R., et al. Immature circulating neutrophils in sepsis have impaired phagocytosis and calcium signaling. Shock. v. 30, n.6, p. 618-622, 2008.

127. GEERING, B., et al. Peculiarities of cell death mechanisms in neutrophils. Cell Death Dif. v.18, n.9, p. 1457-1469, 2011.

128. DRIFTE, G., et al. Innate immune functions of immature neutrophils in patients with sepsis and severe systemic inflammatory response syndrome. Crit Care Med. v. 41, p. 820832, 2013.

129. LUKÁSOVÁ, E., et al. . Granulocyte maturation determines ability to release chromatin NETs and loss of DNA damage response; these properties are absent in immature AML granulocytes. Biochim Biophys Acta. v. 1833, n. 3, p. 777-779, 2012.

130. YIZENGAW, E., et al. Visceral leishmaniasis patients display altered composition and maturity of neutrophils as well as impaired neutrophil effector functions. Front Immunol. v. 7, n. 7, a. 517, 2016. 


\section{ANEXOS}

\section{A- Avaliação da pureza da separação celular}
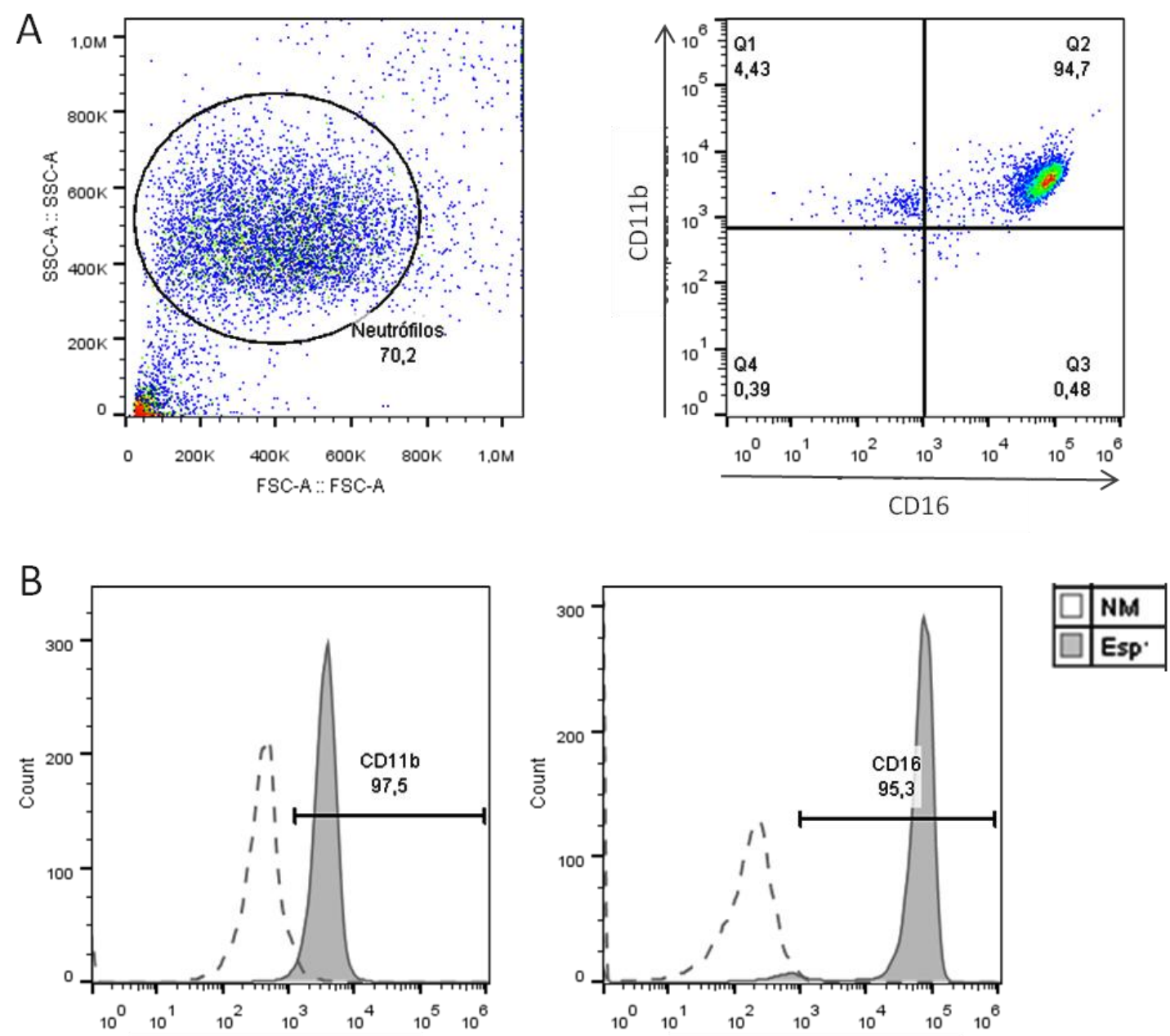

Após separação celular, o isolado celular $\left(5 \times 10^{5}\right.$ células) foram marcados para as moléculas de superfície CD11b e CD16 para caracterização da população isolada. (A) Gráfico de pontos da população celular isolada após separação (esquerda) e histograma com marcações para as moléculas CD11b (eixo y) e CD16 (eixo x) a partir de população selecionada (direita). Dupla expressão das moléculas acima de $90 \%$ confirma eficiência da separação celular. (B) Histograma da marcação das moléculas CD11b (esquerda) e CD16 (direita) no isolado celular. NM: não marcado; Esp: expressão espontânea da molécula. Figura representativas de 5 experimentos independentes realizados com amostra de indivíduos saudáveis. 


\section{B- Avaliação da viabilidade celular}

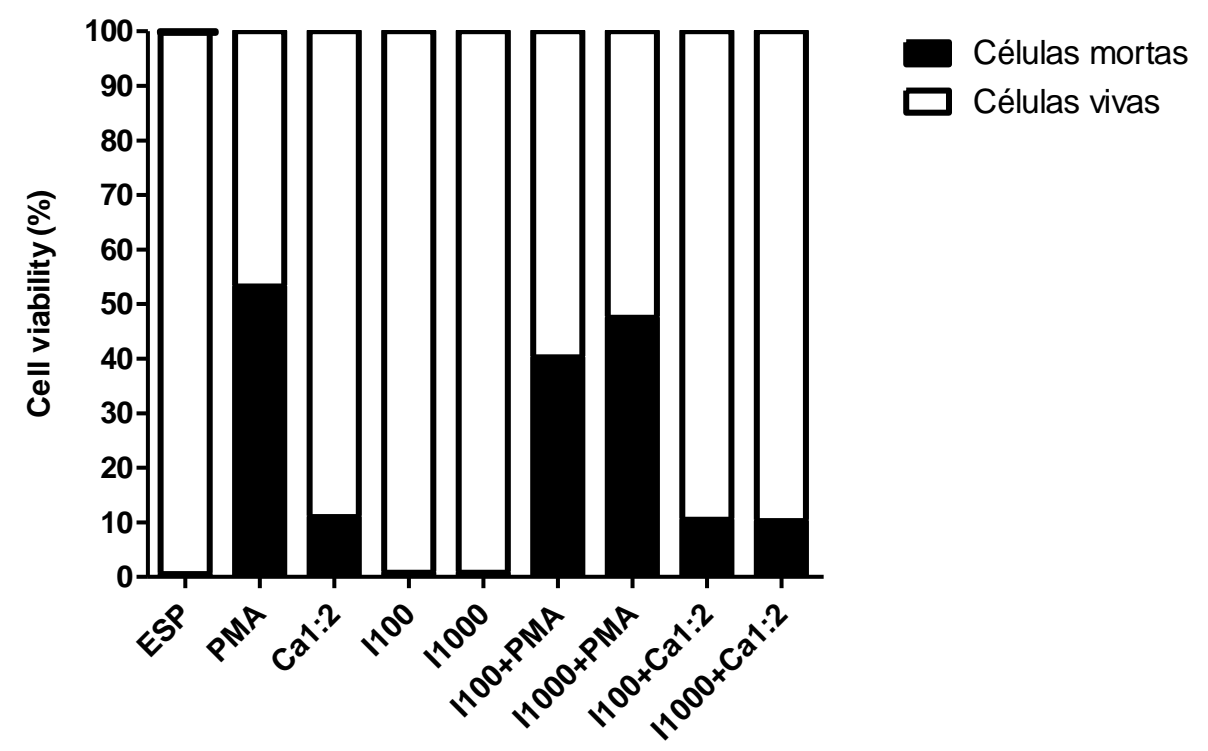

Os neutrófilos de indivíduos saudáveis ( 5 × $10^{5}$ células) foram tratados por 2 horas com IFN-y nas concentrações de 100 e $1000 \mathrm{UI} / \mathrm{mL}$. Após tempo de tratamento, foram adicionados aos respectivos poços PMA e C. albicans e placa incubada por 3 horas em estufa $\mathrm{CO}_{2}$ a $37^{\circ} \mathrm{C}$. Após incubação, células foram marcadas com reagente de viabilidade celular LIVE/DEAD ${ }^{\circledR}$ e análise realizada por citometria de fluxo. Esp: geração espontânea sem estímulo; Ca: C. albicans; IFN 100: IFN-y 100UI/mL; IFN 1000: IFN-y 1000UI/mL. *p<0,05 dentre os grupos comparados, teste One-way ANOVA seguido do teste de Tukey. $\mathrm{n}=4$, experimentos independentes. 


\section{C- Avaliação morfológica das C. albicans utilizadas nos protocolos experimentais}
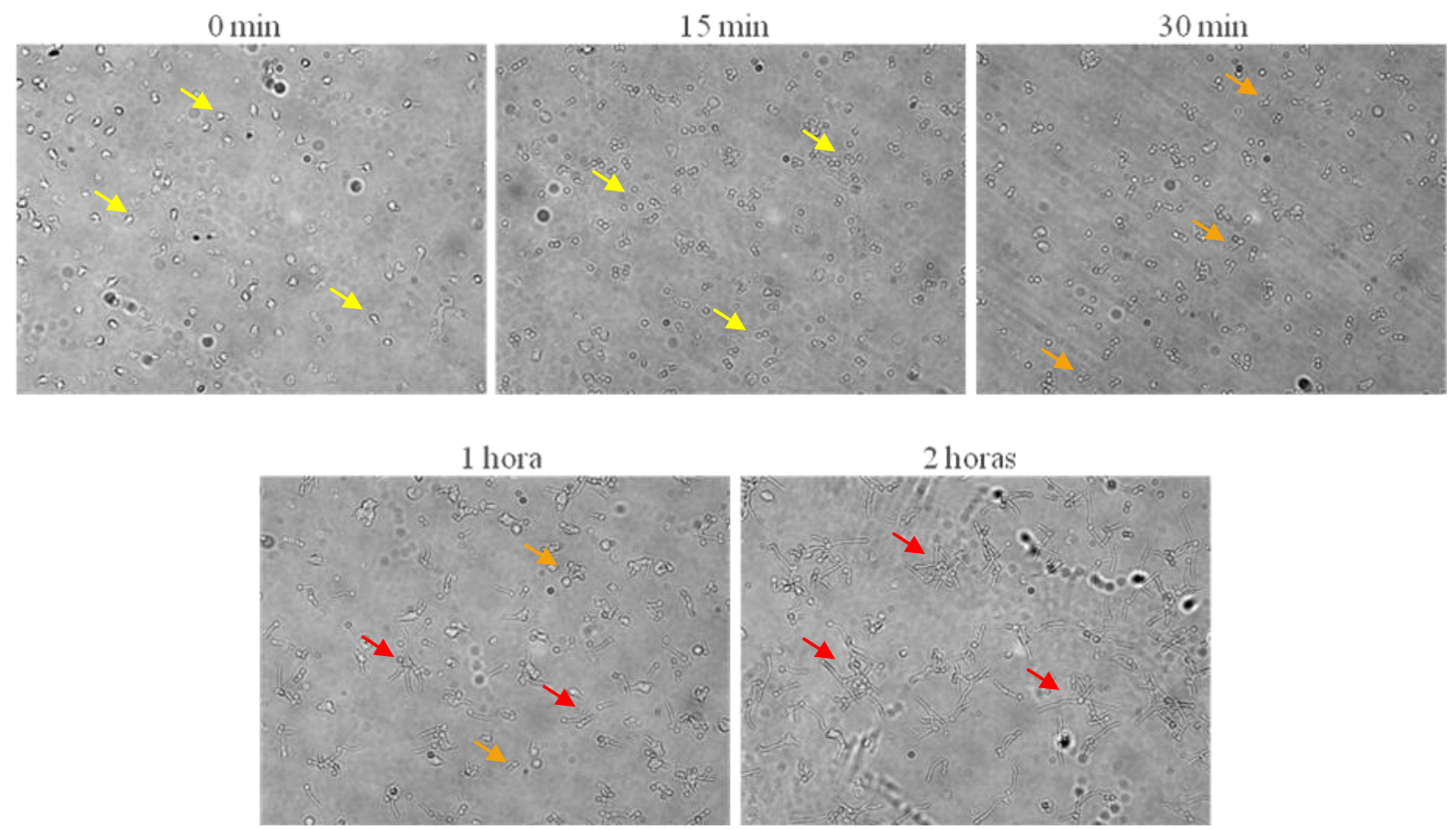

Após separação celular, os neutrófilos $\left(2 \times 10^{5}\right.$ células) foram pulsados com $C$. albicans na morfologia de levedura (setas amarelas; MOI 1:2) em placa de 24 poços e avaliação qualitativa realizada em microscopia de luz nos tempos de 0 minuto, 15 minutos, 30 minutos, 1 hora, 2 horas e 3 horas (imagem de 3 horas não apresentada). Transição morfológica iniciada com 30 minutos de incubação (formação de tubos germinativos, setas laranjas) e transição completa para morfologia de hifa (setas vermelhas) em 2 horas de co-cultura. Figura representativa de 3 experimentos realizados de maneira independente. 
D- Marcação de neutrófilos para visualização da formação de NETs
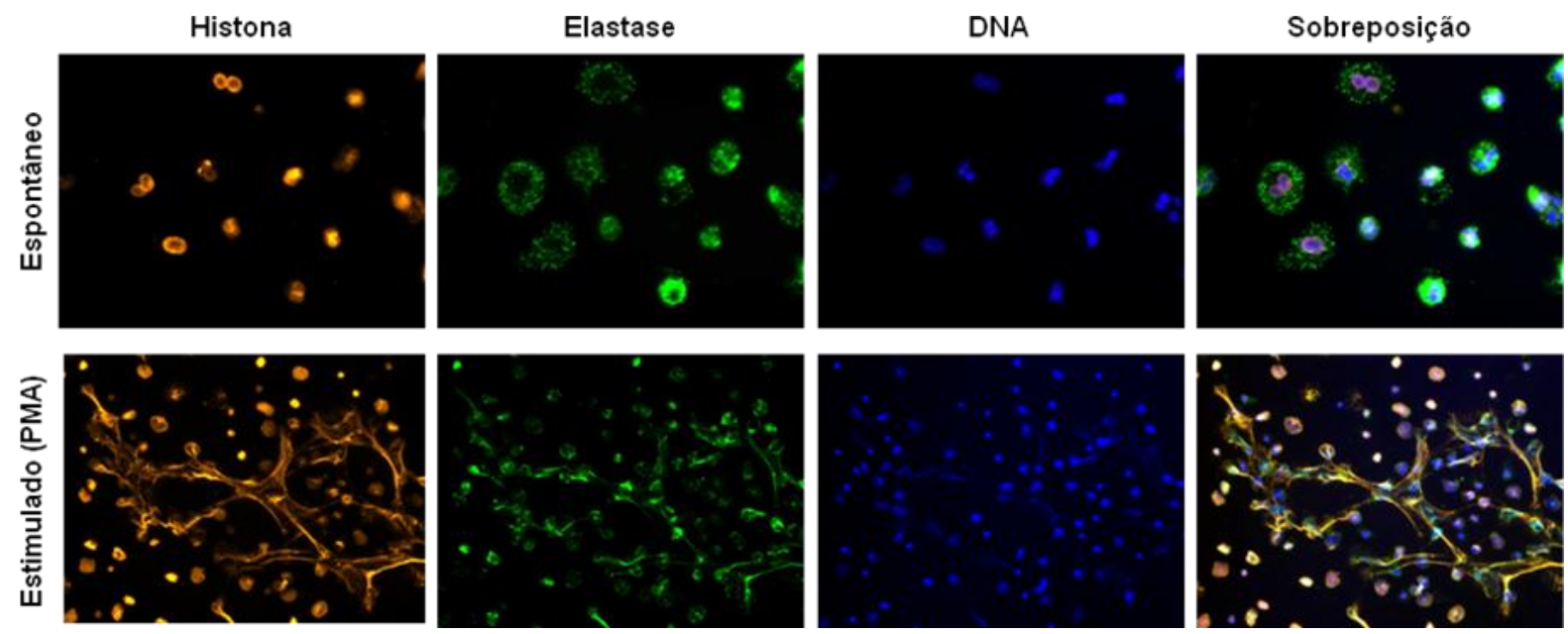

Neutrófilos $\left(2 \times 10^{5}\right.$ células $)$ de indivíduo sadio incubados pelo período de 3 horas em estufa $\mathrm{CO}_{2}$ a $37^{\circ} \mathrm{C}$ na ausência ou presença de PMA para geração de NETs. Laranja: histona H2A/H2B; Verde: elastase de neutrófilo; Azul: DNA. 


\section{E- Avaliação da expressão de CD40 nos neutrófilos de pacientes deficientes de CD40L}
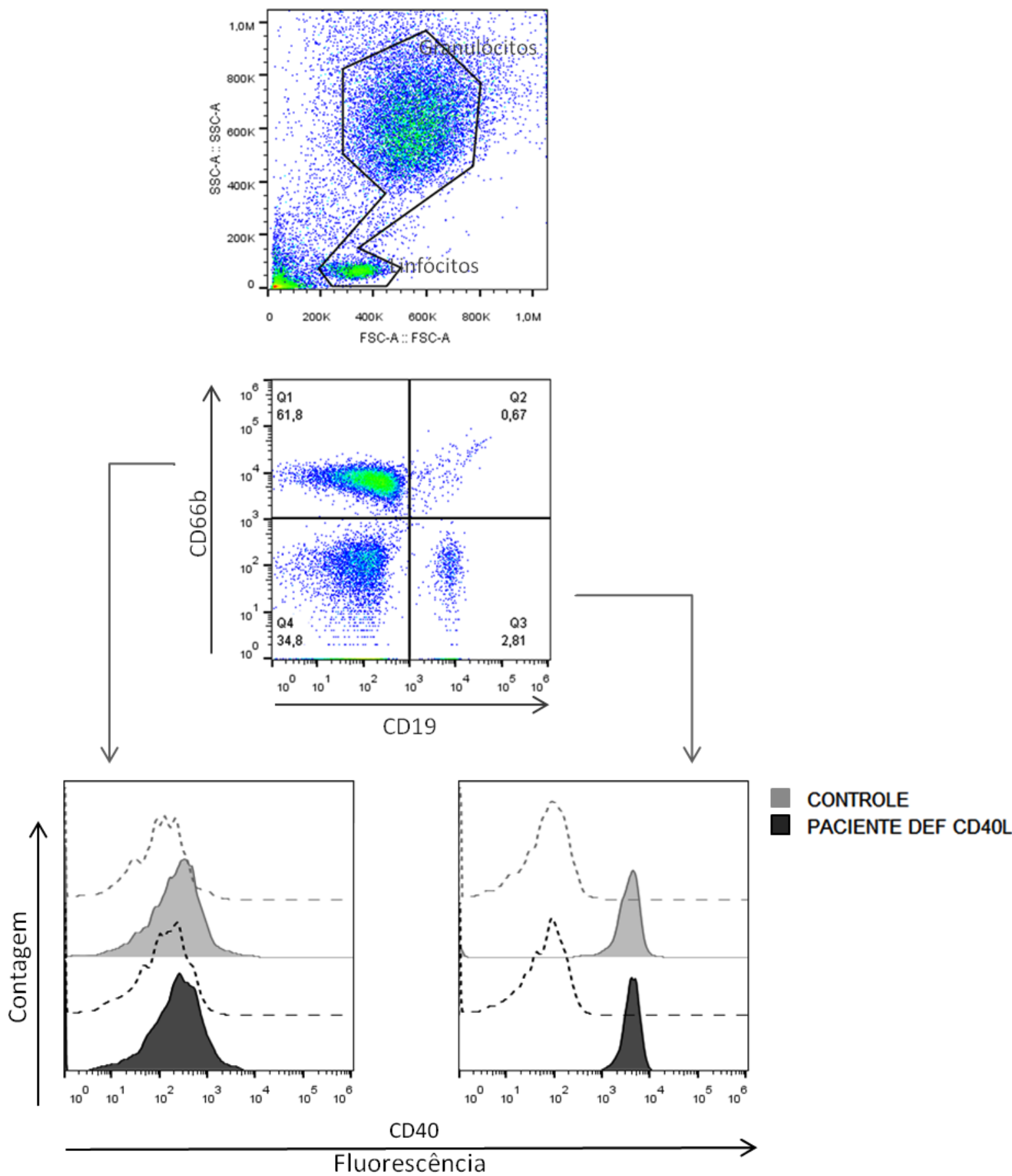

Amostra de sangue total em heparina $(100 \mu \mathrm{L})$ foram marcadas para as moléculas de superfície CD66b e CD19, para a seleção das populações de neutrófilos e linfócitos $\mathrm{B}$, respectivamente, e para a molécula CD40. Histograma com marcações para a molécula CD40 a partir das populações CD66b $^{+}$e CD $19^{+}$. CONTROLE: indivíduos saudáveis; PACIENTE DEF CD40L: paciente deficiente de CD40L. Figura representativas de 3 experimentos independentes. 


\section{F- Ficha clínica}

Estudo de Pacientes com Suspeita de Imunodeficiência Primária

Laboratório de Imunologia Humana- LIH

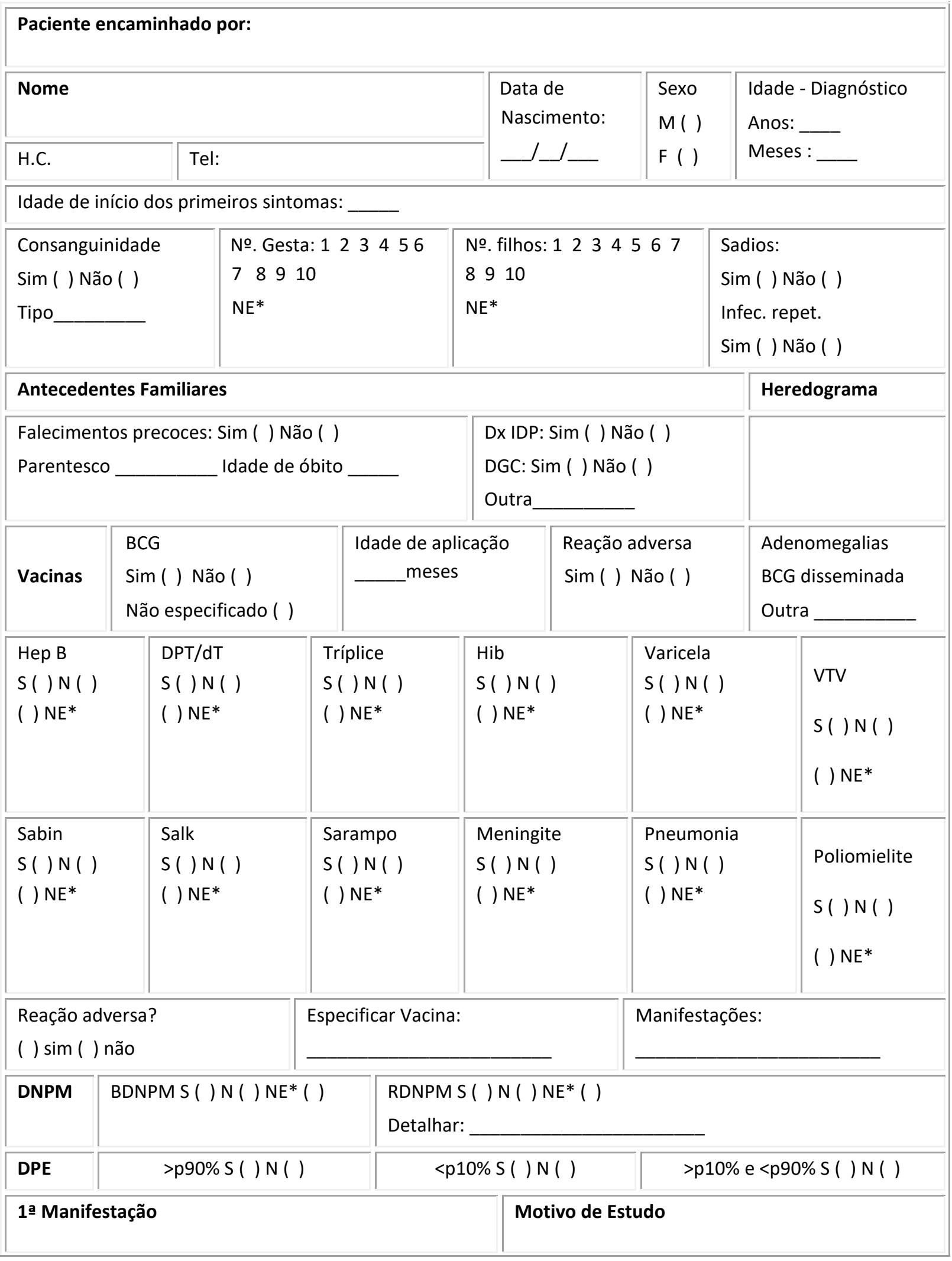




\begin{tabular}{|c|c|c|c|c|}
\hline $\begin{array}{l}\text { Idade } \\
\qquad \begin{array}{l}\text { ano } \\
\text { meses }\end{array}\end{array}$ & Local & & $\begin{array}{l}\text { Infecção Repetição: Sim ( ) Não ( } \\
\text { Manifestação Grave: Sim ( ) Não ( } \\
\text { História Familiar :Sim ( ) Não ( ) } \\
\text { Outro: Sim ( ) Não ( ) Especificar: }\end{array}$ & \\
\hline Manifestações & $\begin{array}{l}\text { №. } \\
\text { de } \\
\text { episódios }\end{array}$ & $\begin{array}{l}\text { Micro-organismo } \\
\text { isolado } \\
\text { Sim ( ) Não ( ) } \\
\text { Nome: }\end{array}$ & $\begin{array}{l}\text { Especificar: idade e data em } \\
\text { cada manifestação e datas } \\
\text { dos episódios da mesma } \\
\text { infecção }\end{array}$ & Localização \\
\hline 1. Otite & & & & \\
\hline 2. Pneumonia & & & & \\
\hline 3. Pneumonia/DF & & & & \\
\hline 4. Amigdalite & & & & \\
\hline $\begin{array}{l}\text { 5. Linfonodo } \\
\text { (HIPERPLASIA) }\end{array}$ & & & & \\
\hline 6. ITU & & & & \\
\hline 7. Meningite & & & & \\
\hline 8. Artrite & & & & \\
\hline 9. Osteomielite & & & & \\
\hline 10. Diarreia & & & & \\
\hline $\begin{array}{l}\text { 11. Infecções de } \\
\text { Pele. Especificar: }\end{array}$ & & & & \\
\hline 12. Artrite & & & & \\
\hline
\end{tabular}




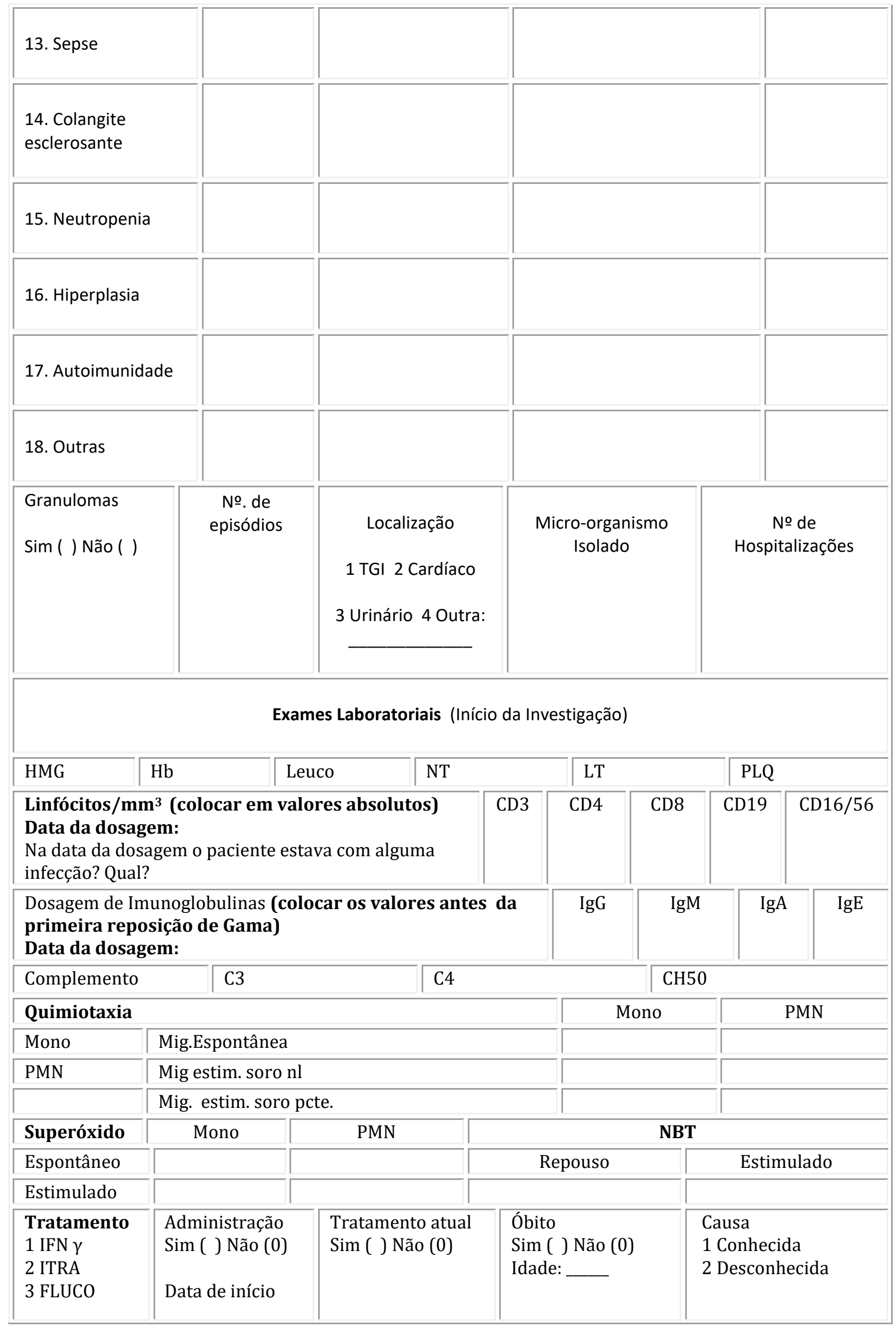


4 SMX + TMP

5 Prednisona

6 TMO

7. Gama (data de início)

\begin{tabular}{|l|l|}
\hline Autópsia & Laudo \\
Sim ( ) Não ( )
\end{tabular}

Outras Manifestações - Livre Relato de Ocorrências 


\section{G- TCLE menores de 18 anos}

Universidade de São Paulo

Instituto de Ciências Biomédicas

TERMO DE CONSENTIMENTO LIVRE E ESCLARECIDO

\section{(menores de 18 anos)}

ESTUDO: Avaliação da formação de neutrophil extracellular traps em pacientes com deficiência de CD40 ligante e influência do tratamento in vitro com interferon-gamma

Seu filho está sendo convidado (a) a participar do projeto de pesquisa acima citado. O documento abaixo contém todas as informações necessárias sobre a pesquisa que estamos fazendo. Caso tenha dúvidas, teremos prazer em esclarecê-las. Se concordar, o documento será assinado e só então daremos início ao estudo. Sua colaboração será muito importante para nós, mas se quiser desistir a qualquer momento, isto não causará nenhum prejuízo, nem a você, nem ao(à) seu (sua) filho(a).

$\mathrm{Eu}$ nascido

(a) em I I

seja voluntário do estudo "Avaliação da formação de neutrophil extracellular traps em pacientes com deficiência de CD40 ligante e influência do tratamento in vitro com interferon-gamma”. Declaro que obtive todas as informações necessárias e que todas as minhas dúvidas foram esclarecidas.

Estou ciente de que:

II) Será realizada coleta de sangue venoso em tubo de heparina;

III) A participação neste estudo não tem objetivo de submeter meu filho a um tratamento, bem como não terá custo algum para mim;

IV) Tenho a liberdade de desistir ou interromper a colaboração neste estudo no momento em que desejar, sem necessidade de dar qualquer explicação;

V) A desistência não causará nenhum prejuízo a mim, nem (a) meu (minha) filho (a), nem interferirá no atendimento ou tratamento médico a que ele (ela) estiver sendo submetido;

VI) Os resultados obtidos durante este estudo serão mantidos em sigilo, mas concordo em que sejam divulgados em publicações científicas, desde que meus dados pessoais não sejam mencionados;

VII) Caso eu deseje, poderei tomar conhecimento dos resultados ao final deste estudo:

( ) Desejo conhecer os resultados desta pesquisa.

( ) Não desejo conhecer os resultados desta pesquisa. 
VIII) Poderei contatar a Secretaria da Comissão de Ética em Pesquisa com Seres Humanos - ICB/USP no telefone 3091-7733 (e-mail: cep@icb.usp.br) ou a pesquisadora responsável Tábata Takahashi França no telefone 3091-7387 para recursos ou reclamações em relação ao presente estudo.

IX) Concordo que o material possa ser utilizado em outros projetos desde que autorizado pela Comissão de Ética deste Instituto e pelo responsável por esta pesquisa. Caso minha manifestação seja positiva, poderei retirar essa autorização a qualquer momento sem qualquer prejuízo a mim ou ao meu (minha) filho (a).

( ) Sim ou ( ) Não

X) O sujeito de pesquisa ou seu representante, quando for o caso, deverá rubricar todas as folhas do Termo de Consentimento Livre e Esclarecido - TCLE- apondo sua assinatura na última página do referido Termo.

XI) O pesquisador responsável deverá da mesma forma, rubricar todas as folhas do Termo de Consentimento Livre e Esclarecido - TCLE- apondo sua assinatura na última página do referido Termo.

XII) Resolução 196/96 - Estou recebendo uma cópia deste Termo de Consentimento Livre e Esclarecido;

São Paulo, de de $20 \ldots \ldots \ldots . . .$.

( ) Paciente / ( ) Responsável

Testemunha 1 :

Nome / RG / Telefone

Testemunha 2 :

Nome / RG / Telefone

Responsável pelo Projeto:

TÁBATA TAKAHASHI FRANÇA 


\title{
H- TCLE maiores de 18 anos
}

\author{
Universidade de São Paulo \\ Instituto de Ciências Biomédicas
}

TERMO DE CONSENTIMENTO LIVRE E ESCLARECIDO

(maiores de 18 anos)

ESTUDO: Avaliação da formação de neutrophil extracellular traps em pacientes com deficiência de CD40 ligante e influência do tratamento in vitro com interferon-gamma

Você está sendo convidado (a) a participar do projeto de pesquisa acima citado. O documento abaixo contém todas as informações necessárias sobre a pesquisa que estamos fazendo Caso tenha dúvidas, teremos prazer em esclarecê-las. Se concordar, o documento será assinado e só então daremos início ao estudo Sua colaboração neste estudo será de muita importância para nós, mas se desistir a qualquer momento, isso não causará nenhum prejuízo a você.

Eu, (inserir o nome, profissão)

residente e domiciliado na portador da

Cédula de identidade, RG e inscrito no CPF/MF nascido(a) em /_________ concordo de livre e espontânea vontade em participar como voluntário(a) do estudo “Avaliação da formação de neutrophil extracellular traps em pacientes com deficiência de CD40 ligante e influência do tratamento in vitro com interferon-gamma". Declaro que obtive todas as informações necessárias, bem como todos os eventuais esclarecimentos quanto às dúvidas por mim apresentadas.

Estou ciente que:

I) O estudo é necessário para que se possam descobrir as possíveis causas e/ou o tratamento da doença denominada "Síndrome do Hiper IgM ligado ao X";

II) Será realizada coleta de sangue venoso em tubo de heparina;

III) A participação neste estudo não tem objetivo de me submeter a um tratamento, bem como não terá custo algum para mim;

IV) Tenho a liberdade de desistir ou interromper a colaboração neste estudo no momento em que desejar, sem necessidade de dar qualquer explicação;

V) A desistência não causará nenhum prejuízo à minha saúde ou bem estar físico, nem interferirá no atendimento ou tratamento médico a que eu estiver sendo submetido;

VI) Os resultados obtidos durante este ensaio serão mantidos em sigilo, mas concordo que sejam divulgados em publicações científicas, desde que meus dados pessoais não sejam mencionados; 
VII) Caso eu desejar, poderei pessoalmente tomar conhecimento dos resultados, ao final desta pesquisa.

( ) Desejo conhecer os resultados desta pesquisa.

( ) Não desejo conhecer os resultados desta pesquisa.

VIII) Concordo que o material possa ser utilizado em outros projetos desde que autorizado pela Comissão de Ética deste Instituto e pelo responsável por esta pesquisa. Caso minha manifestação seja positiva, poderei retirar essa autorização a qualquer momento sem qualquer prejuízo para mim.

( ) Sim ou ( ) Não

IX) Poderei contatar a Secretaria da Comissão de Ética em Pesquisa com Seres Humanos - ICB/USP no telefone 3091.7733 (e-mail: cep@icb.usp.br) ou a pesquisadora responsável Tábata Takahashi França no telefone 3091-7387 para recursos ou reclamações em relação ao presente estudo.

X) O sujeito de pesquisa ou seu representante, quando for o caso, deverá rubricar todas as folhas do Termo de Consentimento Livre e Esclarecido - TCLE - apondo sua assinatura na última página do referido Termo.

XI) O pesquisador responsável deverá da mesma forma, rubricar todas as folhas do Termo de Consentimento Livre e Esclarecido - TCLE- apondo sua assinatura na última página do referido Termo.

XII) Resolução 196/96 - Estou recebendo uma cópia deste Termo de Consentimento Livre e Esclarecido.

São Paulo, de de 20.........

( ) Paciente / ( ) Responsável

Testemunha 1 :

Nome / RG / Telefone

Testemunha 2 :

Nome / RG / Telefone

Responsável pelo Projeto:

TÁBATA TAKAHASH FRANÇA 


\title{
Human CD40 ligand deficiency dysregulates the macrophage transcriptome causing functional defects that are improved by exogenous IFN- $\gamma$
}

\author{
Otavio Cabral-Marques, PhD, , ${ }^{a, b}$ Rodrigo Nalio Ramos, PhD, ${ }^{a}$ Lena F. Schimke, MD, ${ }^{a, b}$ Taj Ali Khan, PhD, \\ Eduardo Pinheiro Amaral, PhD," Caio César Barbosa Bomfim, MSc, ${ }^{2}$ Osvaldo Reis Junior, MSc, \\ Tabata Takahashi Franç, MSc, "Christina Arslanian, BSc," Joanna Darck Carola Correia Lima, MSc, \\ Cristina Worm Weber, MD, Janaíra Fernandes Ferreira, MD, ${ }^{9}$ Fabiola Scancetti Tavares, MD, Jing Sun, MD,' \\ Maria Regina D'Imperio Lima, PhD," Marilia Seelaender, PhD, " Vera Lucla Garcia Calich, PhD," José Alexandre Marzagão \\ Barbuto, MD, PhD, ${ }^{-1}$ Beatriz Tavares Costa-Carvalho, MD, PhD, ${ }^{k}$ Gabriela Riemekasten, MD, ${ }^{\mathrm{b}}$ Gisela Seminario, MD,' \\ Liliana Bezzodnik, MD,' Luigi Notarangelo, MD,"' Troy R. Torgerson, MD, PhD," Hans D. Ochs, MD," and \\ Antonio Condino-Neto, MD, PhD ${ }^{a} \quad$ São Paulo, Caxias do Sul, Fortaleza, and Brasilia, Brazil; Lübeck, Germany; Kohat, \\ Pakistan; Cincinnati, Ohio; Buenos Aires, Argentina; Bostan, Mass; and Seattle, Wash
}

Background: CD40 ligand (CD40L) deficiency predisposes to opportunistic infections, including those caused by fungi and intracellular bacteria. Studies of CD40L-deficient patients reveal the critical role of CD40L-CD40 interaction for the function of T, $B$, and dendritic cells. However, the consequences of CD40L. deficiency on macrophage function remain to be investigated. Objectives: We sought to de termine the effect of CD40L absence on monocyte-derived macrophage responses.

Methods: After observing the improvement of refractory disseminated mycobacterial infection in a CD40L-deficient patient by recombinant human IFN- $\gamma($ rhIFN- $\gamma)$ adjuvant therapy, we investigated macrophage functions from CD40Ldeficient patients. We analyzed the killing activity, oxidative burst, cytokine production, and in vitro effects of rhIFN- $\gamma$ and soluble CD40 ligand (sCD40L) treatment on macrophages. In addition, the effect of CD40L absence on the macrophage transeriptome before and after rhIFN- $\gamma$ treatment was studied. Results Macrophages from CD40L-deficient patients exhibited defective fungicidal activity and reduced oxidative burst, both of

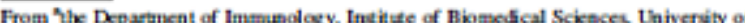

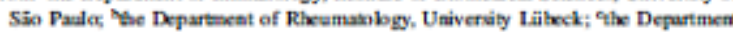

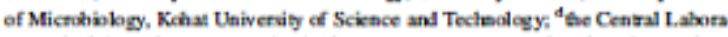
tory of High Performance Teclnologies (LaCTAD), State Univeruity of Campinan, Sin Pazk; "the Cancer Metahdism Research Coopp, Intitute of Biomedical Sciences, Uriu wervity of Sion Pask: "Pediatric Alkrgy \& Immundogy Clitric, Caxias do Sul: ${ }^{8}$ N

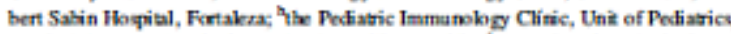
Hognital de Base do Distris Federal Brasilia, Bracilia; the Univervity of Cincinnati College of Medicine; the Cell and Molecular Therapy Cener, NETCFM Univervity of Sio Pavk; "the Division of Alergy-Immunology and Rheumatology, Departmem

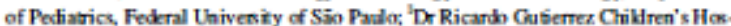
pital, Immunokgy, Buenos Aires, "the Division of Immumology, Bostcn Childen's Hospital, Harvard Medical School Bostcn; and "the Departmert of Pedartics, Univer sity of Whshington School of Medicine, and Seatk Crildren's Research Institure.

Surported by Fundaço de Amparo à Peequia do Extado de Sỉo Paulo (grant 2012 50615-4 to O.C.M. and gant 2012/51745-3 to AC.-N.) and the Jeffrey Modell Foundation

Disclosare of potential conflict of interest C. C. Barbos Bomfim receives payment for lectures frum the S3̄o Paub Research Foundation and travel support from Sino Pauk Research Foundation. M. Seebender receives grant sapport fom FAFSP and University Sarbonne Psis Cie-University of Sbo Paulo and serves as a consultan foom Metabolic Foods Brail. J. A. Marragbo Barbuto neceives gant suppont from which improved in the presence of rhIFN- $\gamma$ but not SCD40L. In contrast, rhIFN- $\gamma$ and $\mathrm{SCD} 40 \mathrm{~L}$ ameliorate impaired production of inflammatory cytokines. Furthermore, rhIFN- $\gamma$ revensed defective control of Mycobacterium tuberculosis proliferation by patients' macrophages. The absence of CD4OL. dysregulated the macrophage transcriptome, which was improved by rhIFN- $\gamma$. Additionally, rhIFN- $\gamma$ increased expression levels of pattern recognition receptors, such as Toll-like receptors 1 and 2, dectin 1 , and dendritic cell-specific intercellular adhesion molecule 3-grabbing nonintegrin in macrophages from both control subjects and patients

Conclusion: Absence of CD40L. impairs macrophage development and function. In addition, the improvement of macrophage immune responses by IFN- $\gamma$ suggests this cytokine as a potential therapeutic option for patients with CD40L. deficiency. (J Allergy Clin Immunol 2017;139:900-12.)

Key words: Macrophages, CD40 ligand, opportunistic infections, IFN $\times y$

FAPESP and serves as a consultant for Recepta Bïpharma. L. Notarangelo serves on the boand for Novimmine, is an employee of Children's Hoppital Pectiatric Asscciates. receives gant sumort from the Naticnal Instituks of Health (NII), and receives royalties from UpToDate. T. R Targerson serves as a consultant for Baxalta Biosciences, CSL. Behring, and ADMA; neceives gant support from Baxalta Biosciences, CSL. Behring, and the NIIt; and receives payments for lectures frum Bazala Besciences CSL. Behring, Questar Pharmaceuticals, and RWJF. H. D. Oths receives gant support from the Jefrey Modell Foundation. The res of the authors declare that they have no velevant conflicts of irteres.

Receival for pablication February 6, 201 \%, revised June 15, 2016; accepted for publica. tion Juy $12,2016$.

Avilahle online August 20, 2016 .

Correpponding authr: Atonio Coadion-Neta, MD, PaD, Deparment of Immunokgy-

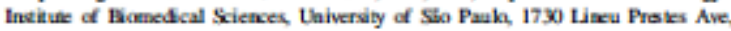

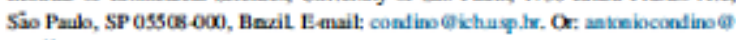
gmaileom.

(1) The CrosMark symbol motifes ond ine readers when updates have bees made to the artick such as crata or mimer corroctions.

$0091-6749 / 5 \times 3,00$

Q 2016 American Acakmy of Allerg, Aatma 8 Immusobg

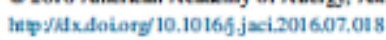




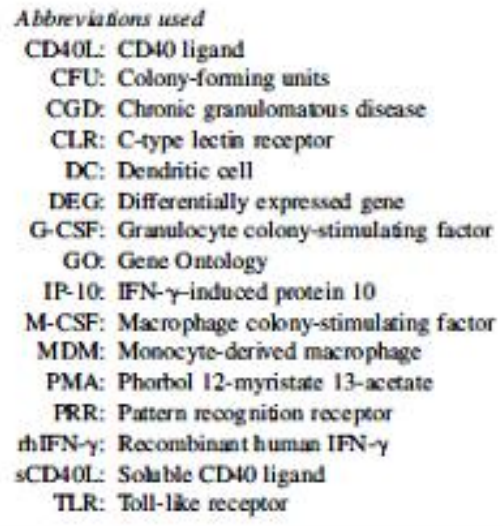

The CD40 ligand (CD40L)-CD40 interaction was initially described to play an essential role during membrane-membrane interactions between activated $\mathrm{CD}^{+} \mathrm{T}$ lymphocytes and $\mathrm{B}$ cells, ${ }^{1-5}$ as well as between $\mathrm{CD}^{+}{ }^{+} \mathrm{T}$ cells and antigenpresenting cells. ${ }^{6.7}$ However, further studies showed that soluble CD40 ligand (SCD40L) produced by $T$ cells and platelets ${ }^{3 / 11}$ can also exert an important role in immune system regulation, including myeloid progenitor cell development. Bone marrow stromal cells, hematopoietic progenitors, and myeloid progenitors express CD40. Furthermore, the CD40L-CD40 interaction has been shown to influence differentiation of these cells directly and indirectly through regulation of cell proliferation and maturation or through control of the cytokine milieu in the bone marrow, respectively. ${ }^{\text {i }} 12-14$

Macrophages are essential myeloid cells, exhibiting microbicidal activity and regulating inflammatory immune responses. Thus macrophages comprise a pivotal component of the innate immune system. Macrophages express CD40 constitutively, ${ }^{15,16}$ but their functional capability in patients with CD40L deficiency has not been investigated.

Patients with X-linked hyper-IgM syndrome caused by mutations in the gene encoding CD40L (CD4OLG) have a broad spectrum of opportunistic infections caused by intracellular bacteria and fungi. These infections resemble infections seen in patients with abnormal myeloid cells, such as those in patients with chronic granulomatous disease (CGD). ${ }^{17-19}$ Although CD40Ldeficient patients can experience intermittent neutropenia, they are also susceptible to fatal opportunistic infections, even when neutrophil counts are normal or when receiving granulocyte colony-stimulating factor (G-CSF) and immunoglobulin replacement therapy. ${ }^{20,2 P}$ These observations indicate that absence of CD40L might impair macrophage function in human subjects and that new therapeutic approaches need to be investigated for optimal treatment of these patients.

Failure to produce IFN- $\gamma$ has been reported in patients with CD40L deficiency. ${ }^{22-24}$ This cytokine primes and activates mature phagocytes. Additionally, IFN- $y$ affects development of progenita cells to generate mature phagocytes capable of efficiently eliminating opportunistic pathogens. ${ }^{25}$ For this reason, recombinant hu$\operatorname{man}$ IFN- $\gamma$ (rhIFN- $\gamma$ ) has been used as an adjunctive therapy for patients with $\mathrm{CGD}^{26,27}$ and patients with defects in the IL-12/FN$\gamma$ axis to prevent and treat imvasive mycobacterial or fungal infections. However, IFN- $\gamma$ has not been broadly used to treat patients with adaptive primary immunodeficiency disorders. 2 -31

Here we aimed to analyze the in vitro macrophage response in patients with CD40L deficiency with respect to macrophage killing activity, oxidative burst, and production of inflammatory cytokines. Furthermore, we investigated the effects of thIFN- $\gamma$ and $s \mathrm{CD} 40 \mathrm{~L}$. treatment on macrophages from CD40L-deficient patients. In addition, we assessed the effect of CD 40 L deficiency on the macro-

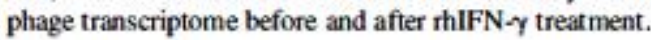

\section{METHODS}

\section{Case report}

An Argentinian CDVOL-deficient patient includad is our collaborative Latin American Society for Immundeficiencies (LASID) studies " was trestod with adjuvant rhiF- $\gamma$ at the Dr Ricardo Gutenez Children's Hospital. The hospital

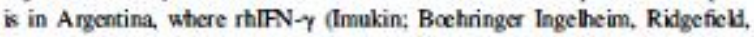
Coen) is atready approwed for clirical use (Disposicion no 1265-12). The patent was bom to nonconsanguinoous fanily and received BCG vaccine in the firs month of life without complication. At 9 month sof age, he was given a diag. noxis of dysgammaglobulnemia (hyper-LgM syndrome), chroeic neutsopenia, and pocumonia causod by Psewdomanas specios. Coeventonal treatment for D40L deficiency (trimethoprim/sulf amethoxseole prophylaxis, intravenoes immunoglobulin, and Granulokine) was initiated, and the patient was given a diagnosis of the mutation Q174X in CDAOLG (detsils have been previoeshy reported ${ }^{18}$ ). At 5 years of age, he had cervical adrenomegly caused by mycobacterial diceace. The extent and severity of this myoobacterial infection were assessed by means of biopsy, which showed groulomas. Additionally, the FCR result was positive for $M$ nberculosis oompler.

Conventional antiuberculosis therapy with a 4-drug regimen (ethembutol, levofloxacin, isoniszid, and rifampicin) was iniobated, but the patient had typhlitispequiring surgery. A bu ndsnt caseaing granulomas were observed in the bowed mucous menbrane, requiring oolostony for 6 months and the parient coetinued to have refractory mycrbacterial disease despite antituberculoxis treatment. Therefore simultaneous with the coeventional (D 40L. deficiency and antitubercubss therapy, subcutanoous hIFN $\gamma\left(50 \mu \mathrm{g} / \mathrm{m}^{2}\right.$ administesed 3 times a wedk) was afministrated for 6 manths. Under this theraprutic reg imen, the patient improwed dinically. After that, rhIRN-y therapy was discontinued and isoniszid and rifsmpicin was con onued for I additional year until no symproms of myonbacterialdisease were observed. Currently, the patient is 9 years old, has nostem cell donor avalable, and has had hepatic cryptooscosis.

\section{Subjects}

We enrolled 6 CD40L-deficient patients (age range, 3-21 years) from 6 unselated Brazilian families. Except for the occurrence of $M$ ruberculasis infection in PI, the clinical, immunologic, and genetic characteristics of these paxients have been previously described ${ }^{18}$ and are summarized in Table EI in this article's Online Repository at ww wejacineline.org. For each experiment, a bealthy subject (age range, 23-30 years) was included for comparison. Informed consent was obtainal froen the patients of their parents and from bealthy control subject. The blood was collected under insatutional guidelinex, and the study was performod in accondance with the Declaration of Helsinkiand approved by the Ethics Commintee of the Institute of Biomedical Sciences, University of Sāo Pulo,

\section{Generation of monocyte-derived macrophages}

Human monocyte-derival macrophages (MDMs) were obained, as peeviously described, wich minor modifications. ${ }^{x}$ In summary, $\mathrm{CD}_{14}{ }^{+}$moeocyes were obeained from PBMCs by using the Monocye Isolation Kit II (Milenyi Biotec, Bergisch Gladbach, Germany) according to the manufacturer's instracions, Monocytes were culturod in RPMI 1640 containing I0\% FBS at 
A

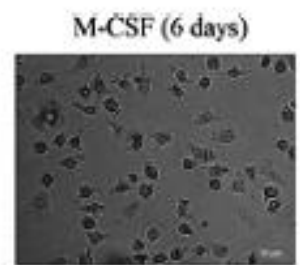

Control

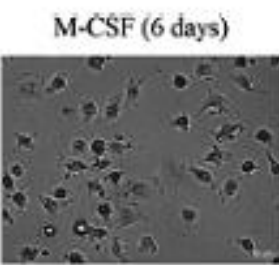

CD40L-def

Patient - marked - Control-markod - Patient - Isotype costsol

ㅁ Control - Isotype control
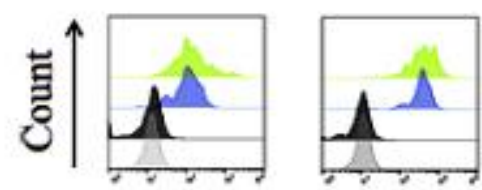

CD14

HLA-DR
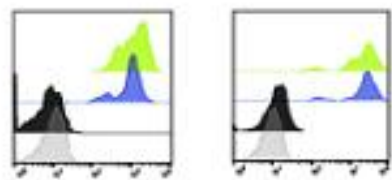

CD163

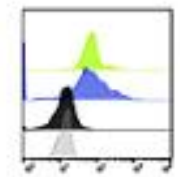

CD86

\section{Fluorescence}

B

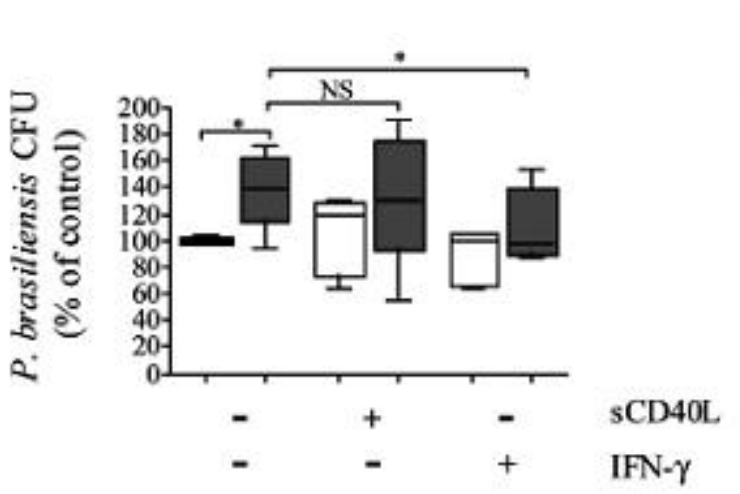

$\square$ Controls

$\square$ Patiats

c

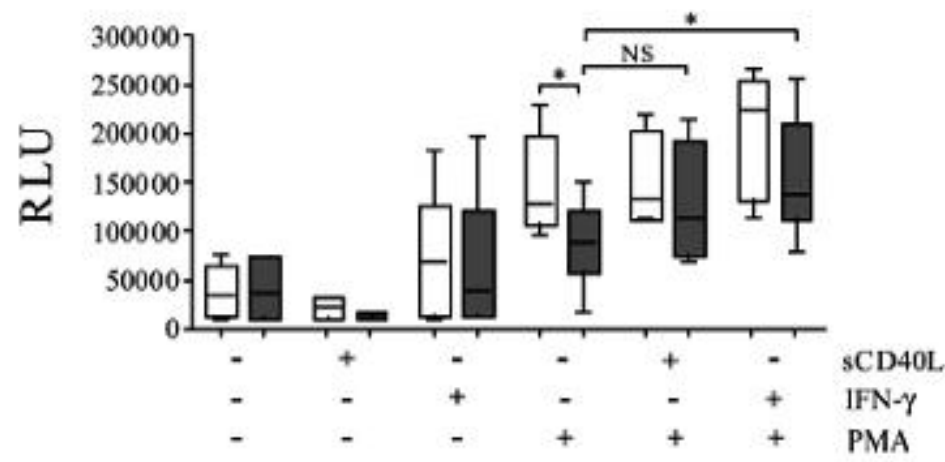

FG 1. THFN-y, but not aCD4OL, improves the defective ungicidal activity and oxidative burst of MDMs from CD4OL-deficient patients. A. Cell morphology (top) was assessed by means of phase contrast (Axio Vert.A1) after 5 days in the presence of M-CSF. Flow cytometric analysis (bottom/ was used to characterize expression of CD14, HLA-DA, CD64, CD163, and CDE8 on the surfaces of MDMs. B, After challenging MOMs with Pbra. siliensis, fungididal activity was assessed by determining CFU values. Before assy, MDMs were untreated $(-)$ or treeted with $(+) / \mathrm{sCD} 40 \mathrm{~L}(500 \mathrm{ng} / \mathrm{mL})$ or thiFN- $\gamma(100 \mathrm{U} / \mathrm{mL})$ for 48 hours. CFU values (as percentsges of control values) were determined in relation to the CFU number of untreated MDMs from healthy control subjects. The resu hs in scatter plots and raw data in CFU per milliliter are shown in Fig E2. C, MDMs remained untreated or were cultured for 48 hours in the presence of sCD40L ( $500 \mathrm{ng} / \mathrm{mL})$ or infFN-y $(100 \mathrm{U} / \mathrm{mL})$; the tespiratory burst of MDMs was induced by PMA $(90 \mathrm{mmoV} L)$. Cells were analyzed with the luminol-enhanced chemiluminescence asay, and values are expressed as relative light units (RLU). A significant difference ia denoted as follows: $* P \leq .05$ (n -6 patients and 6 control subjocts), Mann-Whitney test. NS. Not significant. 

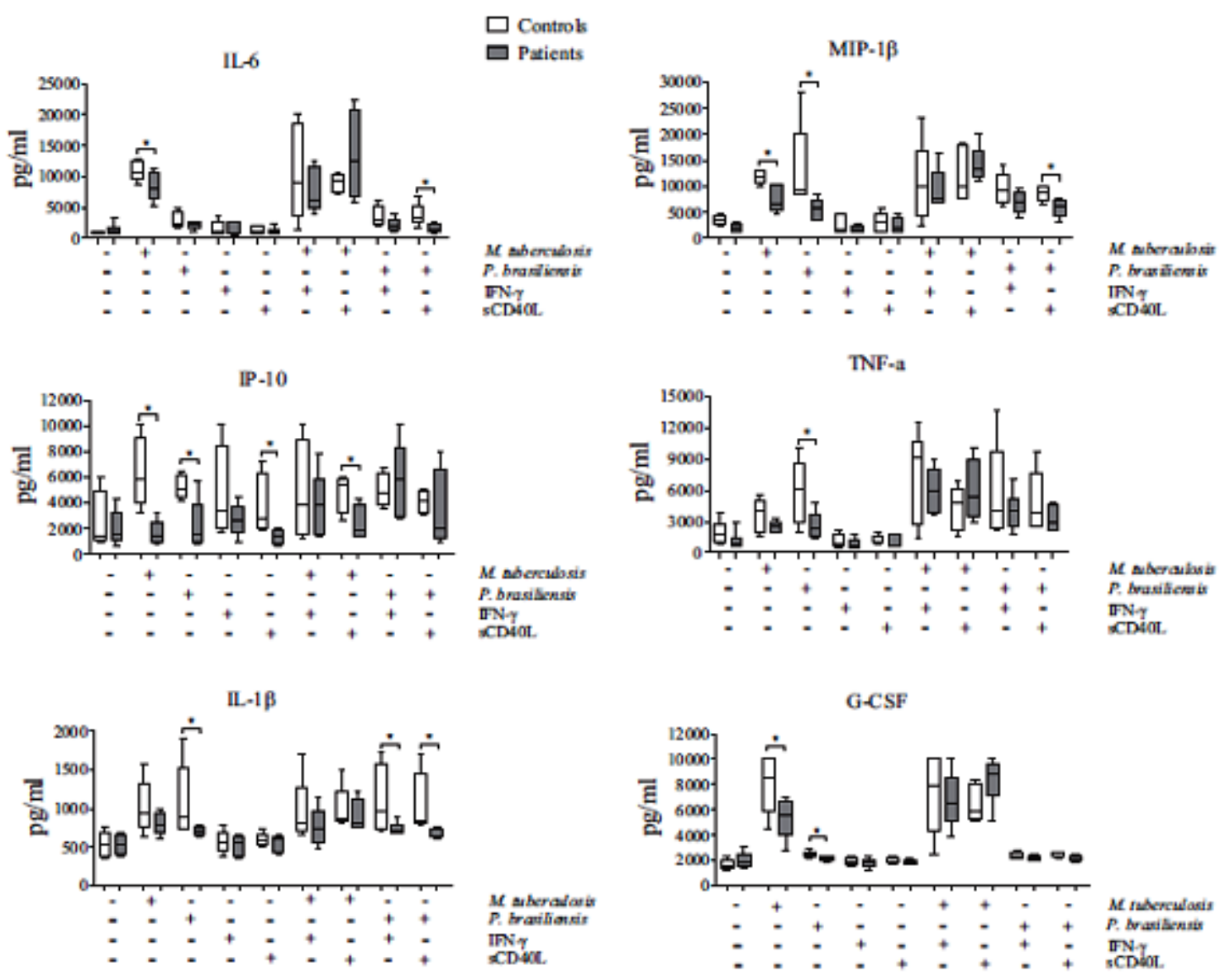

FG 2. Impaired cytokine production by macrophages from CD4OL-deficient patients. Patients macro-

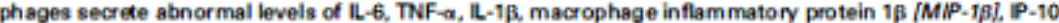
and G-CSF in reaponse to Mtubercubsly and Pbrasillensis. After 48 hours of sCD4OL (500 ng/mL) or hiFN-y $(100 \mathrm{U} / \mathrm{mL})$ treatment, cytokine production by patients' macrophages achieved a pattern similar to that observed in heatthy control subjects. Significant differences are denoted as follows * $P \leq .05$ (n -6 patients and 6 control subjects), Mann-Whitney test.

$37^{\circ} \mathrm{C}$ in a hamidified $\$ \% \mathrm{CO}_{2}$ smosphere for 5 days in the presence of $50 \mathrm{ng}$ $\mathrm{mL}$ macrophage colony-stimulating factor (M-CSF; PeproTech, Princeton, NJ). A fterward, the cells underwent phenotypic characterization, including analysis of HLA-DR, CD14, CD 40, CD64, CD86, CD80, and CD163. They were also characterized for the following pattern recognition receptors (PRRs): Toll-Eke receptos (TL.Rs; TL.R1, TLR2, and TL.R4) and C-type lectin recepbrs (CL.Rs dectin-1, dectin-3, mannose receptor, CD206, and dendritic cell-specific intercellular adhesion molecule 3-grabbing nonintegrin [DC. SIGND. Fhenotypic expeession was analyzed by using tlow cytometry (BD FACSCanto II Cytometer). The data obtained were analyzed with FlowJo software (TreeStar, Ashland, Ore). When indicated, MDMs were incubated for 2 more days in the presence of $100 \mathrm{U} / \mathrm{mL}$. hIFN-y (Immukine, Bochringer Ingelheim), $20 \mathrm{ng} / \mathrm{mL}$. IL -4 (PeproTech), or $500 \mathrm{ng} / \mathrm{mL}$ sCD40L_(Life Technologies, Frederick, Md).

\section{Fungicidal activity}

MDMs were challenged with Puracocoidioides brasiliensis (Pol8, a highly virulent isolate), and the microbicidal activiry was determined by counting colony-forming units (CFU), as previously described. ${ }^{33}$ Briefly, $0.2 \times 10^{3}$ MDMs were culared in $200 \mu \mathrm{L}$. of RPMI 1640 in 96-well flat-bottom plates and challenged with $P$ brasiliensis (ratio 1:10, fungus/MDMs) for 48 hours.
Five days after seeding and challenging, $P$ brasiliensis CFU were countod, and CFU values (percentage of control values) were detemined in rebtion to the CFU numbers of untreated MDMs from healthy control subjects

\section{Analysis of respiratory burst by means of} chemiluminescence

MDM oxidative burst was measured by using luminotdependent chemiluminescence, as previously described. ${ }^{34}$ Laminol (I mmol/L; Sigma Laboratonies St Lou is, Mo)-preloaded MDMs $\left(0.2 \times 10^{5} / 300 \mu \mathrm{L}\right)$ were activated with phorbol 12-myristate 13-actste (PMA: $90 \mathrm{nmol} / \mathrm{L}$, Sigma Laboratories), and chemiluminescence was monitored for 2 hours with a microplate bminometer realer (EG\&G Berthold LB96V, Bad Wildbad, Germany). Results were expressed as relative light units

\section{Analysis of cytokine production}

Supernatants of masrophages trested or untreated with rhIFN-y or SCD40L. were harvested 48 hours after $P$ brasiliknsis or $M$ a berculosis (lysste $)^{35}$ incubasion. Cyokine levels were evaluated by using a HCYTMAG-60K-PK 30 Cytokine Kit (Millipore, Bedford, Mass), and dza obtainod were analyned with a Luminex insrument acoording to the manuf $x$ turer's instructions, 
A

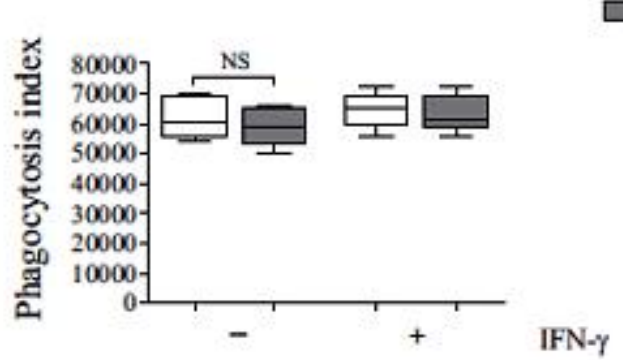

B

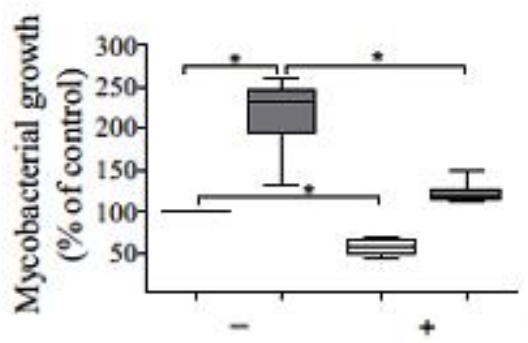

IFN- $\gamma$

FG 3. Defectivecontrol of the proliferstion of M tuberaulosis by MDMs from CD40L-deficient patients is improved by ihIFN- $y$. A, Macrophages werechallenged with $M$ abberculosis (H37hiv strain), and the phagocytosis index was determined on day 0 based on CFU courts. $B$, The bacterial proliferation index on day 6 was determined based on the ratio of CFU numbers on day 6 to CFU numbers on day 0. Data were normalized according to the sverage mycobacterial growh of untreated MDMs from healthy control subjects Significant differences are denoted as follows: $* P \leq .05$ (n -6 patients and 6 control subjects), Mann-Whitney test. NS. Not significant

\section{Phagocytosis and control of $\boldsymbol{M}$ tuberculosis proliferation by MDMs}

Analyses of $M$ ruberculosis (H37Rv strain) phegocytosis and proliferation control by MDMs were carried out, as previoucly described. ${ }^{36}$ In brief. MDMs were chalkenged at a 1:1 natio ( $M$ nuberculosis/MDMs) for 3 hours (day 0 ) and washed to remove extracellular my cobacteria. On day 0 and 6 days later, the MDMs were ly sed with $0.1 \%$ saponin treatment, and the bomogenses were diluted and phted in Middlebrook 7H10 modium supplemented with $10 \%$ OADC (Difco, scid/albumia/dextrosekatalse). The resultant colonies were assessed after 21 days of incubation at $37 \mathrm{C}$. M nuberculasis uptake (phagocytosis index) daxa were obxained from CFU counts performed on day 0 , and the $M$ tuberculasis growth index was determinod based on the ratio of CFU numbers on day 6 t CFU numbers on diy 0 .

In addition to MDMs, to gain evidence about the sole of CD40L-CD40 interaction in myeloid cell development, we analyzed the ability of the promyelocytic HL- 60 cell line to control M tuberculosis proliferation by challenging the cells at a I:I rato ( $M$ nubercubsib/HL-60 cells). HL-60 cells were only challenged for 3 bours becanse of rapid HL- 60 proliferation. After this, HL- 60 cells were lysed, and $M$ ouberculbsis proliferation was assessed based on CFU values, as performed for MDMs.

\section{RNA sequencing and data processing}

Macrophage transcriptome profiles from $3 \mathrm{CD} 40 \mathrm{~L}$-deficient patients and 3 healthy control subjocts were analyzed, as previously described. ${ }^{12,13}$ Toca RNA was obtained by using TRIsol (tavitrogen, Carkhad, Calif), accoeding to the manufacturer's instractions RNA integrity and concentration were assessed by using the Agilent 2100 Biosalyser RNA Nano chip (Agilent Technologies, Santa (lan, Calif) and orthogonally validated by means of visualization of the integrity of the 285 and 185 band on an agarose gel. DNA libraries were obtained with the Illumina CBox sation and HiScanSQ using the Illumina TruSeq RNA Ssmple Preparation Kit (Illumina, San Diego, Calif), according to the manu facturer's instructions. Sequencing was carried oet with the Illumina HiSeq 2000 paired-end 100-bp (PE 100) system.

\section{Bioinformatic analysis}

After quality assessment with Fass $Q \mathrm{C}$ (wwwhioinformatics.bahyaham ac. uk/poojects/fastgich), reads were aligned with the human cDNA transcripvme from Ensembl 82 by using Kallisto. ${ }^{35}$ Data were further processed by using Sleuth (pachterlab, githubio/sleuth), and the read vahues were expressed as transcripts per million. The tanscripes with more than 5 rexds in each sample for at least $47 \%$ of the sample and false discovery rate-adjusted $P$ values (or $q$ values) of less than 05 were considered differentially experssed genes (DEGs). Hierarchical clustering analysis was perfomed with Perseus (MaxQuant, v1. 11, Martinsried, Gemany) G Gene Ontology (GO) functional ennichment analysis was perfomed with STRING ${ }^{99}$ and DAVID ${ }^{\text {tat1 }}$ to categoria and group DEGs based on a known functional association, as defined by the Gene Ontology Consortium. ${ }^{22}$ Gene MANIA/Cytoscape 43 was used to predict interactions between DE.Gs by using GO biological process and sousce organism Homo sapiens as additional parameters.

\section{Statistical analysis}

Statistical significance was assesed by using the nonpanmotric MannWhiney test. Data were expressed as molians and 25 th and 75 th percentiles Statistical analyses were perfomed with GraphPad Prism 4.03 sottware (GraphPad Software, San Dicgo, Calif), and $P$ values of .05 or less were con sidered significant.

\section{RESULTS}

MDMs from CD40L-deficient patients have defective fungicidal activity and oxidative burst that are reversed by rhIFN- $\gamma$ but not SCD40L

Based on the morphologic characteristics and expression patterns of the CD14, HLA-DR, CD64, CD163, and CD86 molecules, a homogeneous population of MDMs from CD40Ldeficient patients and heal thy control subjects was successfully generated (Fig 1,A), When challenged with $P$ brasiliensis, macrophages from patients demonstrated reduced fungicidal activity compared with those from healthy control subjects (Fig 1, B and see Fig El in this article's Online Repository at www.jacionline. org). Although SCD40L treatment did not significantly increase the killing activity of macrophages from CD40L-deficient patients, rhIFN- $\gamma$ improved the fungicidal activity of macrophages from patients. This finding is consistent with IFN- $\gamma$ 's established beneficial therapeutic effect for patients with opportunistic infections and its well-known role as a phagocyte activator.

Considering the essential role of the oxidative burst during macrophages killing activity, we evaluated the production of reactive oxygen species by PMA-activated MDMs from CD40Ldeficient patients. Patients' macrophages did not trigger the oxidative burst after activation in comparison with those from healthy subjects (Fig 1, C). Although SCD40L showed a slight increase in macrophage responses, no significantenhancement was achieved. However, rhIFN- $\gamma$ statisticall yenhanced the oxidative burst of macrophages in both patients and control subjects. After rhIFN- $\gamma$ treatment, patients' MDMs displayed no significant difference compared with untreated or miFN $\gamma$-treated MDMs from heal thy control subjects. 
A

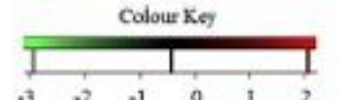

Down-regulated genes in macrophages in CD40L deficiency

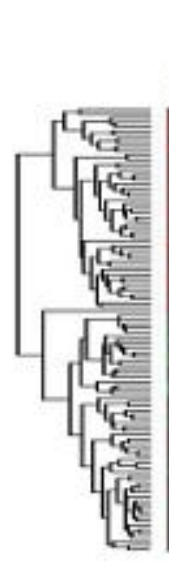
$\frac{\text { Untreated }}{\mathrm{C} 1 \mathrm{C} 2 \mathrm{C} 3 \mathrm{P}_{1} \mathrm{P} 2 \mathrm{P} 3}$

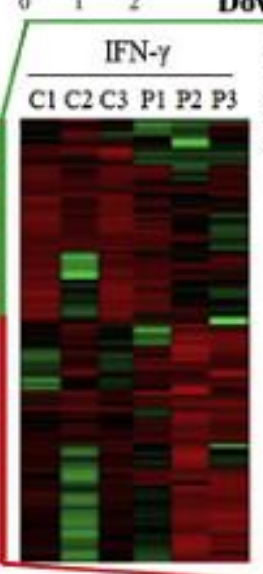

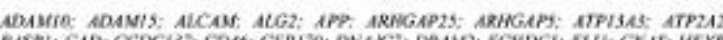

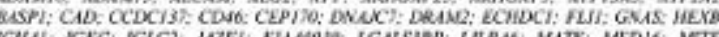

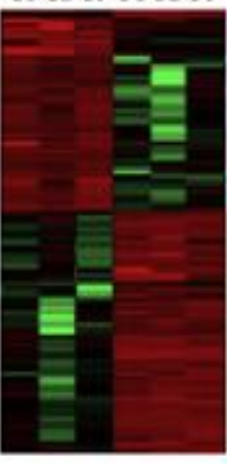

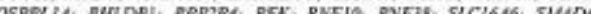

$\mathbf{B}$

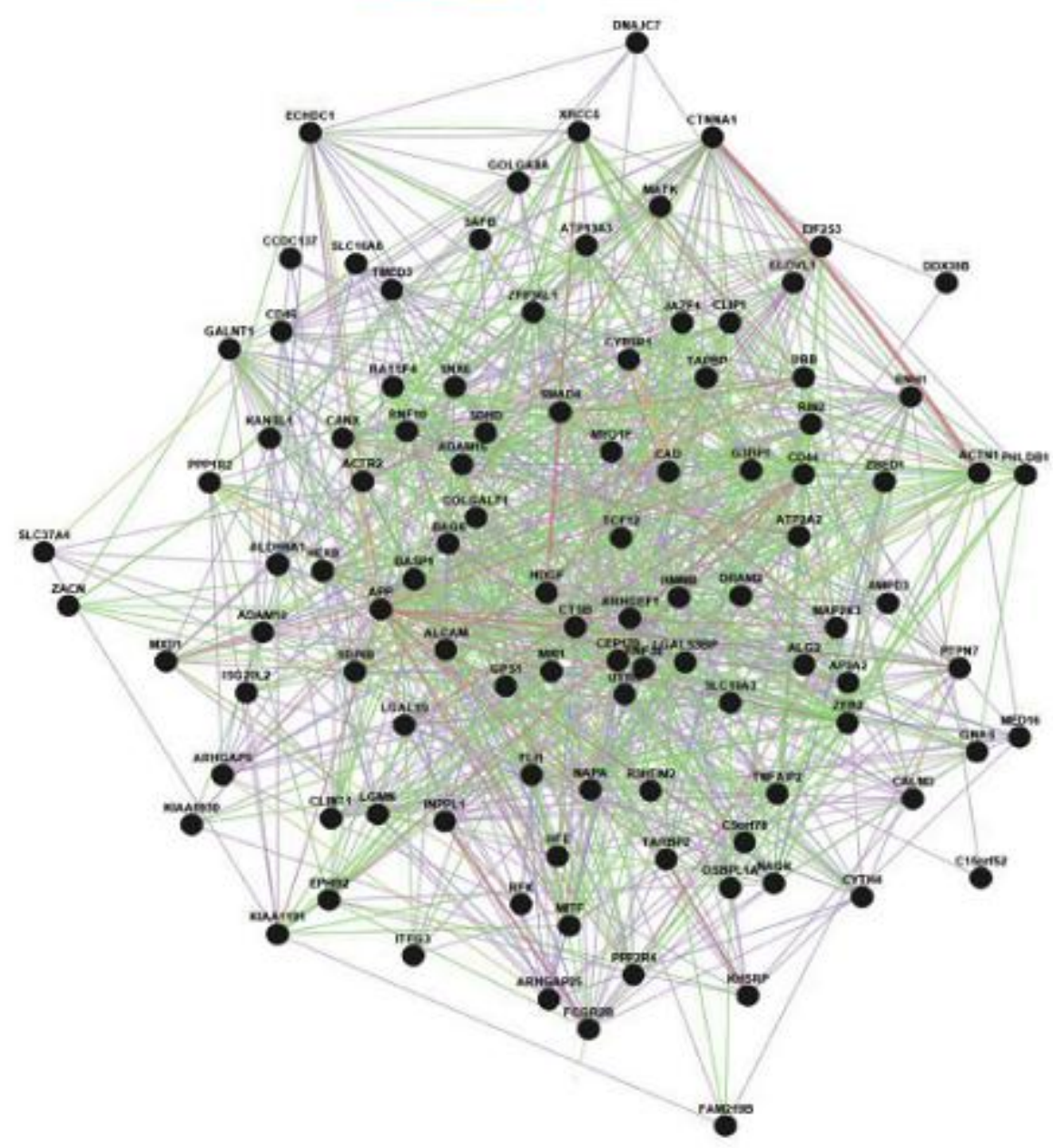

p-regulated genes in macrophages in CD40L deficiency

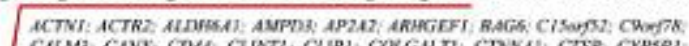

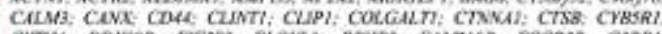

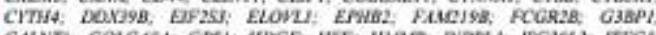

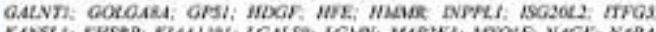

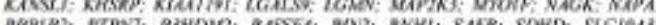

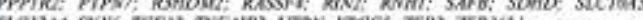
DPPSCL:

FG 4. Hierarchical cluster analysis showing MDM gene signature in patients with CD4OL deficiency and the subsequent effects of IFN- $y$. A. RNA from MDMs was sequenced, and the transcripts per million (TPM) values are represented on a $\log _{2}$ scale, where green shows low expressibn and red shows high expression. The results of untreated (left panel) and rhlPN-y-treated (right panel) cells are shown in the heat map. $B$. Interaction networka for the DEGs in CD40L deficiencyare shown. Networks are shown as predicted by GeneManis and visualized with Crtoscape. 


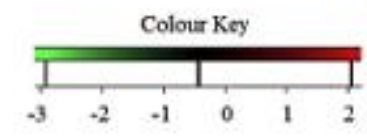

Untreated

C1 C2 C3 P1 P2 P3
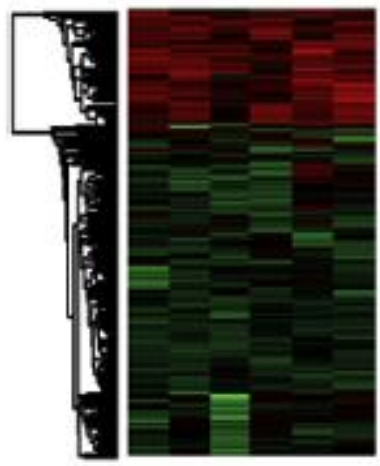

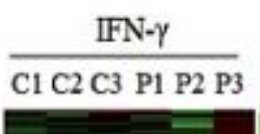

\section{Genes down-regulated by IFN- $\gamma$}

ACER3: ADAMI2: ALK: ANKH: ARHGAP26: ARUCG: ARMTI: ARROCS: ASNCF: ASPH: ATP2BH: ATPOIDDZ: BACEI: BCATI: BIACS: BNIP3L: Cllor44: CSARI

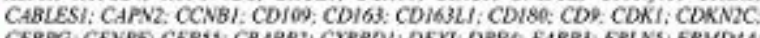

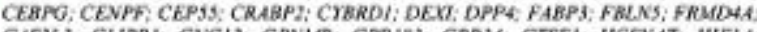

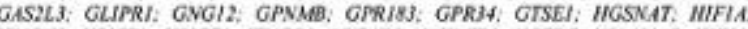

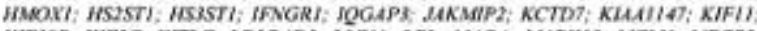

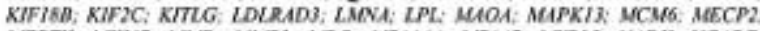

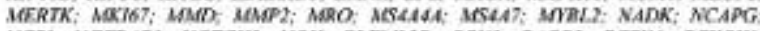
NCSI: NGFRIPI: NOTCH3; NOV OLTMLB: OPN3; PAOR3; PCSK6; PCYOKI PIUCTRI; PIDI: PIK 3R5- PITHDI; PLXI: PIXNA2; PPMIL; PRCI: PTGRRN PTGRI; PIXZ; PVRLA; RIBOB: RAPHI; RDHIV; RGCC RPII-36X/21.3; RRAR; SDC2. SERINCZ SERINCS; SHSDLI: SHE; SIGLECIS; SLCHIAI: SLCIOAIO: SLCTAII.

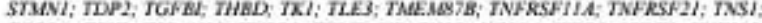

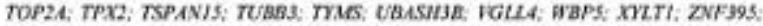
ZNF589:

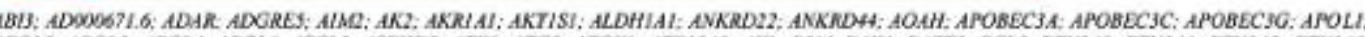

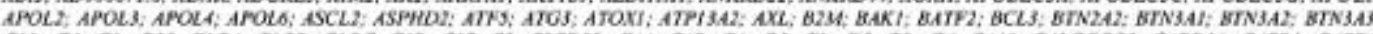

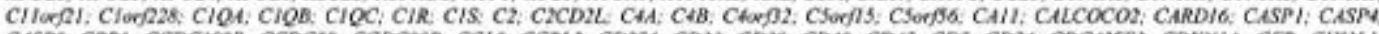

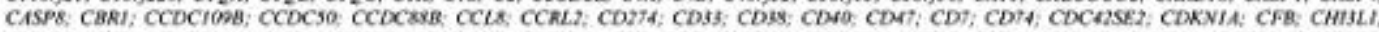

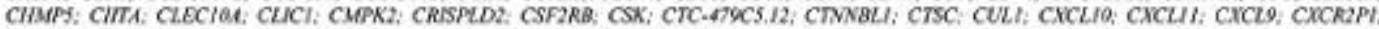

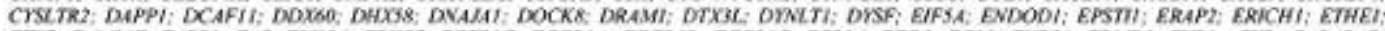

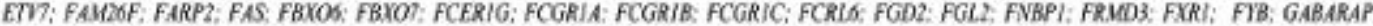

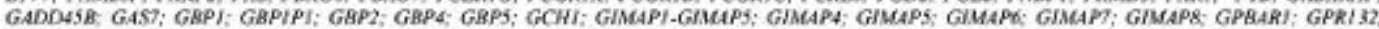

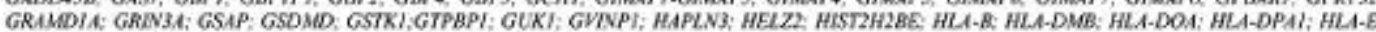

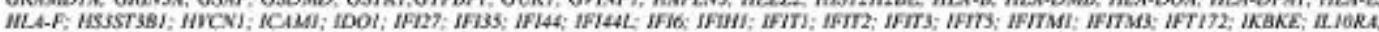

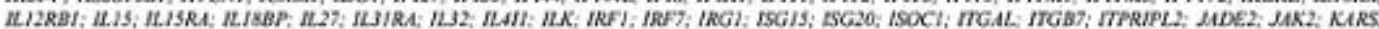

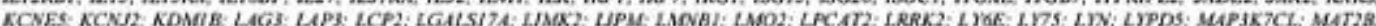

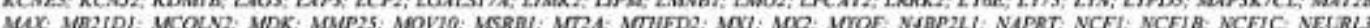

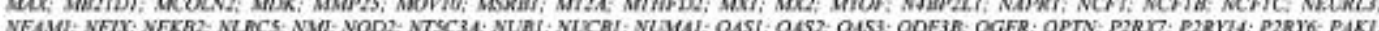

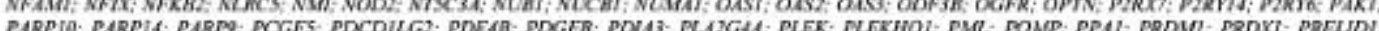

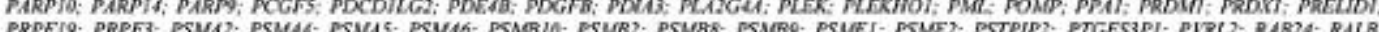
RAPGEF

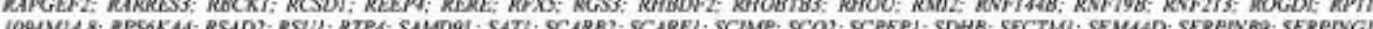

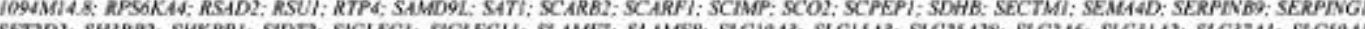
SIFA SLCAA 2.

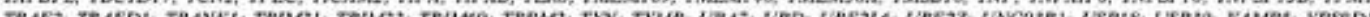

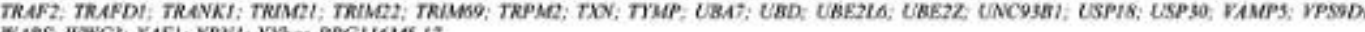
WARS WWCH; XAFI; XRVI: XXBac-BPGIISWS I?

FG 5. Heat map of genes not dysregulated in patients wikh CD4OL deficiency but affected by thiFN-y treatment. Results for untreated and rhiFN-y-treated cells are shown in the heat map. RNA from MDMs wer sequenced, and the transcripts per million (TPM) values are represemed on a log, scale, where green shows low expression and red shows high expression. Genes significantly upregulated or downregulated are listed.

Defective production of inflammatory cytokines by macrophages from CD40L-deficient patients is reversed by rhIFN- $\gamma$ and sCD40L

In addition to responding to invading pathogens by inducing microbicidal activity, macrophages produce inflammatory cytokines in response to CD40L-CD40 interaction. ${ }^{42}$ Therefore we analyzed inflammatory cytokines released by MDMs from patients or control subjects treated or untreated with thIFN- $\gamma$ or sCD40L in response to $P$ brasiliensis. In addition, considering the increased susceptibility to mycobacterial diseases reported in patients with CD40L deficiency, ${ }^{18,20,45}$ we also challenged the macrophages with $M$ tuberculosis. After 48 hours of culture in the presence of $P$ brasiliensis or $M$ tuberculosis, macrophages from CD40L-deficient patients had significantly impaired production of IL -6 , TNF $-\alpha$, IL-1 $\beta$, macrophage inflammatory protein 1 $\beta$, IFN- $\gamma$-induced protein 10 (IP-10), and granulocytecolony stimulating factor (G-CSF) compared with those of healthy control subjects (Fig 2). With few exceptions, the impaired cytokine production in CD40L-deficient patients was significantly improved by both rhIFN- $\gamma$ and $s \mathrm{CD} 40 \mathrm{~L}$.

Impaired control of $M$ tuberculosis proliferation by macrophages from CD40L-deficient patients is reversed by rhlFN- $\gamma$

Considering the essential role of IFN- $\gamma$ in the response to mycobacteria ${ }^{26}$ and the increased susceptibility to mycobacteria 


\begin{tabular}{|c|c|c|c|}
\hline GO term & GO eategory & $\begin{array}{c}\text { Dysregulated genes } \\
\text { in patients with } \mathrm{CD} 40 \mathrm{~L} \text { deficiency }\end{array}$ & $\begin{array}{l}\text { Genes not affected by the CO4OL deficiency but } \\
\text { modulated by rhiN- } y \text { treatment }\end{array}$ \\
\hline Go:0002376 & Immune system process & $\begin{array}{l}\text { ACIR2, ADAMIO, ADAMIS, AP2A2, APP, BAG6, } \\
\text { CANX, CDA4, CDH6, CTSB, FCGR2B, FLII, } \\
\text { IGUL, INPPL, LGMN, ULRA6, MAP2K3, } \\
\text { MATK, MITF, MYOIF, OSBPLIA, PPP2R4, } \\
\text { TCFI2, UBB, ZFP 36LII }\end{array}$ & 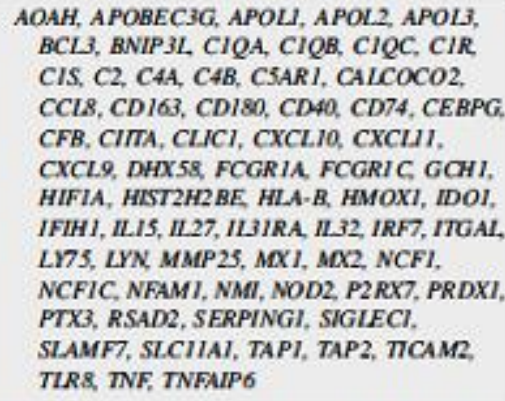 \\
\hline G0:0048002 & $\begin{array}{l}\text { Antigen processing and } \\
\text { presentasion of peptide } \\
\text { antigen }\end{array}$ & $\begin{array}{l}\text { AP2A2, CANX, HFE, KGLLS, LGMN, OSBPLIA, } \\
\text { UBB }\end{array}$ & $\begin{array}{l}\text { B2M, CD74, ERAP2, FCERIG, HLA-B, HLA- } \\
\text { DMB, HLA-DOA, HLA-DPAI, HLA-E, HLA-F, } \\
\text { ICAMI, PSMBR, PSMB9, PSMEI, SICIIAI, } \\
\text { TAP2, TAPBPL }\end{array}$ \\
\hline G0:0045087 & Innate immune response & $\begin{array}{l}\text { ACTR2, ADAMIS, APP, CDAS, CDA6, CTSB, } \\
\text { IGLSS, LGMN, MAP2 K3, MATK, UBB, XRCCS }\end{array}$ & $\begin{array}{l}\text { APOBEC3G, APOLI, CIQA, CIQR, CIQC, CIR, } \\
\text { CIS, C2, CAA, C4B, CALCOCO2, CDIBO, } \\
\text { CEBPG, CFB, CIIIA, DHXS8, FCGRIA, } \\
\text { FCGRIC, GCHI,IFIHI, II27, NCFI, NCFIC } \\
\text { NOD2, PRDXI, SERPINGI, SIAMF7, } \\
\text { SLCIIAI, TICAM2, TIR8 }\end{array}$ \\
\hline GO.0080134 & Regulation of response to stress & $\begin{array}{l}\text { AP2A2, CD44, CD } 46, C T S B, D D X 39 B, D N A J C 7, \\
\angle G M A N, M A P 2 K, M Y O I F, T A R B P 2, U B B \\
\text { XRCC5, ZEB2 }\end{array}$ & - \\
\hline GO:0007259 & JAK-STAT cascade & - & II.3IRA, LAK2, NMI, SOCS1, STATI, STAT2 \\
\hline GO:0055114 & Oxidation reduction process & $\begin{array}{l}\text { ALDHGA I, CYB5R1, GNUS, KLAAII91, PPPIR2, } \\
\text { UBB }\end{array}$ & \\
\hline G0.0006897 & Endocytosis & $\begin{array}{l}\text { ACIR2, AP2A2, APP, CUNTI, IGLLS, INPPLI, } \\
\text { RINR, SNX6 }\end{array}$ & $\begin{array}{l}\text { CDCA2SE2, CLECIOA, FCERIG, FCGRIA, } \\
\text { FCGRIC, FNBPI, LYTS, MERTK, P2RX7, } \\
\text { PTX3, SCARFI, SLCIIAI }\end{array}$ \\
\hline GO:0030335 & Positive regulation of cell migration & ADAMIO, ARHGAP5, MYOIF & CXCLIO, HIFIA, ICAMI, IIK, JAK2, PDGFB \\
\hline GO:0007264 & $\begin{array}{l}\text { Small GTPase-madiated signal } \\
\text { transduction }\end{array}$ & $\begin{array}{c}\text { ACIR 2, ARHGAP25, ARHGEFI, CLIPI, } \\
\text { CINNA1, G3BPI, PPP2R4, RIN2 }\end{array}$ & $\begin{array}{l}\text { FARP2, HMOXI, IQGAP3, LRRK2, MAPK13, } \\
\text { RAB2A, RABTB, RALB, RAPGEF2, RHOU, } \\
\text { RSUI }\end{array}$ \\
\hline G0:0016192 & Vesicle-mediated transport & $\begin{array}{c}\text { ACTN1, ACTR2, APP, CLINT1, IGLI, INPPLI, } \\
\text { MYOIF, OSBPLIA, RIN2, SNX6, TAPBP }\end{array}$ & $\begin{array}{l}\text { CCIR, CDC42SE2, CHMP5, C.ECIOA, } \\
\text { FCERIG, FCGRIA, FCGRIC, FNBPI, LVI, } \\
\text { LMN, MERTK, OPTN, P2RX7, PLEK, PTX3, } \\
\text { RHOBTB3, SCARFI, SLCIIAI, STXI1, } \\
\text { VAMP5 }\end{array}$ \\
\hline GO:0007599 & Hemostasis & $\begin{array}{l}\text { ACTNI, APP, ATP2A2, CD44, FLII, GNAS, } \\
\text { PPP2R4 }\end{array}$ & CD40, CD9, FBLN5, PLEK, SERPINGI, THBD \\
\hline G0:0010628 & $\begin{array}{l}\text { Positive regulation of gene } \\
\text { expression }\end{array}$ & $\begin{array}{l}A P P, D D X 39 B, F U 1, H E X B, M A P 2 K 3, M E D I 6, \\
\text { SAFB, UBB }\end{array}$ & $\begin{array}{l}\text { BCI3, CIITA, HIFIA, II.3IRA, IRF1, PRDMI, } \\
\text { SLCIIAI, TNF, TNFSFI3B }\end{array}$ \\
\hline GO:0045892 & $\begin{array}{l}\text { Negative regulxion of transcription, } \\
\text { DNA templated }\end{array}$ & $\begin{array}{l}\text { RASP1, HDGF, JAZF1, MITF, MXDI, MXXI1, } \\
\text { SMADA, SNX6, UBB, XRCCS }\end{array}$ & CIITA, IRF7, MEECP2, PRDMI, RFXS, TNF \\
\hline GO:0030154 & Cell differentiation & $\begin{array}{l}\text { ACTR2, ADAM10, ADAM15, ALDH6AI, AP2A2, } \\
\text { APP, ARHGEFI, BAG6, BASPI, CD74, CTSB, } \\
\text { EPHB2, FLII, GMAP5, HEXB, HIFIA, II.K, } \\
\text { JAK2, KITLG, LPL, LYN, MATK, NAPA, } \\
\text { PRPFI9, SEMASD, SMADS, TCFI2, TNFAP2, } \\
\text { UBB, XRCCS, ZFB2, ZFP36L] }\end{array}$ & $\begin{array}{l}\text { CD46, CD74, CTNNA1, EPHB2, GIMAP5, GNAS, } \\
\text { HIFIA, ILK, JAK2, KITLG, LPL, LYN, } \\
\text { PRPFI9, SEMA4D, TCF12, XRCC5 }\end{array}$ \\
\hline G0:0002521 & Leukocyte differentiation & ZFP36LI & $\begin{array}{l}\text { BAKI, BCLI, CASP8, CD74, CEBPG, FASI, } \\
\text { GIMAPS, GPRI83, ILI5, ILIIRA, IRFI, } \\
\text { NFAMI, TNF }\end{array}$ \\
\hline G0:0030099 & Myebid cell differentistioe & FLII, GNAS, MITF & $\begin{array}{l}\text { CASPS, CEBPG, GMAPS, ILIIRA, JAK2, LYN, } \\
\text { PML TNF }\end{array}$ \\
\hline
\end{tabular}


TABLE I. (Continued)

\begin{tabular}{|c|c|c|c|}
\hline Go term & GO category & $\begin{array}{c}\text { Dysregulated genes } \\
\text { in patients with CD40L deficiency }\end{array}$ & $\begin{array}{l}\text { Genes not affected by the } \mathrm{CD} 40 \mathrm{O} \text { defidency but } \\
\text { modulated by rhliFN- } \gamma \text { treatment }\end{array}$ \\
\hline G0.0010608 & $\begin{array}{l}\text { Postranscriptional regulution of } \\
\text { gene expression }\end{array}$ & $A P P$ & $\begin{array}{l}\text { BCL 3, EIF5A, FBXO7, MOVIO, PML, SLCIIAI, } \\
\text { TNF }\end{array}$ \\
\hline GO:0006417 & Regulation of translation & APP, TARBP2, ZFP36LI & BCL3, EIF5A, PML, TNF \\
\hline G0:0031401 & $\begin{array}{l}\text { Positive regulation of prosein } \\
\text { modification process }\end{array}$ & CDA4, HDGE, HFE, PPP $2 R 4, U B R, 7 E B 2$ & $\begin{array}{l}C C N B 1, C D K 1, C U L 1, \text { II3IRA, JAK2, KITLG, } \\
\text { LRRK2, LWN, NOD2, P2RX7, PLKI, PMI, } \\
\text { PSMA2, PSMU4, PSMAS PSME2, PSMA6, } \\
\text { PSMB1O, PSMB2, PSMBS, PSMB9, PSMEI, } \\
\text { TNF }\end{array}$ \\
\hline GO,0045859 & Regulation of protein kinase activity & APP, GPS1, HDGE, SNX6, TARBP2, UBR, ZFB2 & $\begin{array}{l}\text { AKTISI, C5ARI, CD74, CDKNIA, CDKN2C } \\
\text { GADD45B, ILK, JAK2, KITLG, P2RX7, PAKI, } \\
\text { PDGFB, RGS3, SLCIIAI,TNF, TRAF2 }\end{array}$ \\
\hline
\end{tabular}

in patients with CD40L deficiency, ${ }^{18,20,45}$ we asked whether macrophages from CD40L-deficient patients have normal capacity to control the growth of $M$ tuberculosis. Macrophages from CD40Ldeficient patients phagocytosed $M$ tuberulosis normally compared with macrophages from healthy control subjects (Fig 3,A) but did not control the intracellular proliferation of $M$ tuberculosis Most importantly, in accordance with the observation that refractory mycobacterial disease improves with rhIFN. $\gamma$ treatment (case report), rhIFN- $y$ significantly increased the control of $M$ tuberculosis proliferation in vitro by macrophages from patients and heal thy control subjects ( $\mathrm{Fig} 3, B$ ).

\section{rhIFN- $\gamma$ improves dysregulation of the macrophage} transcriptome in patients with $\mathrm{CD} 40 \mathrm{~L}$ deficiency

Based on the multiple macrophage functional defects observed in CD40L-deficient patients, we hypothesized that macrophages from CD 40L-deficient patients have systemic dy sregulation at the gene expression level. Therefore we analyzed the transcriptome of MDMs from CD40L-deficient patients using RNA sequencing and evaluated the effect of rhIFN- $\gamma$ on gene expression. Because it was not possible to collect enough macrophages to stimulate them with both thIFN- $\gamma$ and $S \mathrm{CD} 40 \mathrm{~L}$, we focused on the effect of rhIFN- $\gamma$ because it had the most potential as a new therapeutic option for patients with CD40L deficiency. We based this decision on the previously observed success of rhIFN- $\gamma$ therapy for certain infections ${ }^{28-31}$ its approval by the US Food and Drug Administration, and its feasibility for clinical use.

We obtained sufficient numbers of MDMs from 3 patients (P1, P2, and P3). Before rhIFN- $\gamma$ treatment, we identified atotal of 109 dysregulated genes (DEGs; 48 downregulated and 61 upregulated genes) when macrophages from $\mathrm{CD} 40 \mathrm{~L}$-deficient patients were compared with those from healthy control subjects (Fig 4, A, left panel). The functional association network of the DEGs in patients with CD40L deficiency is demonstrated in Fig 4, B. Dysregulation of the macrophage tran scriptome in patients with $\mathrm{CD} 40 \mathrm{~L}$ deficiency was not due to M-CSF-induced CD40L effects during MDM generation because M-CSF was unable to induce CD40L expression on MDMs (see Fig E2 in this article's Online Repository at www.jacionline.org). Furthermore, no CD40L. transcript was undetectable by using RNA sequencing. On the other hand, sCD40L increased the capacity of the promyelocytic HL-60 cells to control $M$ tuberculosis proliferation (see Fig E3 in this article's Online Repository at www.jacionline.org), indicating a role of
CD40L-CD40 interaction on myeloid cell development. A detailed investigation about the effect of the CD40L-CD40 interaction on promyelocytic HL-60 cells will be published elsewhere (manuscript in preparation).

It is noteworthy that milN-y restored the gene expression profile of the majority of DEGs in patients' macrophages. After thIFN- $\gamma$ treatment, only 11 of 109 genes remained differentially expressed in comparison with results seen in bealthy control sabjects (Fig 4, A, right panel). In addition to improving the expression of 109 DEGs, mifN- $y$ influenced the expression of 526 additional genes (133 downregulated and 393 upregulated genes) compared with that seen in healthy control subjects (Fig 5). The subsets of 109 DEGs and the additional 526 genes that were affected by the rhIFN- $\gamma$ treatment are shown with in GO categories (Table I). The main subsets of genes are directly involved with the immune system (GO0002376), including the inflammatory response (GO0006954) and wound response (GO0009611). Moreover, genes responsible for regulation of transcription (GO:0010628 and GO:0045892) and cell differentiation (GO:0030154, GO:0000904, GO:0045597, GO:0002521, and $\mathrm{GO} .0030099)$ were also affected.

\section{rhIFN- $\gamma$ increases TLR and CLR expression levels}

Production of proinflammatory cytokines, oxidative burs, and effective microbicidal activity are essential functions of M1 macrophages, which contrast with M2 macrophages (called alternatively activated macrophages), ${ }^{47,48}$ Despite the functional defects we observed, no phenotypic alteration was identified on macrophages from $\mathrm{CD} 40 \mathrm{~L}$-deficient patients. The normal expression of CD86, CD163, and CD206 molecules is shown in Fig E4 in this article's Online Repository at www.jacionline.org, all of which are markers that have been used todistinguish $\mathrm{M} 1 / \mathrm{M} 2$ subpopulations. $^{.05-51}$ Moreover, macrophages from patients with CD40L deficiency expressed TLRs and CLRs normally (Fig 6). Remarkably, thIFN- $\gamma$ significantly increased expression of TLR1, TLR2, dectin-1, and CD209 molecules in macrophages from patients and healthy control subjects.

\section{DISCUSSION}

Here we show that human CD40L deficiency impairs innate immune responses by affecting macrophage differentiation and function. Macrophage defects associated with impaired dendritic 
A

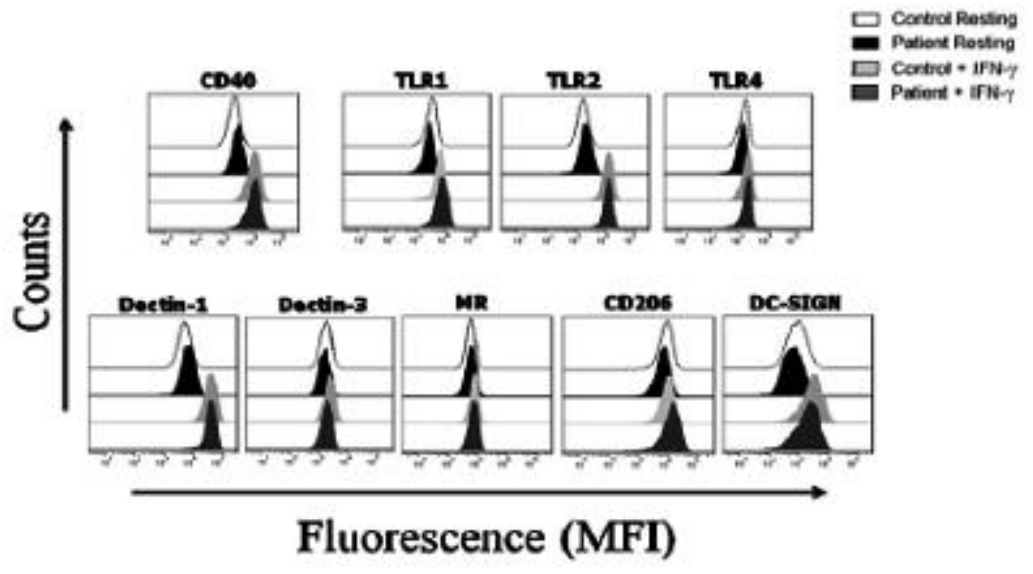

B
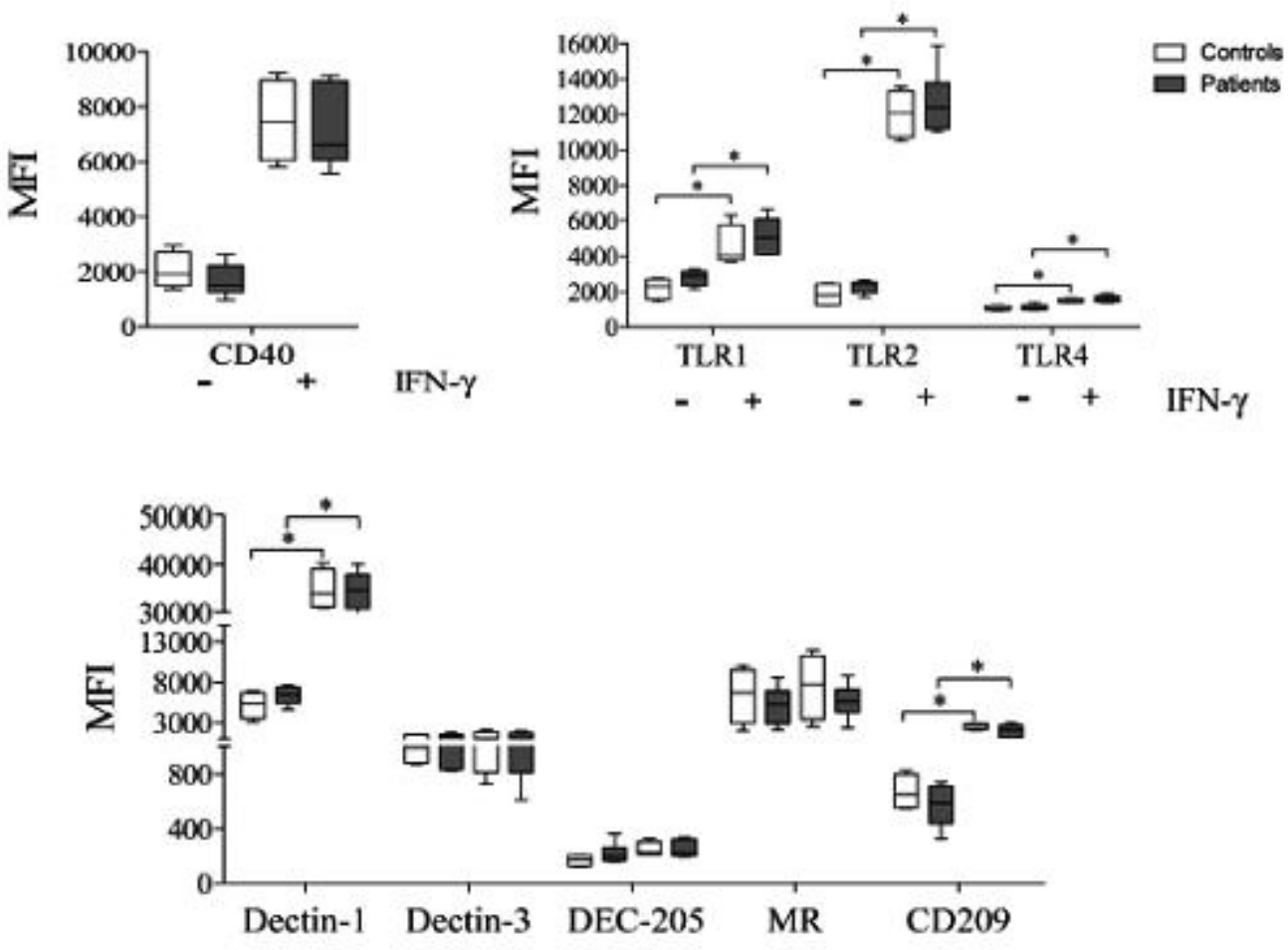

FG6. Effect of rWFN-yon expression of CD40, TLRs, and CLRs by macrophages. Representative histograms (A) and graphics (B) ahowing CD40, TLR (TLA1, TLA2, and TLA4), and CLR (dectin-1, dectin-3, manno an re: ceptor or MR, DEC-205, and CD209/ expressbn, as analyzed by means of eytometry. MDMs were analyzed after 5 days in the presence of M-CFS, folbwed by 2 additional days in the presence or absence of rhiFN-y. No significant differences in MDMs from patients versus healthy aubjects were obeerved. $* P \leq .05$ in -6 patients and 6 control subjects), Mann.Whitney teat. NS, Not signficant; MFL Mean fluorescence intenaity.

cell (DC) response in patients with $\mathrm{CD} 40 \mathrm{~L}^{22}$ and $\mathrm{CD} 40^{52}$ defciencies point to an essential role of the CD40L-CD40 interaction during differentiation of myeloid cells. This fact clarifies a new immunopathologic mechanism underlying the increased susceptibility of CD40L-deficient patients to opportunistic infections, which might explain the increased rate of deaths observed in 
patient with CD40L deficiency despite the current treatment armamentarium. ${ }^{18.20}$ The possibility that the differences observed between CD40L-deficient patients and young adult control subjects are age related is unlikely. It is well known that innate immune cells, such as macrophages, from neonates and infants less than 2 years of age have inherent defects; however, older children display immune responses comparable with those of adults. $^{5.39}$ In our diagnostic laboratory we have routinely observed that infants in the first years of life with undefined primary immunodeficiency disorders, in whom the diagnosis of CGD has been ruled out by demonstrating normal NADPH activity, have normal phagocyte responses compared with those in heal thy control subjects (data not shown).

Macrophages have to undergo maturation to a stage that allows normal clearance of invading pathogens through different mechanisms, including generation of a fully potent oxidative burst. The importance of this path way is illustrated by CGD, which is caused by defects affecting components of the phagocyte NADPH oxidase complex that are crucial in oxidative burst. Patients with CGD face life-threatening infections, even when oxidative burst is only slightly reduced or partially inhibited. ${ }^{17,00,61}$ There. fore the partially defective oxidative burst observed in macrophages from CD40L-deficient patients might contribute to the abnormal microbicidal activity that we demonstrated in our experiments and might be a risk factor for the increased susceptibility to opportunistic fungal and intracellular bacterial infections. However, it seems unlikely that defective fungicidal activity in macrophages from CD40L-deficient patients is solely due to reduced reactive oxygen species production because additional nonoxidative killing mechanisms might also be affected.

The impaired microbicidal activity, oxidative burs, and defective production of cytokines (eg, IL-6, TNF- $\alpha$, IL-1 $\beta$, macrophage inflammatory protein $1 \beta$, IP- 10 , and G-CSF) by patients' macrophages suggest that the absence of CD40L not only impairs effector function of macrophages but also initiation of inflammatory responses. These results are in accordance with the proinflammatory role of CD40L-CD40 interaction on activation of macrophages from heal thy subjects., ${ }^{9,42}$ The multiple defects identified in macrophages from patients with CD40L deficiency indicate that more than 1 aspect of the macrophage immune response can be affected in these subjects. In accordance with the numerous functional defects displayed by patients' macrophages, we al so observed ady sre gulated gene expression signature, which was improved in the presence of rhIFN- $\gamma$. Considering the high number of DEGs in macrophages from CD40L-deficient patients, multiple other functions of these cells remain to be investigated further.

Contradictory results regarding IFN- $\gamma$ production by $\mathrm{CD} 40 \mathrm{~L}$ deficient $\mathbf{T}$ cells have been reported. However, such incongruences might be explained by the fact that PBMCs/T cells from CD40L-deficient patients are intrinsically capable of producing IL-12 and IFN- $\gamma$ but do not respond to certain stimuli. We found that PBMCs from CD40L-deficient patients normally produce IL- 12 in response to IFN- $\gamma$ and release IFN- $\gamma$ in response to IL- 12 stimulation (see Fig E5 in this article's Online Repository at www.jacionline.org). These findings contrast with our previous observation of a significantly impaired IL- $12 / \mathrm{IFN}-\gamma$ axis $^{22}$ in DC/T-cell cocultures stimulated by Candida albicans of $P$ brasiliensis. Both Jain et $\mathrm{al}^{23}$ and Subauste $\mathrm{et} \mathrm{al}^{24}$ described impaired IFN- $\gamma$ production by PBMCs from CD40L-deficient patients after anti-CD3 stimulation and Toxoplasma gondii exposure, respectively. In contrast, Uronen and Call ard ${ }^{62}$ reported normal IFN-y release by Tcells from CD40L-deficient patients in response to PMA plus ionomycin. In turn, Felipe-Santos et al ${ }^{6}$ observed decreased production of IL-12 and IFN- $\gamma$ in response to PHA; however, normal generation of $\mathrm{IL}-12$ by LPS and IFN$\gamma$ by PMA/ionomycin was seen in PBMCs from CD40Ldeficient patients compared with generation in healthy control sabjects.

The treatment of opportunistic infections in CD40L-deficient patients with rhIFN- $y$ might reduce the high mortality rate associated with CD40L deficiency, despite currently available treatment options. ${ }^{1,19,64,65}$ This possibility has been illustrated by the response of one of our CD40L-deficient patients who, despite all the treatment available, had refractory disseminated mycobacterial infection that was improved after hiFN- $\gamma$ adjuvant therapy. Taken together, our data point to thIFN- $\gamma$ as a possible adjunct immunotherapy, in combination with conventional therapy, for cases of disseminated opportunistic infections in CD4OL-deficient patients. Furthermore, this cytokine is already available and licensed for clinical use. $2,52,54$

Another mechanism by which thIFN- $\gamma$ might potentiate macrophage immune responses of macrophages from CD40L deficient patients is by increasing the expression of TLRs and CLRs, both of which are essential for immune responses against different pathogens ${ }^{66}$ hIFN- $\gamma$ treatment of macrophages from both patients and control subjects caused significantly increased expression of TLR1, TLR2, dectin-1, and CD209. The potential of IFN- $\gamma$ influencing PRR expression might explain how thIFN- $\gamma$ can restore microbicidal activity in macrophages from CD40L-deficient patients. However, we did not observe signifcant changes in TLR1, TLR2, dectin-1, and CD209 mRNA expression after in vitro rhIFN- $\gamma$ treatment in our transcriptome analysis (data not shown). Whether IFN- $\gamma$ regulates the protein expression of these PRRs by modulating mRNA expression at a different time point than those we assessed or whether it acts at a postranseriptional level requires further investigation.

In conclusion, our data demonstrated that in the absence of the CD40L-CD40 interaction, macrophages from CD40L-deficient patients exhibit impaired function and differentiation because of dysregulation of gene expression that might contribute to their susceptibility to opportunistic infections. Furthermore, rhIFN- $\gamma$ might represent a new therapeutic option for patients with CD40L. deficiency by restoring certain functions to macrophages.

We thank all the patients and their families for participation in this study. We atso thank Dr Eunice Dusire from the Lab Alfa LTDA and Lasinete Tavares from the Federal Univesity of S3̌o Paulo for bbodsample collection.

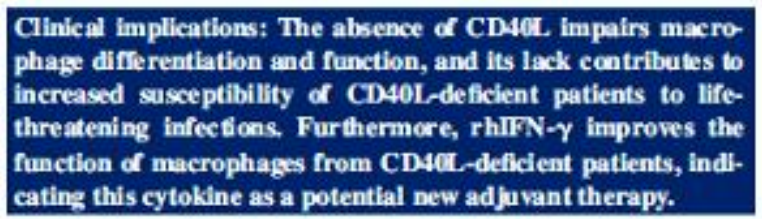

\section{REFERENCES}

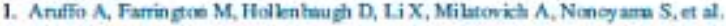
The CDX0 lizand $\mathrm{g}^{39}$, is defective in stivand $T$ cells from parients with $\mathrm{X}$. linked byper-IgM syndome, Cell 1993;72:291-300 
2. Alke RC, Armitage RU, Canley ME, Rosenblat H, Jenuins NA, Copebnd NG et al. CD 20 tigand gene delects responsible for X-linked hyper-IgM syndrone. Scieace $1993259990-3$.

3. DiSunte JP, Bomefoy JY, Gauchat N, Fischer A, \& Saint Bade G. CD $\$ 0$ ligand mutatios in x-linked immumaleficiency whis hyper-1gM. Nature 1993;361. $541-3$.

4. Fuležas R, Rameah N, Lah R, Jahuna It, Ronen RS, Chatila T, et al. Defoctive eqpewion of the CD40 tigand in X clromonome-linted inmusoglobutit

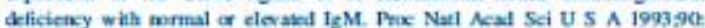
$2170-3$.

5. Konthiner U, Graf D, Mages HW, Brizer F, Palayachee M, Makolm S, ef al Defective exprevion of T-gell CDaO ligand caswes $\mathrm{X}$-linknd immenodeficiency with hype-IgM. Nature 1993:361539-41.

6. Kim VIS, Thang X, Ckai YS. Activation and peoliferatioe of fillikulan denchiti cell-bike cells by actirated T lymphocytes, J Immanol 1994:153:2951-61.

7. Caux C. Mascacrier C, Varbertlict B, Dubois B, Van Kootes C, Duraad I et al Activation of human denditic cells throuph CD40 cross-Enking J Exp Med 1994:189: 1263-72.

8. Heschen C, Dimmeker S, Haram CW, van den Brand MJ, Boersma E, Zeher AM, et al. Soluble CDa fipand in acue corcnary syniromes N Engl J Mod 2003348:110411.

9. Henn V,Sl-psly R, Grafe M, Aregnostcponkos L, Forster R, Muller-Berghaus G. et al. CDos ligand an activated piseles aiggers an inflammutory reaction of eadcoheliel cels. Nature 1998:391591.4.

10. Mavoudi 1, Papadali it. The rok of CDasycDato ligand imeractions in bone manow granulopdevis. Sci Warld J 201 1;11:201 1-9.

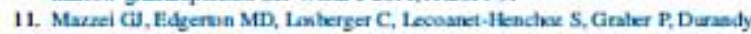

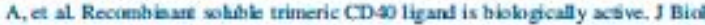
Chen 1995,270:7025-8.

12 Saeland S, Duven V, Caux C, Pandras D, Favae C, Valle A, et al Distiledion of suface-mentrane mokeuks on bore marrow and cond bood CD34+ hemats. peiesc cells. Exy Hemated 1992;30:24:33,

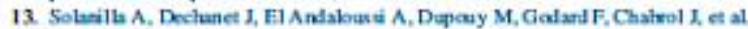

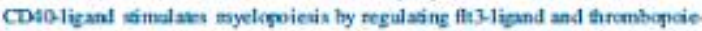
tin frodaction in bone mamiw stromal cells. Bhod 200095:3758-64.

14. Fores Romo L, Bgïzk R, Duvent V, van Kocten C, Sacland S, Bancherean J.

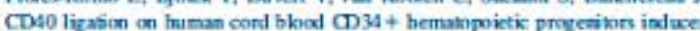
their proliferation and deffereariation into finctional dendritic cells. J Exp Med 1997:185:341-9.

15. Malik N, Groenfiekd BW, Wahl AF, Kizner PA. Activation of human monocyles through CD\&0 induces matrix met llopiseimeses. J Immunol 1996:156:3952-60.

16. Geissmann F, Manz MGG, Jusg S, Siewele MI, Mernd M, Ley K. Devebpment of monxyes, macrophases and dendrixic cells Science 2010,327:656-61.

17. Kulas De, Atwond WG, Heller T, Feld JJ, Püke KM, Marciano BE, et al. Resifual NADPH akidase and survival in cluraic granulamatcus disease. N Eggl I Med $20103632600-10$

18. Cahad-Marques O, Klaver S, Sctimbe L.F, Axcendios LH, Khan TR, Percira PVS, et al. Fire repors of the hyper-Ir M syndrone regitgy of the Latin American

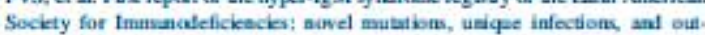
comes. $J$ Cin tmmumi 2014,34: 146-56.

19. de Otiveira-Jurie IB, Zumo NB, Prands C, Calral-Marquer O, Perein PV Schimie LF, et al, Clinical and gnotypic pectrom of clrotic granikmabus dineaxe in 71 Latin American patience find ropert frem the L.ASID regiery. Po dialf Hilod Cancer 2015 \$2:2101 7.7,

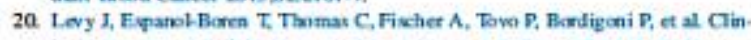
ical spectrum of X-linked hyper IgM syalrume. I Podse 1997:131:47.54,

21. Cahrd-Marques $O$, Schimike LF, Pescira PV, Fakai A, de Oliveira M, Fucket! MU, et al. Fxpanding the chrical and genetic spectrum of human CDACI. defi. ciency: the occumence of prosococidioidonycosis and ether unusual infection is Brariban patients. I Clin Imminol 2012:32:212:20

22 Cahnl-Marques O, Arslanian C, Ramos RN. Morato M, Sctimla L, Sociro Per eira PV, et al. Dendritic cells from X-linked byper-IgM patients present impared responses is Candida abicans and Furacoccidioides brasibiensis. J Alkrgy Clin Immund 2012:129:778-86.

23 Jain A, Atlinson TP, Lipky PE, Slater NE, Nelson DL, Sirober W. Defects of Tcell effectar finction and post-dymic maturation in X- linked hyper-IgM syn. drome. J Cin Invest 1999, 103:1151-8.

24. Suhusk CS, Wesendap M, Sorensen RU, Leiva LI. CD4OCDAO lignd inter actioa is ceatral b cell -modiated immunity againe Toxoplasma gondë: patient with hyper $\operatorname{tgM}$ syndrome tave a defective type 1 immune response that can

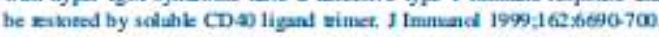

25. Erekowize R.A. Siff CA, Dtruaer MC, Nahan DG, Onlin SH, Newhurger PE Restoration of plagseyte function by hiteferongamma in X-liked chronic granubmatcus disease occurs at the kvel of a pogenion cell. Bkod 1990; $76: 2443-8$.

26. Bemiller L.S, Roherts DH, Stanio KM. Curmute IT. Safecy and effectiveness of

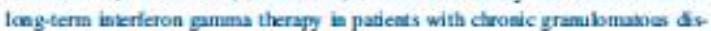
case. Blond Cells Mal Dis 1995:21:239.47.

27. Marciane BE, Weley R, De Carlo ES, Anderson VL, Bambant LA, Dannell D,

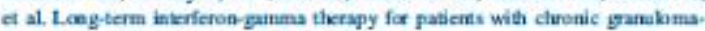
tous diseave Clin Infect Dis 2004;39 \$529.

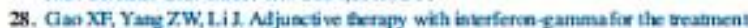

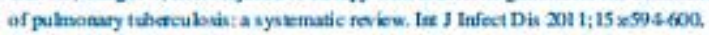

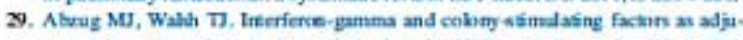
vamt therapy for refactory fungal infectiome is clikeren. Peliaz Infoet Din 1 XDA; 23.769.73.

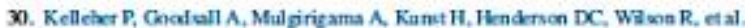
Inerfenco-gamma therapy in two paferks with progressive chronic pulmorary aspergilbsis. Fur Respir J 200627:1307-10.

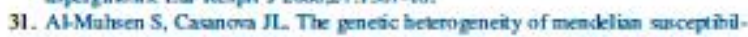
ity to mycribucterial diseases J A lergy Clin lmmunol 2008;122:1043-51.

32. Beyer M, Malhann MR, Xue J, Staratschek-box A, Vortolt D. Krebs W, et al High-resolution transcripwme of haman macrophages. PLoS One 2012,7:045466.

33. Pina A, Salliva PH, Restrepo LE, Cafich VL. Neutruphal rok in pulmonary pera. coccidicidonycosis depends on the esistance pertern of hosts. J Leokoc Biol $2006,79=1202,13$.

34. Soeiro-Pereina PV, Falai A, Kabo CA, Otivein-Jinior EB, Manques $O C$, An tueses Lf et al. BAY $41 \cdot 2272$, a solukle guany late cyclase agouist, activates human monouackar plagocyes. Br J Pharmacol 2012; 16 $61617-30$.

35. Verrock M, de Boer T, Langeaherg DM, Hoeve MA, Kramer M, Vabherg E,

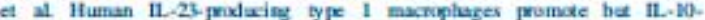
proclaxing type 2 macrophtages mulvort imminity to (myco) tacteria. Proc Nall Acad Sci U \$ 12000,$101 ; 450-5$.

36. Amaral $\mathrm{E}$, Rilkifo SCM, Lanes VR, Almeida FM, de Anchade MR, Bomfim CC

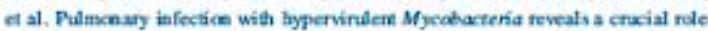
for the P2X7 recopeis in agerestive foms of tuherculokis. PL.oS Pabog 2014;10. e1004185.

37. Dang C, Zhao G, Zhong M, Yue Y, Wu L, Xiceng S. RNA wequencing and transcripomal analysis of human monocyte to macroplage diffetentiation. Cene 2013:519:279.57.

38. Hensman J, Papastamoulis P. Q Q aus P. Honkeb A, Ratray M. Fast and accurate approximate inference of tenccript expession from RNA - oeq data. Bioinformatics 201 5-31-3851-9.

39. Szklarcxyk D, Franceschïri A, Wyder S, Forslund K, Helker D, Huerts-Cepas J. et al. STRING y 10: proteipprotein interacticn networks, integrated over the tree of life. Nacleix Acids Res 2015;43:D447-52

40. Huang DW, Sherman BT, Lempicid RA. Bioinfarmatics emrichunent tools: poths tow and the comprehensive functional andysis of large geare lists. Nuckic Acids Res 2019-37:1-13

41. Hang da DW, LempickiRA, Sterman BT. Sysematic and ireegrative andysis of lange gebe lists ushg D.AVID bicisformates rescurces. Nat Prokec 2009:4:44-57.

42. Astherner M, Ball CA, Blate $\mathrm{A}$, Bostein D, Buiker H, Cierry JM, et al. Cene ondolegy: tool for the unificadion of bialog. The Gene Omology Comortius Nat Clenet $2000125: 25-9$.

43. Warde-Farky D, Donaldew St, Comes $O, Z$ Zuheri $K$, Hatrawi $R$, Chas $P$, el al.

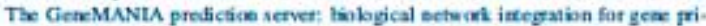
oritiation and preticding gene function. Nuckic Acids Res 20 10:38: W214.20.

44. Bestamante J, Ariau M, Wig G, PicandC, Galicis L.B. Prande C, ef al, Germine CVBB matakiom that electivel y affect macrophages in lincheds with X-Lik.ed pre dieposition to thenculous myechaserial divesse. Nat Immanol 201 1:12:213-21.

45. Wang LI. Thou W, Zhoo W, Tan ZQ, Wang WF, Wang XF, et al. Clinical fea. tures and grnetic aralysis of 20 Chinese putie res with X-linkad hyper-IgM syndrame. J Imminol Res 2014:2014683160.

46. Bustamante J, Boison-Dupuis S, Abel L, Cacanova HL. Mendelian suxcepéhifity to mycohacterial desas: genetic, immundngical, and clinical features of inhorm emors of IFN-y immunity. Semin Immunol 2014:26:454-70.

47. Covarrulias A, Byles V, Homg T. ROS sets the stage for macroplege differentiation. Cell Res 2013:23:984:5.

48. Pollad $M$. Troptic macrophages in development and disease. Nat Rev lmmuool 2009:9:259-70.

49. Weber M, Mocbius P, Bütner-Herdid M, Amarn K. Preid R, Neulam FW, et al. Macrophage polaristion changes witin the time hetween diagnostic biopsy and tumour resection in oral squamous cell carcincmas - an inmemotistochemical stedy. B 1 Cancer 2015;113510.9.

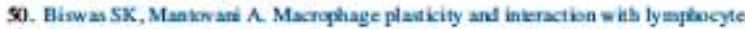

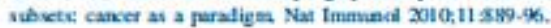


51. Röver T. Understanding the mysterious M2 macrophage throupt activaticn markers and effector mechunisma. Mediators Inflamm 2015:2015:816460.

52. Fortana S Morato D, Mangal S, De franceseo M, Vermi W, Fermari S, et al Functional defects of dendrisic cells in putients with CD40 deficiency Bbod 2003:100:4099-106.

53. De Kleer L, Wilkms F, Lambrecte B, Geriely S. Ontogeny af myelcid cellk. Fron temunol 2014:5:423,

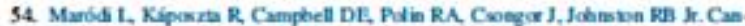
didacidal mechunisma in the human seonate. Impaired IIN-ganma activation of mactophags in newborn infarts. $J$ lmmunt 1994;153:569-9.

55. Lu CY, Calamai EC, Ubanue ER. A defect in the antigen presenting function of macrophages from neonatal mice. Nutue 1979,282:127.9.

56. Wown WL, Canon BS, Harkin RM, Stare GD, Desin RD, Haht SX. Monocyte macophage finction in the newhom $\mathrm{Am}$ J Dis Cild 197; 131:1241.2

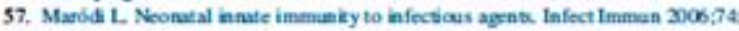
1999.2006 .

58. Wikon CB, Lewis Det. Ravis and implications of electively denisibed cyeckibe

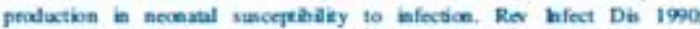
12 เu丶p 14$) 5410-20$.

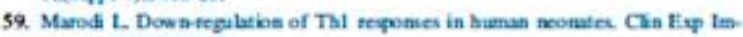
mami 200; 1 28:1-2
6. Bomegand N, Chos AR, Herlin T, lones or, Sepl AW, Wherias Nat. A variurt form of X-linked chnnic granubmunous disease with normal nitroblue tetnofium dide test and cyloctrome h. Fur 1 Clin lmest 1953;13:243-8.

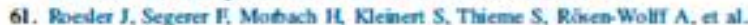
987-phos (NCF2) lacling exins 11 and 12 is functionally active and kads at

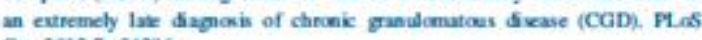
One 2012,7:e34296.

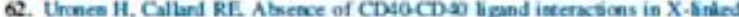

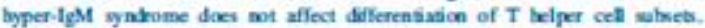
Cie Exp Immuat 2000, 121:346-52

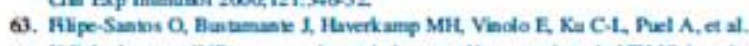

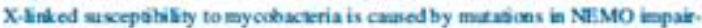
ing CD40-depesdrat II- 12 production. J Fivp Med 2006:203:1745-59

64. Seminaío MG, Dix Ballue D, Coman D, Gomer Raccio A, Di Giovani D,

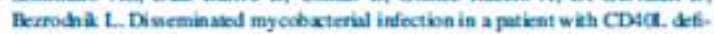
cieacy. J Clin tmmanol 2013,33:5108.

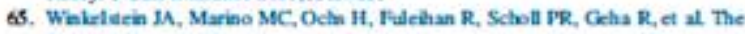

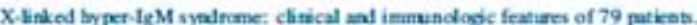
Maficine (Blalimare) 2003, K2:373-54.

66. Gejiteabeek TBH, Ceinghin S1. Sigmalling thongh Ctype ketin moepton:

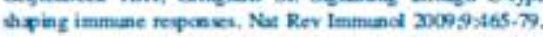

